\title{
Progress in the direct catalytic conversion of methane to fuels and chemicals
}

\author{
Canan Karakaya ${ }^{a}$, Robert J. Kee ${ }^{a, *}$ \\ ${ }^{a}$ Mechanical Engineering, Colorado School of Mines, Golden, CO 80401, USA
}

\begin{abstract}
This paper reviews the state-of-the-art in catalytic processes to convert methane (a major component of natural gas) to more valuable hydrocarbons as fuels or chemicals. The scope is restricted to "direct" conversion, meaning that processes involving synthesis gas as an intermediate are not considered. Oxygenated products (e.g., alcohols) are also not considered. In all cases, the processes are concerned with catalytic dehydrogenation. The two most widely studied processes are Oxidative Coupling of Methane (OCM) and Methane Dehydroaromatization (MDA). After reviewing the relevant catalysis literature, the paper goes on to review reactor implementations. Hydrogen- and/or oxygenpermeable membranes can potentially play valuable roles in improving methane conversion and product yields. Despite over 30 years of research, there are still no direct-conversion processes that can compete commercially with methane reforming followed by processes such as Fischer-Tropsch synthesis. Thus, the future practical development and deployment of OCM and MDA will rely on the research and development of advanced catalysts and innovative processes. The present review helps to document the foundation on which the needed development can build.
\end{abstract}

Keywords:

Methane activation, Membranes, Catalytic chemistry, Gas to liquids, Process intensification

1 Introduction

1.1 Catalysts

1.2 Temperature and pressure tradeoffs

1.3 Membranes

1.4 Processes

2 Oxidative conversion of methane

$2.1 \mathrm{Li} / \mathrm{MgO}$ catalyst

$2.2 \mathrm{Mn} / \mathrm{Na}_{2} \mathrm{WO}_{4} / \mathrm{SiO}_{2}$ catalys

$2.3 \mathrm{La}_{2} \mathrm{O}_{3}$ catalyst

$2.4 \mathrm{Fe}_{2} \mathrm{O}_{3}$ catalyst.

2.5 Low temperature catalysts

2.6 OCM Reaction kinetics

3 Non-oxidative conversion of methane

3.1 Methane to ethylene and ethane

3.2 Methane to ethylene and aromatics

4 Methane dehydroaromatization (MDA)

4.1 Catalyst and active sites .

4.2 Catalyst deactivation

4.3 Catalyst regeneration

4.3.1 Co-feeding $\mathrm{O}_{2}, \mathrm{CO}$ and $\mathrm{CO}_{2}$

4.3.2 $\mathrm{H}_{2} \mathrm{O}$ co-feeding.

4.3 .3 Reaction of steam with naphthalen

4.4 Incorporating a second metal into Mo/Zeolite

4.5 Alternative catalysts .

4.6 MDA reaction kinetics

*Corresponding author. Tel: +1-303-273-3379.

Email address: rjkee@mines . edu (Robert J. Kee)
Reactor technologies

1 OCM reactors

5.1.2 One-dimensional packed-bed formulation . . . . . . . . . 25

5.1.3 Modeling OCM membrane reactors . . . . . . . . . 25

5.1 .4 Combined OCM processes . . . . . . . . . . . . . . 26

5.2 MDA reactors. .28

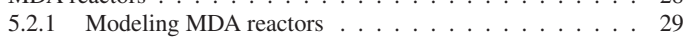

5.2 .2 Combined MDA processes . . . . . . . . . . 30

6 Membrane materials and transport 31

6.1 Palladium membranes . . . . . . . . . . . . . . . . . . 32

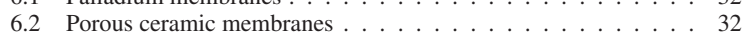

6.3 Oxide-ion conducting membranes . . . . . . . . . . . 33

6.4 Mixed ionic-electronic conductors, MIEC . . . . . . . . . . . 34

6.4 .1 Protonic ceramic membranes .............. 34

6.4.2 Oxygen-ion transport membranes . . . . . . . . . . . 36

6.4 .3 Ion-transport membrane conductivity . . . . . . . . . . . 37

6.4.4 Nernst-Planck-Poisson model .......... 37

6.5 Ion-catalyst interactions . . . . . . . . . . . . . . . . . . . 38

6.6 Membrane summary characteristics $\quad \ldots \ldots \ldots$

7 Membrane reactor technology 38

8 Hydrogen-membrane assisted processes 40

8.1 Pd-based $\mathrm{H}_{2}$ membranes ....... 40

8.2 Protonic-ceramic membranes . . . . . . . . . . . . . 41

9 Oxygen-membrane assisted processes $\quad 42$

9.1 Ion-transport membranes for OCM . . . . . . . . . . . . 42

9.2 Porous membranes for OCM . . . . . . . . . . . . . . 43

9.3 Oxygen membranes for MDA $\ldots \ldots \ldots \ldots$

10 Summary and outlook $\quad 44$

11 Acknowledgements 44

12 References 45

Preprint submitted to Prog. Energy Combust. Sci. 


\section{Introduction}

The growing availability of low-cost and domesti- 112 cally sourced natural gas leads to increased interest in its conversion to more-valuable fuels and chemicals. Al- ${ }_{114}$ though natural gas is a mixture of small hydrocarbons 115 and other components such as sulfur compounds, the 116 dominant component is methane. This review focuses 117 on the conversion of methane alone, where numerous 118 research and development challenges remain to be met ${ }_{119}$ and overcome. To narrow the scope even further, the 120 review is particularly concerned with the direct con- 121 version of methane to hydrocarbons, not to oxygenated 122 products such as alcohols or intermediates such as syn- 123 thesis gas (i.e., $\mathrm{CO}$ and $\mathrm{H}_{2}$ ). The term direct conversion 124 here refers to the processes that do not involve the in- 125 termediate production of synthesis gas. In other words, 126 "direct" means that reforming agents (i.e., $\mathrm{H}_{2} \mathrm{O}$ and/or ${ }_{127}$ $\mathrm{CO}_{2}$ ) are not added, or are added in very low levels that ${ }_{128}$ are not intended as reforming agents. Such low-level 129 reforming agents can also be produced as reaction inter- 130 mediates within the process, and can participate in some ${ }_{131}$ reforming chemistry within a so-called "direct" process. ${ }_{132}$ Previous authors have used a similar definition [1,2]. ${ }_{133}$

Essentially all such direct methane conversions re- 134 quire dehydrogenation, with details depending upon the 135 desired products. Because its regular tetrahedron struc- ${ }_{136}$ ture forms a perfectly symmetric zero dipole moment, 137 methane is a very stable molecule. Without any func- 138 tional groups to facilitate the chemical attacks, methane 139 activation requires breaking a strong $\mathrm{C}-\mathrm{H}$ bond (approx- 140 imately $439 \mathrm{~kJ} \mathrm{~mol}^{-1}$ ). Thus, elevated temperatures ${ }_{141}$ are necessary. Although still considered to be high- 142 temperature processes, catalysts can decrease reaction 143 temperatures to approximately $800{ }^{\circ} \mathrm{C}$ and lower. De- 144 spite the potential value of direct dehydrogenation pro- 145 cesses and despite considerable fundamental research, 146 practical, commercially viable, technology remains elu- 147 sive.

This review is concerned primarily with aspects of ${ }_{149}$ Oxidative Coupling of Methane (OCM) and Methane 150 Dehydroaromatization (MDA) [3-9]. Particular topics 151 range from catalyst performance to innovative reactor 152 design and development. The development and inte- 153 gration of permselective membranes can be important 154 aspects of process intensification and reactor develop- 155 ment.

A wide range of chemicals could be produced from ${ }_{157}$ methane. This paper focuses on the processes to form 158 small hydrocarbons with aliphatic, olefinic, or aromatic 159 content. The processes considered all involve ethy- 160 lene formation, which may be an intermediate compo- ${ }_{161}$ nent to produce compounds with higher olefin, paraffin, and aromatic (e.g., benzene) content. Oligomerization of ethylene can produce higher olefins that could be used in gasoline $\left(\mathrm{C}_{5}-\mathrm{C}_{10}\right)$ or in diesel fuel $\left(\mathrm{C}_{10}-\mathrm{C}_{20}\right)$. The higher olefins can also be converted to paraffins via catalytic hydrogenation processes $[10,11]$, leading to constituents needed for energy-dense fuels. Of course, ethylene itself is already a valuable chemical feedstock fro numerous downstream processes. Oxygenates (e.g., methanol, ethanol) are not within this paper's scope.

Processes such as Fischer-Tropsch (F-T) have been practiced commercially for decades. In this case, the methane is first catalytically reformed or partially oxidized to produce synthesis gas (primarily a mixture of $\mathrm{H}_{2}$ and $\mathrm{CO}$ ). The synthesis gas is then further processed to deliver a wide range of hydrocarbon or oxygenated products. However, assuming that a hydrocarbon product is desired, the sequence of first oxidizing to syngas and then reducing to the product has inherent inefficiencies. Nevertheless, despite any such inefficiencies, these processes are practical and industrially viable [12].

Direct conversion of methane to ethylene, as well as further oligomerization and hydrogenation, are all proven concepts. Ethylene oligomerization is an industrial-scale process, first developed by Shell in 1977 [10]. In that process, the ethylene is produced via a F-T process. However, despite substantial efforts in the last three decades, direct conversion of methane to ethylene requires improvements to be commercially successful.

In recent years, several patented technologies have been developed with the objective of commercializing gas-to-liquids (GTL) processes. Siluria Technologies [13] is apparently in the process of upscaling a pilot plant to produce ethylene as a precursor for logistic fuels. A large European Union framework program (2009-2014) focused on developing fully integrated processes for oxidative coupling of methane, where ethylene also served as a precursor for liquid logistic fuels. A number of alternative catalysts, processes, and reactors were investigated to demonstrate a proof of concept for ethylene to liquid fuels [14]. Nevertheless, despite significant efforts, these processes have not yet achieved commercial viability.

Direct methane conversion faces a number of significant challenges, including:

- Thermodynamically limited conversion,

- Catalyst selectivity to desired products,

- Catalyst deactivation via carbon deposits.

Membranes and membrane reactors can play important roles in mitigating the obstacles associated with direct conversion. 
Consider, for example, methane dehydroaromatiza- 207 tion (MDA) to produce benzene, which may be repre- 208 sented globally as

$$
6 \mathrm{CH}_{4} \rightleftharpoons 9 \mathrm{H}_{2}+\mathrm{C}_{6} \mathrm{H}_{6}, \quad \Delta H_{298}^{\circ} \approx+532 \mathrm{~kJ} .
$$

Another example is direct ethylene production, represented globally as

$$
2 \mathrm{CH}_{4} \rightleftharpoons 2 \mathrm{H}_{2}+\mathrm{C}_{2} \mathrm{H}_{4}, \quad \Delta H_{298}^{\circ} \approx+202 \mathrm{~kJ} .
$$

In both cases, the extent of methane conversion is thermodynamically limited by hydrogen accumulation within the reactor. In other words, the reaction can equilibrate with only a fraction of the methane being converted. Ideally, a hydrogen-permeable membrane that selectively removes $\mathrm{H}_{2}$ can promote increased conversion and product yield.

Although reactions 1 and 2 represent desired global results, no actual processes can achieve such ideal outcomes. Catalysts must be designed and fabricated to be as selective as possible. However, even with the best catalysts, numerous side products are inevitably produced. Although membranes can usually increase conversion, they can also affect (both favorably and unfavorably) the selectivity to the desired products and a wide range of undesired side products. Undesired side products often include catalyst-fouling coke precursors and polyaromatic hydrocarbon (PAH) deposits. Membranes can play important roles in limiting or controlling the production of these unwanted and damaging products.

\subsection{Catalysts}

Today, more than $90 \%$ of all transportation fuels at 241 some point during their production have passed over at ${ }_{242}$ least one catalyst. Some $80 \%$ of all chemical products 243 are manufactured with the aid of catalysis and more than 244 $20 \%$ of all industrial products rely on catalytic reaction 245 technology [15].

Catalysts decrease activation barriers by altering re- 247 action pathways, including the production of alternative 248 species that may not be formed via gas-phase chemistry. 249 Catalyst performance is usually governed by active sites 250 on the catalyst surface. For example, noble metals $(\mathrm{Rh}, 251$ $\mathrm{Pt}, \mathrm{Ru}, \mathrm{Pd})$ are effective reforming catalysts. Ironand chromium-oxides are effective for F-T synthesis. Some processes require catalytic bi-functionality, meaning two different catalytic groups fractionalize sequen- 253 tial reactions. For example, Mo/zeolite catalysts are 254 effective for methane dehyroaromatization (MDA). In 255 this case, methane is activated on $\mathrm{Mo}_{2} \mathrm{C}$ sites, primarily ${ }_{256}$ forming $\mathrm{C}_{2} \mathrm{H}_{4}$ and $\mathrm{H}_{2}$. The $\mathrm{C}_{2} \mathrm{H}_{4}$ is further oligomerized and cyclized at Brønsted acid sites on the zeolite, forming benzene, toluene, and naphthalene.

Effective catalysts must enable desired reactions to proceed at suitable rates under conditions that are technologically desirable (e.g., at low temperature and pressure). Low temperature and pressure usually decrease design and operational complexity, thus decreasing the production cost and promoting safe operating environments. Achieving catalyst selectivity to desired product mixtures is a major objective. Undesired products (e.g., solid carbon and $\mathrm{PAH}$ ) not only decrease the product yield but can also cause catalyst degradation and deactivation. Separating desired products from undesired side products can involve significant technical complexities and production costs, usually as downstream processes.

Effective catalysts should have structural integrity and chemical stability. Structural and mechanical integrity is important because catalysts can fracture under harsh operating conditions (e.g., acidic environments, high pressures). Chemical stability is important to prevent deleterious transformation of catalytically active surface sites. Impurities in reactant streams can poison the catalyst surfaces by strong adsorption on active sides, thus preventing desired adsorption of the reactants. For example, sulfur compounds are known to poison platinum and palladium catalysts. It is often possible to regenerate degraded or deactivated catalysts. However, doing so requires additional non-productive processes and time, increasing operational and production costs.

High-performance catalysts need to present readily accessible high surface areas to the reactant gases. Typical catalyst structures are formed as particles or pellets that are housed in packed-bed or washcoat configurations. In packed beds, gases flow around relatively large catalyst particles or pellets, which also have micro- and nano-scale pore structures that further increase active surface area. Washcoat structures are usually formed as thin layers (order of tens of microns) on the walls of millimeter-scale channels in monolithic structures or microchannel reactors [16, 17]. Especially with expensive noble-metal catalysts, it is important to design porous microstructures such that the active sites are readily accessible to the reactants.

\subsection{Temperature and pressure tradeoffs}

Essentially all processes that involve methane activation require elevated temperature (i.e., $\geq 700{ }^{\circ} \mathrm{C}$ ). However, operating pressure can vary, depending on the particular process and its integration with upstream 
and downstream processing requirements. For example, industrial-scale methane reformers often operate at elevated pressure ( $20 \leq p \leq 40$ bar), primarily to avoid the post-reforming compression of high temperature gases to be supplied to downstream processes that require high pressure (Fisher-Tropsh synthesis). High pressure actually compromises the performance of the reformation process. The design of particular chemical processes often depends on the integration with related processes, seeking overall optimal performance.

Similar to the methane reforming processes, the MDA process requires high temperatures and favors low pressure due to Le Châtelier's principle. MDA process is thermodynamically limited. Even at $700{ }^{\circ} \mathrm{C}$ and 1 bar, methane conversion is limited around $12 \%$ and the benzene yield is limited to approximately $8 \%$ [18]. Increasing pressure to 4 bar decreases methane conversion to $7 \%$, and by 10 bar methane conversion is reduced to approximately $5.5 \%$. Increasing temperature to $900{ }^{\circ} \mathrm{C}$ increases the methane conversion to approximately $40 \%$. However, the higher temperature favors the undesired formation of naphthalene over the desired benzene. Additionally, higher temperatures promote carbon deposits 308 and accelerated catalyst fouling. Unlike reforming pro- 309 cesses, MDA processes operate do not require reform- 310 ing agents $\left(\mathrm{H}_{2} \mathrm{O}, \mathrm{CO}\right.$ and $\left.\mathrm{CO}_{2}\right)$ that tend to suppress car- 311 bon deposits. However, introducing low levels of $\mathrm{H}_{2} \mathrm{O} \quad 312$ $(\leq 2 \%), \mathrm{CO}$ and $\mathrm{CO}_{2}(\leq 10 \%)$ can be beneficial but not ${ }_{313}$ fully eliminate catalyst-fouling carbon deposits. In iso- 314 lation, an MDA reactor should operate at temperatures 315 and pressures as low as possible.

The OCM process is significantly different from 317 MDA. Methane conversion is limited by oxygen avail- 318 ability, with the process being oxygen mass-transport 319 limited. Although increasing oxygen in the feed stream 320 increases methane conversion, it also favors undesired 321 total oxidation rather than the desired $\mathrm{C}_{2}$ formation. 322 The global rate OCM reaction $\left(2 \mathrm{CH}_{4}+\mathrm{O}_{2} \rightarrow \mathrm{C}_{2} \mathrm{H}_{4}+{ }_{323}\right.$ $2 \mathrm{H}_{2} \mathrm{O}$ ) is mole-neutral. Thus, at comparable residence 324 times, increasing pressure has a negligible effect on the 325 methane conversion. However, because the OCM pro- 326 cess competes with total oxidation, increasing pressure 327 increases methane conversion rate toward to total oxi- 328 dation products and significantly decrease the $\mathrm{C}_{2}$ yield. 329 Although increasing temperature can increase the $\mathrm{C}_{2}$ se- ${ }_{330}$ lectivity, catalyst stability is a major concern.

\subsection{Membranes}

A variety of membranes can play potentially ben- 334 eficial roles in methane-conversion technology. In 335 dehydrogenation processs, hydrogen-permeable mem- 336 branes such as palladium or palladium-alloy membranes 337

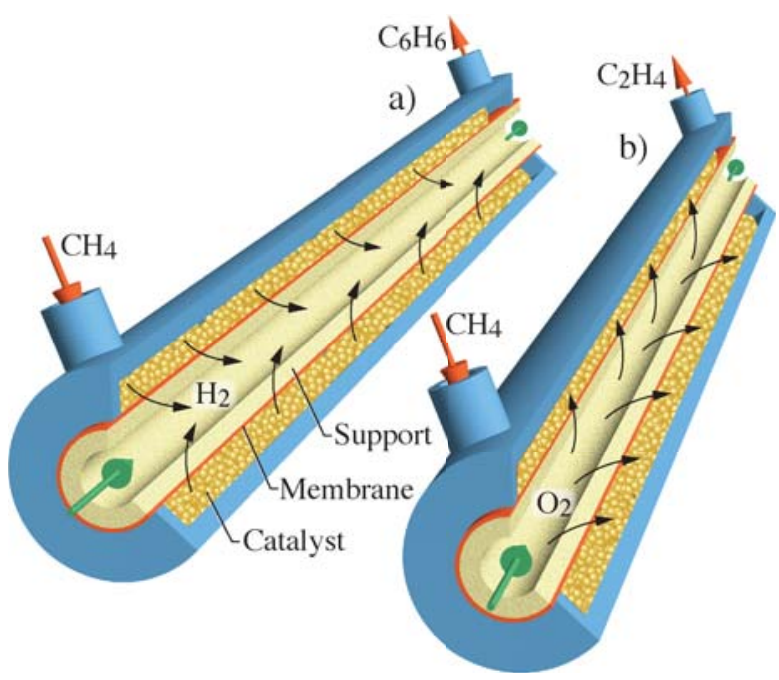

Figure 1: Illustration of a shell-and-tube membrane reactors. a) The left-hand reactor uses a hydrogen-permeable such as for an MDA process. b) The right-hand reactor uses an oxygen-permeable membrane as for an ethylene-production process.

may be relevant. A variety of dense-ceramic ionconducting membranes are also relevant. The protoonconducting ceramics are typically doped pervoskites (e.g., $\mathrm{BaZr}_{0.9} \mathrm{Y}_{0.1} \mathrm{O}_{3-\delta}$, BZY10), which are usually mixed ionic-electronic conductors (MIEC). Depending on the particular membrane material, these ceramics may also have significant oxide-ion conductivity. In some cases, the material may also have significant electronic conductivity. Because of the required high temperatures for methane activation, polymer-based membranes are usually not relevant and not considered here.

Depending on the conversion process, the membranes may be hydrogen permeable, oxygen permeable, or a combination of both. Figure 1 illustrates two possible membrane-reactor configurations. In both cases, a packed-bed catalyst fills the annular space outside of a central sweep tube. The sweep tube is configured as a porous support, with a thin (order of tens of microns) membrane applied to the outer surface. The lefthand reactor illustrates a hydrogen-permeable membrane, such as might be used for an MDA process. In this case, hydrogen is transported from the catalyst bed, through the membrane, and into the sweep tube. Ideally, by reducing the hydrogen concentration within the catalyst bed, the thermodynamic equilibrium shifts in favor of increasing methane conversion and benzene yield (cf., Eq. 1). However, as discussed subsequently, the benzene yield may not always increase because of competition with the production of undesired side products such as naphthalene, toluene, or higher aromatics. 
As illustrated in Fig. 1a, the membrane transports ${ }_{387}$ only hydrogen. A palladium membrane would de- 388 liver such performance. However, a ceramic mixed- 389 conducting membrane can perform differently. Mate- 390 rials such yttrium- and cerium-doped barium zirconates 391 (BCZY) can simultaneously transport both protons and 392 oxide ions [19]. Depending on the sweep-gas and 393 catalyst-bed composition, the net effect can be hydro- 394 gen leaving the catalyst bed and steam entering the cat- 395 alyst bed. Because steam can react with deleterious side products such as naphthalene, ceramic MIEC mem- 396 branes can offer potentially significant advantages com- 397 pared to pure hydrogen-permeable membranes. 398

Figure 1b illustrates an oxygen-permeable mem- 399 brane. Even in non-oxidative processes, low levels of 400 oxygen onto the catalyst can be beneficial, including 401 promotion of methane activation and preferential mit- 402 igation of carbon deposits. However, it should be em- 403 phasized that only low oxygen fluxes are relevant. If 404 too much oxygen enters the catalyst bed, then undesired 405 reforming or complete oxidation can dominate. In de- 406 hydrogenation processes, $\mathrm{H}_{2}$ is readily available within 407 the catalyst bed. Thus, under most circumstances, the 408 oxygen (or oxide ions in the case of ion-transport mem- 409 branes) emerging from the membrane reacts rapidly to 410 produce $\mathrm{H}_{2} \mathrm{O}$.

Stated globally the oxidative coupling of methane 411 (OCM) can be represented as

$$
2 \mathrm{CH}_{4}+\mathrm{O}_{2} \rightarrow \mathrm{C}_{2} \mathrm{H}_{4}+2 \mathrm{H}_{2} \mathrm{O}, \quad \Delta H_{298}^{\circ} \approx-281 \mathrm{~kJ} .
$$

Typically, the oxygen and methane are premixed before ${ }_{41}$ entering the catalyst bed. However, there are potential ${ }_{417}$ benefits associated with oxygen-permeable membranes 418 that deliver oxygen along the length of the bed (e.g., 419 Fig. 1b). One approach is to use porous-alumina tubular 420 structures. Another approach uses dense ceramic oxide- 421 ion-conducting membranes such as $\mathrm{La}_{1-x} \mathrm{Ca}_{x} \mathrm{FeO}_{3-\delta} 422$ (LCF).

Certain dense-ceramic ion-conducting membranes 424 offer the possibility of control via electrical polariza- 425 tion. Ceramic membranes with low electronic conduc- 426 tivity compared to ionic conductivity can be polarized in 427 the sense of using an external circuit to impose an elec- 428 trostatic potential across the membrane. Yttria-stablized ${ }_{429}$ zirconia (YSZ) is such a material, with good oxide-ion 430 mobility but very little electronic conductivity. Such 431 membranes are widely used in solid-oxide fuel cells 432 (SOFC) and electrolyzers (SOEC). Doped barium cer- 433 ates and zirconates have proton mobility, but relatively 434 low electronic conductivity [20]. An applied electro- 435 static potential serves to mediate (accelerate or retard) ${ }_{436}$ the electronically charged ion fluxes through the membrane. Electrodes that are spatially segmented along the length of the reactor provide an opportunity to locally control the fluxes through the membrane. However, because the ion conductivity of the ceramic membranes is relatively low, there can be substantial electrical costs associated with the polarization control.

Sections 6 and 7 discuss membrane materials and membrane reactor technologies in more detail.

\subsection{Processes}

This review concentrates on catalytic processes involving the initial conversion of methane to ethylene, and subsequently to gas mixtures with aliphatic and aromatic content. Broadly speaking, the processes may be oxidative or non-oxidative. However, in the oxidative case, this review is not concerned with reforming or partial oxidation to synthesis gas or the production of oxygenated compounds such as alcohols. The first sections of the paper are primarily concerned with reviewing and discussing alternative catalysts and catalytic processes. The following sections are concerned primarily with reactor design and performance. An important aspect of the paper is the consideration of membranes and membrane reactors.

\subsection{Prior reviews on methane conversion}

Direct conversion of methane to valuable chemical products has been the subject of several previous review articles. Because the topic involves a wide range of processes (oxidative, non-oxidative), products (aliphatic, aromatic, oxygenates), reactor concepts (flow reactors, membrane coupled flow reactors) and catalysts, some of the reviews are specific to subtopics.

A 2003 review by Choudhary et al. [21] considered the direct conversion of methane under non-oxidative conditions. They addressed some the main challenges associated with direct conversion, such as thermodynamic limitations and catalyst deactivation resulting in low yield. A 2014 review by Tang et al. [7] focused on methane activation either by high temperature or via oxygenates. Their review concluded that among the oxidative and non-oxidative conversion routes, nonoxidative processes such as methane to ethylene and aromatics are promising future technologies.

In 2013, Majhi et al. [22] reviewed the methane dehydroaromatization (MDA) process with a specific focus on Mo/zeolite catalysts, catalyst preparation methods, operating conditions (i.e., temperature and pressure), and reaction pathways. Their review discussed catalyst deactivation as a major technological impediment. They also discussed the effects of doping 2-3\% 
noble metals into Mo/zeolite catalysts, increasing ben- 489 zene yield and catalyst stability. Also in 2013, Ma et 490 al. [6] reviewed MDA processes. That review discussed 491 key technologies for process up-scaling, including cata- 492 lyst development and hydrogen-permeable membranes. 493

Mamonov et al. [23] published another 2013 re- 494 view on methane dehydroaromatization, concentrating 495 on Mo/ZSM-5 catalysts. This review concentrated on 496 physical and chemical properties of the catalyst, in- 497 cluding the structure of active sites, chemical mecha- 498 nisms, and deactivation processes. The paper suggested 499 approaches for improving catalytic activity, such as a 500 second-metal doping.

Spivey and Hutchings [9] reviewed the status of MDA chemistry as of 2014. The primary focus of that review was on catalysts and catalytic reactor designs. Thermodynamic limitations, coke formation, and rapid ${ }_{503}$ catalyst deactivation were identified as significant prob- 504 lems. The review suggested that computational mod- 505 eling would likely play a major role in understanding 506 the catalytic chemistry and mitigating the deactivation 507 problems.

Numerous studies have been published on the direct 509 conversion of methane via oxidative processes, espe- 510 cially concentrating on catalyst research $[24,4,5,25,8]$. 511 Zavyalova et al. [4] published an extensive review of 512 the OCM catalysts, including the effects of metals and ${ }_{513}$ metal doping. A 2012 review by Takanabe [5] that re- 514 ported the status of OCM processes, emphasizing the 515 importance of developing alternative catalysts that im- 516 prove ethylene selectivity.

Usachev et al. [3] published a 2009 review that fo- 518 cused on oxidative processes for small alkanes, in- 519 cluding the oxidative coupling of methane. That re- 520 view identified the primary challenges as being low se- 521 lectivity, low $\mathrm{C}_{2}$ yield, catalyst stability, coke forma- ${ }_{522}$ tion, and temperature control. Integration with oxygen- ${ }_{523}$ permeable membranes was discussed in the context of ${ }_{524}$ improving thermal control and $\mathrm{C}_{2}$ yield.

Liu et al. [26] published a 2001 review that concen- ${ }_{526}$ trated on membrane-coupled methane-conversion pro- ${ }_{527}$ cesses, with a specific focus on protonic and mixed- ${ }_{528}$ conducting membrane reactors. Low hydrogen or oxy- ${ }_{529}$ gen fluxes through the membranes were identified as ${ }_{530}$ important drawbacks for the membrane technology. ${ }_{531}$ The paper suggested that the successful development ${ }_{532}$ of ultra-thin inorganic hollow-fiber perovskite mem- ${ }_{533}$ branes would play important roles in increasing the ion ${ }_{534}$ fluxes. Other reviews generally come to similar con- ${ }_{535}$ clusions [27-31]. There are certainly opportunities for 536 developing new high-performance membranes, seeking ${ }_{537}$ to increase and control fluxes and to improve chemical ${ }_{538}$ and mechanical stability.

Compared with membrane-coupled oxidative processes, MDA processes coupled with hydrogenpermeable membranes are much less mature. Although removing hydrogen from the product stream increases methane conversion, it also tends to increase carbon deposits and catalyst deactivation rates. Hydrogen removal can also promote selectivity toward unwanted polyaromatic hydrocarbons, thus competing with the desired benzene yield. Although limited to only a few studies, there is growing interest in oxygen membrane coupled MDA processes [32, 33]. However, to date there are no published reviews in this area.

\section{Oxidative conversion of methane}

In the early 1980s, Keller and Bhasin [34] first introduced the concept of direct conversion of methane to ethylene, written globally as Eq. 3. Methane was first activated by oxygen in the absence of a catalyst at temperatures above $800{ }^{\circ} \mathrm{C}$. The process was later called Oxidative Coupling of Methane (OCM).

Assuming that the OCM process behaves as shown by Eq. 3, the downstream $\mathrm{H}_{2} \mathrm{O}$ separation is straightforward by condensation. However, together with the desired $\mathrm{C}_{2} \mathrm{H}_{4}$, the process also yields considerable levels of $\mathrm{C}_{2} \mathrm{H}_{6}$ and low levels of higher hydrocarbons (e.g., $\mathrm{C}_{3} \mathrm{H}_{6}, \mathrm{C}_{3} \mathrm{H}_{8}$ ). Unfortunately, significant levels of undesired oxidation products $\mathrm{CO}, \mathrm{CO}_{2}$, and $\mathrm{H}_{2} \mathrm{O}$ are also formed, thus decreasing the desired $\mathrm{C}_{2+}$ selectivity. Moreover, the $\mathrm{CO}$ and $\mathrm{CO}_{2}$ separations can be difficult.

All practically viable OCM processes depend on a catalyst. High reaction temperatures (i.e., $T \geq 700{ }^{\circ} \mathrm{C}$ ) are generally necessary to activate methane. However, with recent advances in catalyst technologies, significant conversion and yield can be obtained at somewhat lower reaction temperatures as well. The methane conversion is controlled by the oxygen concentration in the mixture. The formation of side products is associated with the high reaction temperature because the total oxidation of $\mathrm{CH}_{4}$ and $\mathrm{C}_{2}\left(\mathrm{C}_{2} \mathrm{H}_{4}\right.$ and $\left.\mathrm{C}_{2} \mathrm{H}_{6}\right)$ are favored at high temperatures. The formation of side products not only decreases the product yield, but also introduces additional downstream gas-separation costs.

To date, despite considerable research, no particular catalyst has emerged that fully meets practical industrial and economic requirements. Two important challenges remain to be overcome. The first is the catalyst selectivity and the second is catalyst deactivation as a function of time-on-stream. Several reviews of OCM catalysts and processes have been published $[35,24,36]$. The 2015 review by Kondratenko et al. [37] explores OCM 
catalyst and process design. Economic analyses suggest 588 commercial viability demands single-pass $\mathrm{C}_{2} \mathrm{H}_{4}$ yields 589 that exceed $25 \%[38,39]$.

Broadly speaking, OCM catalysts and processes 591 can be categorized as being either high- and low- 592 temperature processes. Most of the literature con- ${ }_{593}$ siders high-temperature catalysis $\left(T \geq 700{ }^{\circ} \mathrm{C}\right)$. The 594 low-temperature processes appear to hold promise, but 595 are relatively new and undeveloped. High tempera- 596 ture catalysts include $\mathrm{Li} / \mathrm{MgO}, \mathrm{Mn} / \mathrm{Na}_{2} \mathrm{WO}_{4} / \mathrm{SiO}_{2}$, and ${ }_{597}$ $\mathrm{Sr} / \mathrm{La}_{2} \mathrm{O}_{3}$.

\section{1. $\mathrm{Li} / \mathrm{MgO}$ catalyst}

$\mathrm{Li} / \mathrm{MgO}$ catalysts were first developed by Ito et al. in 1985 [40]. Although the ethylene yield was considered to be good $\left(\approx 12 \% \mathrm{C}_{2}\right)$, it did not meet the economic expectations of $25 \% \mathrm{C}_{2+}$ single-pass yield [41]. Another problem was catalyst stability, with significant Li loss after long time-on-stream [42]. An electron microscopy study by Myrach et al. [43] revealed that $\mathrm{Li} / \mathrm{MgO}$ undergoes morphological changes under OCM operating conditions. Above $427^{\circ} \mathrm{C}, \mathrm{Li}$ segregates and above $777^{\circ} \mathrm{C} \mathrm{Li} \mathrm{desorbs} \mathrm{from} \mathrm{the} \mathrm{MgO}$. Because there is a strong relationship between the $\mathrm{Li}$ loss and the catalyst deactivation, early findings by Lunsford and colleagues [40, 44] and Peng et al. [45] concluded that the catalytically active center was $\mathrm{Li}^{+} \mathrm{O}^{-}$. Both research groups supported their findings with the experimental surface characterization techniques, including Electron Paramagnetic Resonance (EPR) [40, 44] and X-ray Photoelectron Spectroscopy (XPS) [45] Recently, Kwapien et al. [46] published a density functional theory (DFT) model that supported the idea of morphological change. However, unlike the early conclusions, more recent studies find no indication of $\mathrm{Li}^{+} \mathrm{O}^{-}$formation, suggesting that the active center is not $\mathrm{Li}^{+} \mathrm{O}^{-}$but rather oxygen-centered radicals on metal oxides (e.g., $\left.\mathrm{Mg}^{2+} \mathrm{O}^{2-}\right)$ [46].

Despite substantial research efforts, the exact structure of the $\mathrm{Li} / \mathrm{MgO}$ and its relationship to the catalytic activity remain unclear [25]. There contihues to be considerable experimental and theoretical research focused on $\mathrm{Li} / \mathrm{MgO}$ [47-49]. Compared to other mixed oxides, $\mathrm{Li} / \mathrm{MgO}$ has a relatively simple microstructure. With only one active center, catalyst preparation and theoretical studies are more easily accomplished than they are with other more complex alternatives. However, the poor stability limits the practical use of $\mathrm{Li} / \mathrm{MgO}$ as an OCM catalyst.

\section{2. $\mathrm{Mn} / \mathrm{Na}_{2} \mathrm{WO}_{4} / \mathrm{SiO}_{2}$ catalyst}

Two reviews on the family of $\mathrm{Mn} / \mathrm{Na}_{2} \mathrm{WO}_{4} / \mathrm{SiO}_{2}$ catalysts were published in 2012 by Takanabe [5] and Arndt et al. [50]. This class of catalyst is expected to deliver practical OCM performance.

In 1992 Fang et al. [51] first reported a mixed-oxide catalyst in the form of $\mathrm{Mn} / \mathrm{Na}_{2} \mathrm{WO}_{4} / \mathrm{SiO}_{2}$. They reported $23.9 \% \mathrm{C}_{2}$ yield at $800{ }^{\circ} \mathrm{C}$ in a packed-bed reactor. The active metals in $\mathrm{Mn} / \mathrm{Na}_{2} \mathrm{WO}_{4} / \mathrm{SiO}_{2}$ catalysts are $\mathrm{Mn}, \mathrm{Na}$, and $\mathrm{W}$. There are also synergic effects with the $\mathrm{SiO}_{2}$ supports. $\mathrm{Mn} / \mathrm{Na}_{2} \mathrm{WO}_{4} / \mathrm{SiO}_{2}$ catalysts can produce higher $\mathrm{C}_{2}$ yield compared to $\mathrm{Li} / \mathrm{MgO}$ and they are more stable at high temperature. However, they are much complicated to understand in terms of structural and chemical complexity and active centers. Elemental composition and relative loadings, as well as the catalyst preparation techniques, play critical roles in the catalytic activity [52-57]. The final chemical composition is a mixed oxide, that contains $\mathrm{MnO}_{2}, \mathrm{Mn}_{2} \mathrm{O}_{3}$, $\mathrm{MnWO}_{4}$ and $\mathrm{Na}_{2} \mathrm{WO}_{4}$ and $\mathrm{SiO}_{2}$ [55]. The synthesis process leads to the formation of bulk oxides. However, the catalyst undergoes further chemical and physical changes under OCM conditions. Amorphous silica undergoes a phase transformation to $\alpha$-cristobalite. Amorphous silica behaves as a total oxidation catalyst whereas $\alpha$-cristobalite is essentially inert. Surface reconstruction also occurs among the metal oxides and the silica [58]. All these dynamic changes make fundamental understanding and catalyst optimization difficult [59-65].

Numerous theories have been proposed about the catalytic active center for $\mathrm{Mn} / \mathrm{Na}_{2} \mathrm{WO}_{4} / \mathrm{SiO}_{2}$. Broadly speaking, two distinct theories arise. The theory proposed by Lunsford and colleagues suggested that the active site contains Na-O-Mn species. The Mn was expected to be responsible for activation of gas-phase oxygen, the Na was essential for preventing the total oxidation of methane, and $\mathrm{W}$ was claimed to be controlling the stability of the catalyst [59]. Using XPS, laser Raman spectroscopy, and XRD diffraction, this theory was later supported by Green and coworkers [63, 64].

An alternative theory, based on the XRD and Raman spectra analysis, suggested that that the catalyst undergoes a surface reconstruction. Surface clusters including $\mathrm{W}=\mathrm{O}$ and $\mathrm{W}-\mathrm{O}-\mathrm{Si}$ species are expected to be the active centers that control methane activation as well as $\mathrm{C}_{2}$ selectivity. The Mn was suggested to increase the mobility of surface lattice oxygen $[66,60,63]$. Bulk metal oxides $\left(\mathrm{MnO}_{2}, \mathrm{Na}_{2} \mathrm{WO}_{4}\right)$ are expected to be physically unstable because their melting points are below $700{ }^{\circ} \mathrm{C}$. Thus, it is more reasonable to believe that the a $\mathrm{MnWO}_{4}$ related bulk oxide is responsible for the active center formation. 
Processes based $\mathrm{Mn} / \mathrm{Na}_{2} \mathrm{WO}_{4} / \mathrm{SiO}_{2}$ catalysts require 690 operating temperatures around $800{ }^{\circ} \mathrm{C}$ and higher. 691 Although recent advances show that the economical 692 goal of 25\% single pass yield can be achieved with 693 $\mathrm{Mn} / \mathrm{Na}_{2} \mathrm{WO}_{4} / \mathrm{SiO}_{2}$, the long-term catalyst stability re- 694 mains a concern at these elevated temperatures. 695

Hiyoshi and Ikeda considered increasing OCM activ- 696 ity by mixing $\mathrm{Mn} / \mathrm{Na}_{2} \mathrm{WO}_{4} / \mathrm{SiO}_{2}$ catalysts with alkali 697 chlorides ( $\mathrm{LiCl}, \mathrm{NaCl}, \mathrm{KCl}, \mathrm{CsC})$ [56]. Doping the cat- 698 alyst with an equimolar mixture of $\mathrm{NaCl}$ and $\mathrm{KCl}$ in- 699 creased the ethylene yield up to $31 \%$ at $750{ }^{\circ} \mathrm{C}$. The 700 catalytic performance was measured in a packed-bed re- 701 actor at atmospheric pressure. Although the paper noted 702 that alkali chlorides are volatile at OCM reaction tem- 703 peratures, stability data was not reported.

Mahmodi et al. [67] prepared $\mathrm{M} / \mathrm{Na} / \mathrm{Mn} / \mathrm{SiO}_{2}$-based 705 nanocatalysts, where " $\mathrm{M}$ " represents a metal. By incor- 706 porating different metals $(\mathrm{M}=\mathrm{W}>\mathrm{Mo}>\mathrm{Nb}>\mathrm{Cr}>707$ V) into the structure, a maximum $\mathrm{C}_{2}$ yield of $31.6 \% 708$ was reported at $775{ }^{\circ} \mathrm{C}$ and 1 bar in a packed-bed re- 709 actor. The gas phase species were measured by online 710 gas chromatography. However, the catalysts were un- 711 stable after $9 \mathrm{~h}$ on stream, with the deactivation being 712 apparently due to the loss of catalytic surface area by 713 sintering. In a related approach, Ha et al. [68] patented 714 a composition of $\mathrm{NaW} / \mathrm{MnO}_{2} / \mathrm{SiO}_{2}$ with 3.5 wt. $\% \mathrm{NaW}, 715$ 1.3 wt. $\% \mathrm{MnO}_{2}\left(\right.$ remainder $\mathrm{SiO}_{2}$ ) catalyst and showed 716 $18.4 \% \mathrm{C}_{2}$ yield at $800{ }^{\circ} \mathrm{C}$. This catalyst was found to be 717 durable even after $40 \mathrm{~h}$ of operation. Catalyst screen- 718 ing experiments were carried out in a packed-bed re- 719 actor, and the effects of gas-hourly space velocity and 720 fuel/oxygen ratio were tested.

A 2011 patent by Zarrinpashne et al. [69] reported ${ }_{722}$ significant increases in $\mathrm{C}_{2}$ yield. The catalyst, which 723 was prepared by either co-precipitation or impregnation 724 techniques, contained 1.9 wt.\% Nb, 2 wt.\% Mn, 1.8725 wt. $\% \mathrm{Na}, 2.8$ wt. $\% \mathrm{~W}$, with a $\mathrm{SiO}_{2}$ support. An ethylene 726 yield of $27.24 \%$ was reported at $8500^{\circ} \mathrm{C}$ in a packed-bed 727 reactor. Substitution of $\mathrm{Nb}$ into the $\mathrm{Mn} / \mathrm{Na}_{2} \mathrm{WO}_{4} / \mathrm{SiO}_{2} 728$ structure was shown to have a promotional effect on the 729 $\mathrm{C}_{2}$ yield.

\section{3. $\mathrm{La}_{2} \mathrm{O}_{3}$ catalyst}

Another potentially viable OCM catalyst is $\mathrm{La}_{2} \mathrm{O}_{3}$. ${ }^{731}$ The catalytic activity can be increased by doping with ${ }^{732}$ alkaline-earth metals ( $\mathrm{Sr}, \mathrm{Mg}, \mathrm{Ca}$ ), which produces strong basic sites [70-72]. Early studies indicated ${ }^{733}$ that $\mathrm{Sr}$ doping showed the most promising OCM ac- ${ }_{734}$ tivity [73-75]. Choudhary et al. [72] reported 17\% 735 $\mathrm{C}_{2}$ yield over $\mathrm{Sr} / \mathrm{La}_{2} \mathrm{O}_{3}$ at $800{ }^{\circ} \mathrm{C}$ in a continuous-flow 736 packed-bed reactor.
Although not as active and selective as $\mathrm{Sr} / \mathrm{La}_{2} \mathrm{O}_{3}$, the catalytic performance of $\mathrm{CaO}$ doped $\mathrm{La}_{2} \mathrm{O}_{3}$ has been investigated. Becker and Baerns [76] reported $76 \% \mathrm{C}_{2+}$ selectivity and $9 \% \mathrm{C}_{2+}$ yield at $740{ }^{\circ} \mathrm{C}$, with the optimum $\mathrm{La}_{2} \mathrm{O}_{3} / \mathrm{CaO}$ ratio being in the range of 60-80\%. Stansch et al. [71] studied the kinetics of $\mathrm{La}_{2} \mathrm{O}_{3} / \mathrm{CaO}$ in a packed-bed reactor and developed a ten-step reaction mechanism among eight gas-phase species. The reaction mechanism was validated using measurements in packed-bed reactors. A 2010 study by Rane et al. [77] showed that the catalyst preparation method (i.e., physical mixing of $\mathrm{La}_{2} \mathrm{O}_{3}$ and $\mathrm{CaO}$ or co-precipitation method) and source of precursors (i.e., acetates, carbonates, nitrates, and hydroxides) strongly influence the catalytic activity. Rane et al. demonstrated $15.2 \% \mathrm{C}_{2}$ yield at $800{ }^{\circ} \mathrm{C}$ in a packed-bed reactor using catalysts prepared by co-precipitation with carbonates as precursors. Unfortunately, the $\mathrm{La}_{2} \mathrm{O}_{3} / \mathrm{CaO}$ shows low stability and activity in OCM processes. Nevertheless, the synthesis is relatively straightforward and the catalytic activity can be controlled by the ratio between $\mathrm{La}_{2} \mathrm{O}_{3}$ and $\mathrm{CaO}$. In part, because validated reaction mechanisms are available, a number of groups use $\mathrm{La}_{2} \mathrm{O}_{3} / \mathrm{CaO}$ as a basis for model-based reactor development and parameter studies [78-83].

Unlike the $\mathrm{Li} / \mathrm{MgO}$ and $\mathrm{Mn} / \mathrm{Na}_{2} \mathrm{WO}_{4} / \mathrm{SiO}_{2}$, the $\mathrm{La}_{2} \mathrm{O}_{3}$ catalysts produce significant yields of $\mathrm{C}_{2} \mathrm{H}_{6}$. The doping metal and the support structure can significantly affect the $\mathrm{C}_{2} \mathrm{H}_{4}$ to $\mathrm{C}_{2} \mathrm{H}_{6}$ ratio. Operating at $730{ }^{\circ} \mathrm{C}$, Baidya et al. [84] reported a $\mathrm{C}_{2} \mathrm{H}_{4} / \mathrm{C}_{2} \mathrm{H}_{6}$ ratio of 0.4 , with the overall $\mathrm{C}_{2}$ yield at approximately $16 \%$. Baidya et al. found that by changing the support to $\mathrm{Al}_{2} \mathrm{O}_{3}$, the $\mathrm{C}_{2+}$ yield can be varied. By tuning the $\mathrm{Sr} / \mathrm{Al}$ ratio in the catalyst mixture, they were able to increase the $\mathrm{C}_{2} \mathrm{H}_{4} / \mathrm{C}_{2} \mathrm{H}_{6}$ ratio to 1.7 , with $18 \%$ overall $\mathrm{C}_{2+}$ yield at $810{ }^{\circ} \mathrm{C}$. The catalyst was durable for $48 \mathrm{~h}$ on stream, showing stable methane conversion and $\mathrm{C}_{2+}$ selectivity.

Stability is a major concern with $\mathrm{La}_{2} \mathrm{O}_{3}$ catalysts, especially when $\mathrm{CO}_{2}$ is present at temperatures above $650{ }^{\circ} \mathrm{C}$. Under these conditions, $\mathrm{La}_{2} \mathrm{O}_{3}$ reacts to form a dioxymonocarbonate structure $[85,86]$,

$$
\mathrm{La}_{2} \mathrm{O}_{3}+\mathrm{CO}_{2} \rightarrow \mathrm{La}_{2} \mathrm{O}_{2} \mathrm{CO}_{3},
$$

which is unstable at high temperature $\left(850-900^{\circ} \mathrm{C}\right)$ [86]

\section{4. $\mathrm{Fe}_{2} \mathrm{O}_{3}$ catalyst}

Another potentially viable OCM catalyst group is based on iron oxides [87, 88]. Although methane conversion can be as high as $55-60 \%$ at temperatures above $700^{\circ} \mathrm{C}$ and the catalyst is stable, the $\mathrm{C}_{2}$ yield is below 
5\% [88]. The low $\mathrm{C}_{2}$ yield is caused by complete ox- 789 idation of methane at high temperatures. Iron forms 790 the active $\alpha-\mathrm{Fe}_{2} \mathrm{O}_{3}$ phase and the oxygen in the lattice 791 promotes the complete oxidation of methane. Van Der 792 Vaart [89] patented a process using a 100-150 $\mu$ m layer 793 of $\mathrm{Fe}_{2} \mathrm{O}_{3}$ catalyst supported on a low-surface-area non- 794 porous $150-215 \mu \mathrm{m}$ layer of $\mathrm{SiO}_{2}$. By mixing steam into 795 the $\mathrm{CH}_{4} / \mathrm{O}_{2}$ mixture, the $\mathrm{C}_{2}$ selectivity was increased 796 with yields up to $7 \%$ at $850{ }^{\circ} \mathrm{C}$ in a fluidized bed re- 797 actor. Van Der Vaart proposed that water preferentially 798 poisoned the catalyst surface by occupying the catalytic 799 sites that would otherwise serve to oxidize the methyl 800 radicals prior to the desired desorption. Although Fe- 801 containing catalysts may not be sufficiently selective 802 for OCM, they may be promising catalysts under non- 803 oxidative conditions $[90,91]$.

\subsection{Low temperature catalysts}

The inherent nature of methane activation generally 807 requires high-temperature processes. Thermal manage- 808 ment, including temperature uniformity, catalyst deacti- 809 vation, and coke formation, presents potential problems 810 in the design and operation of high-temperature reac- 811 tors. Thus, there is ongoing interest in finding OCM 812 catalysts that are effective at relatively low operating 813 temperatures.

Early catalyst screening studies focused on decreas- 815 ing reaction temperatures by considering different met- 816 als and metal oxides. Using alkali- and alkaline-doped 817 metal oxides, Roos et al. [92] showed that reaction tem- 818 peratures could be decreased to around $530{ }^{\circ} \mathrm{C}$ with 819 approximately $12 \% \mathrm{C}_{2}$ yield over a $\mathrm{Li} / \mathrm{MgO}$ catalyst 820 $(5.3$ wt.\% Li) in a packed-bed reactor. Alternatively, 821 Fe-P-O catalysts, which belong to the transition-metal 822 group, also showed promising low-temperature activ- 823 ity $[93,94]$. Using mass spectrometry and gas chro- 824 matography, Annapragada and Gulari reported approxi- 825 mately $6.5 \% \mathrm{C}_{2+}$ yield at $575^{\circ} \mathrm{C}$ over a Fe-O-P catalyst 826 in U-shaped and straight packed-bed reactors [93]. $\quad 827$

A number of recent studies have shown that the cat- 828 alyst activity depends not only on the catalyst's metal 829 composition, but also on particle size and morphol- 830 ogy [95-98]. Nano-structured catalysts were found to 831 activate the methane at lower temperatures $[99,98]$. The 832 superior catalytic activity of nanorods and nonofibers 833 was attributed to high surface areas, well defined crys- 834 talline structures, and their ability to form surface oxide 835 species [95].

Noon et al. [99] showed that $\mathrm{La}_{2} \mathrm{O}_{3}-\mathrm{CeO}_{2}$ nanofibers ${ }_{837}$ delivered superior OCM performance compared to the 838 same catalysts in powder form. Earlier studies by De- 839 dov et al. [100] measured catalytic activity of $\mathrm{La}_{2} \mathrm{O}_{3}-{ }^{-} 84$
$\mathrm{CeO}_{2}$ in powder form and they reported optimum reaction temperatures in the range of $715-830^{\circ} \mathrm{C}$. The Noon et al. study also showed that the methane activation temperatures can be as low as $470{ }^{\circ} \mathrm{C}$ using the same catalyst composition as the earlier findings of Dedov et al. Noon et al. reported a maximum of $18 \% \mathrm{C}_{2+}$ yield at $520{ }^{\circ} \mathrm{C}[99]$ in a packed-bed reactor.

Hou et al. [97] studied $\mathrm{La}_{2} \mathrm{O}_{2} \mathrm{CO}_{3}$ catalysts with different nanoscale plate and rod morphologies, particle sizes, and calcination temperatures. Catalytic performance was measured in a packed-bed reactor at atmospheric pressure. The process delivered $30 \% \mathrm{CH}_{4}$ conversion and $50 \% \mathrm{C}_{2+}$ selectivity at $420{ }^{\circ} \mathrm{C}$. The catalyst was fond to be stable for over $50 \mathrm{~h}$ on stream.

Huang et al. [95] studied shape effects for nanostructured $\mathrm{La}_{2} \mathrm{O}_{3}$ catalysts under OCM conditions. The catalytic performance was measured in a packed-bed reactor where the catalyst was diluted with the quartz sand. They reported that $\mathrm{La}_{2} \mathrm{O}_{3}$ nanorods were more active than nano-particles. Approximately $10 \% \mathrm{C}_{2}$ yield was reported at $450{ }^{\circ} \mathrm{C}$, with reaction being initiated at $400{ }^{\circ} \mathrm{C}$. However, elevated-temperature stability was a problem with the $\mathrm{La}_{2} \mathrm{O}_{3}-\mathrm{CeO}_{2}$ material. Above $550{ }^{\circ} \mathrm{C}$, the $\mathrm{C}_{2}$ selectivity decreased greatly. A recent study by Song et al. [96] developed a stable $\mathrm{Sr} / \mathrm{La}_{2} \mathrm{O}_{3}$ nano-fiber catalyst. They reported approximately $16 \% \mathrm{C}_{2}$ yield at $500{ }^{\circ} \mathrm{C}$, with the catalyst being stable up to $800{ }^{\circ} \mathrm{C}$.

Siluria Technologies filed patent applications for a series of nanowire catalysts that operate at reaction temperatures below $600{ }^{\circ} \mathrm{C}$ [101]. One group of the nanowire lanthanum oxides catalysts were composed of $\mathrm{Ln} 1_{4-x} \mathrm{Ln} 2_{2-x} \mathrm{O}_{6}$, where $\mathrm{Ln} 1$ and $\mathrm{Ln} 2$ are two different lantanide-group metals (i.e., Y-La, Zr-La, Pr-La and CeLa). The $\mathrm{C}_{2+}$ yield was reported to exceed $22.5 \%$. Another catalyst composition recently patented by Siluria Technologies was a nanowire catalyst composed of 20 wt. $\% \mathrm{Mg}, 5$ wt. $\% \mathrm{Na}$, and 75 wt. $\% \mathrm{La}_{2} \mathrm{O}_{3}$. The reported $\mathrm{C}_{2+}$ yield was approximately $12 \%$ at $600{ }^{\circ} \mathrm{C}$ [102]. Using these catalysts, Siluria Technologies has apparently commercialized an ethylene production process. Although the reported single-pass $\mathrm{C}_{2+}$ yields do not meet the nominal target of $25 \%$, the process temperature is below $600{ }^{\circ} \mathrm{C}$ and the catalyst is durable over a long operating periods. The low reaction temperature reduces overall heating costs and decreases catalyst-deactivation rates. The up-scaled reactor was composed of multiple OCM packed-bed reactors. Thermal management systems were designed to achieve either adiabatic or isothermal conditions.

Fina Technology Inc. patented a composition using $\mathrm{MgO}$ as a second support for the $\mathrm{Sr} / \mathrm{La}$ catalyst on a low-temperature process $\left(T=500{ }^{\circ} \mathrm{C}\right)$ [103]. Although 
the $\mathrm{C}_{2}$ yield was relatively low at approximately $10 \%$, the low reaction temperature offered other potential benefits. At low temperature, deactivation from sintering is greatly diminished.

\subsection{OCM Reaction kinetics}

Although OCM is generally understood to be a catalytic process, it does depend on homogeneous chemistry as well. Especially above $600{ }^{\circ} \mathrm{C}$ the homogenous chemistry can produce ethylene and ethane without a catalyst. The relative importance of gas-phase chemistry depends on residence time and pressure, as well as the $\mathrm{CH}_{4} / \mathrm{O}_{2}$ ratio in the feed stream [104-106].

Experimental studies show that $\mathrm{C}_{2}$ formation rates depend strongly on gas-phase methyl-radical concentrations $[70,107,44,108,74,75,109]$. Increasing the temperature and pressure increases the formation rate of methyl radicals almost independently of the catalyst. However, in low-pressure regimes, the methylradical formation rate depends weakly on temperature, but varies significantly depending upon the particular 889 catalyst. Because the catalyst increases the methyl- 890 radical formation rate, the $\mathrm{C}_{2}$ formation rate also in- ${ }^{891}$ creases.

Despite differences in the active catalytic sites on par- ${ }^{893}$ ticular catalysts, there is general consensus that at high ${ }^{894}$ temperature the methane needs to be activated to form ${ }^{895}$ $\mathrm{CH}_{3}$ radicals, with the $\mathrm{CH}_{3}$ formation step being the rate ${ }^{896}$ determining step. The activation may be via C-H bond 897 breaking,

$$
\begin{gathered}
\mathrm{CH}_{4}+(\mathrm{s}) \rightarrow \mathrm{CH}_{4}(\mathrm{~s}), \\
\mathrm{CH}_{4}(\mathrm{~s}) \rightarrow \mathrm{CH}_{3}+\mathrm{H}(\mathrm{s}),
\end{gathered}
$$

or by surface-oxygen attack,

$$
\mathrm{CH}_{4}+\mathrm{O}(\mathrm{s}) \rightarrow \mathrm{CH}_{3}+\mathrm{OH}(\mathrm{s}) .
$$

A study by Takanabe and Iglesia [110] proposed an ${ }^{905}$ alternative reaction pathway for methane activation. In addition to the thermal cracking and surface oxygen attacks, Takanabe and Igleisa's study suggested that 906 the reaction product $\mathrm{H}_{2} \mathrm{O}$ has a promotional effect on 907 methane conversion and $\mathrm{C}_{2+}$ yield. Their study intro- 908 duced an additional $\mathrm{CH}_{3}$ formation pathway via $\mathrm{OH} 909$ radicals. According to the reaction steps 8 and $9, \mathrm{OH} 910$ radicals are generated either via surface-adsorbed oxy- ${ }^{911}$ gen $\mathrm{O}(\mathrm{s})$ or in the gas-phase via $\mathrm{O}_{2}$ and $\mathrm{H}_{2} \mathrm{O}$ reactions. ${ }_{912}$

$$
\mathrm{H}_{2} \mathrm{O}+\mathrm{O}(\mathrm{s}) \rightleftharpoons \mathrm{OH}+\mathrm{OH}(\mathrm{s})
$$

(8) 914

$$
2 \mathrm{H}_{2} \mathrm{O}+\mathrm{O}_{2} \rightleftharpoons 4 \mathrm{OH} \text {. }
$$

Between these reactions it is more likely that the Re- 917 action 8 is the dominant pathway to form $\mathrm{OH}$ radicals. 918

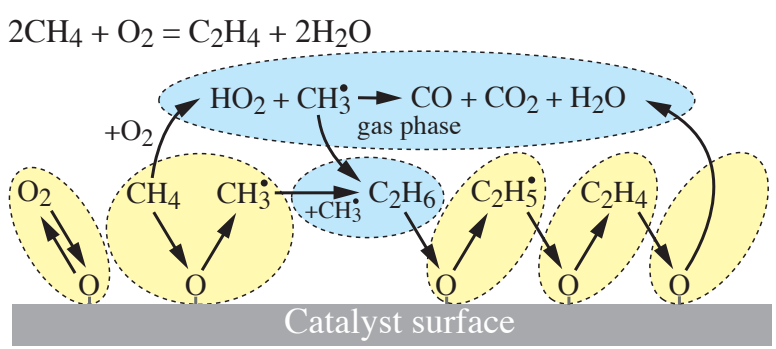

Figure 2: Reaction pathways for the oxidative coupling of methane proposed by Lunsford [111] and Sun et al. [112]. Yellow highlighted reaction paths indicate the catalytic routes where as blue highlighted reaction paths indicate the gas-phase reactions.

$\mathrm{H}_{2} \mathrm{O}$ is a very stable molecule and $\mathrm{O}-\mathrm{H}$ bonds in $\mathrm{H}_{2} \mathrm{O}$ $\left(497 \mathrm{~kJ} \mathrm{~mol}^{-1}\right)$ are stronger than $\mathrm{C}-\mathrm{H}$ bond in $\mathrm{CH}_{4}(439$ $\mathrm{kJ} \mathrm{mol}^{-1}$ ). The $\mathrm{OH}$ can react with $\mathrm{CH}_{4}$ in the gas phase to form $\mathrm{CH}_{3}$ radicals as

$$
\mathrm{CH}_{4}+\mathrm{OH} \rightarrow \mathrm{CH}_{3}+\mathrm{H}_{2} \mathrm{O} \text {. }
$$

Takanabe and Iglesia [110] conducted a series of OCM experiments in a recirculating batch reactor to support the proposed reactions. They studied the effects of contact time and $\mathrm{H}_{2} \mathrm{O}$ addition or removal on $\mathrm{CH}_{4}$ conversion and $\mathrm{C}_{2}$ yield. Their results showed that adding approximately $4 \% \mathrm{H}_{2} \mathrm{O}$ into the $\mathrm{CH}_{4} / \mathrm{O}_{2}$ mixtures at $800{ }^{\circ} \mathrm{C}$ significantly improved the $\mathrm{CH}_{4}$ conversion and $\mathrm{C}_{2+}$ yield. However, when $\mathrm{H}_{2}$ was removed the $\mathrm{CH}_{4}$ conversion was significantly suppressed.

Lunsford and colleagues studied OCM reaction kinetics for a wide range of catalysts, including $\mathrm{Li} / \mathrm{MgO}, \mathrm{Sr} / \mathrm{CaO}, \mathrm{Sr} / \mathrm{La}_{2} \mathrm{O}_{3}, \mathrm{Mn} / \mathrm{Na}_{2} \mathrm{WO}_{4} / \mathrm{SiO}_{2}$ and $\mathrm{Mn} / \mathrm{Na}_{2} \mathrm{WO}_{4} / \mathrm{MgO}$ [70, 107, 108, 74, 111]. Using matrix isolation electron spin resonance (MIESR), they identified active sites as well as methyl-radical formation pathways. The results showed that $\mathrm{C}_{2} \mathrm{H}_{6}$ is formed in the gas phase via $\mathrm{CH}_{3}$-radical recombination as

$$
\mathrm{CH}_{3}+\mathrm{CH}_{3}+\mathrm{M} \rightarrow \mathrm{C}_{2} \mathrm{H}_{6}+\mathrm{M},
$$

where $\mathrm{M}$ represents a gas-phase third body. Further $\mathrm{C}_{2} \mathrm{H}_{6}$ dehydrogenation produces $\mathrm{C}_{2} \mathrm{H}_{4}$ (cf., Fig. 2). The surface oxygen further increases the ethyl radical $\left(\mathrm{C}_{2} \mathrm{H}_{5}\right)$ formation rate. Lundsford argued that $\mathrm{CO}$ is formed via a gas-phase reaction, whereas $\mathrm{H}_{2} \mathrm{O}$ and $\mathrm{CO}_{2}$ are formed on the surface and then desorb [111]. Sun et al. [112], proposed that the $\mathrm{CO}, \mathrm{CO}_{2}$, and $\mathrm{H}_{2} \mathrm{O}$ are formed both via homogenous and heterogeneous pathways. Consistent with these studies, Fig. 2 illustrates methane activation and formation of $\mathrm{CO}, \mathrm{CO}_{2}$, and $\mathrm{H}_{2} \mathrm{O}$ via both homogeneous and heterogeneous pathways.

Reyes et al. [38] developed an OCM reaction mechanism involving both homogenous and heterogeneous 
reaction pathways. The homogeneous reaction pathways and rates were taken from earlier studies [113116]. Methane-oxygen reactions can proceed in the gas phase as

$$
\mathrm{CH}_{4}+\mathrm{O}_{2} \rightarrow \mathrm{CH}_{3}+\mathrm{HO}_{2},
$$

or on the surface as Eq. 7. The surface-reaction model included global representations of the $\mathrm{CH}_{3}$ (Eq. 13) and $\mathrm{C}_{2} \mathrm{H}_{5}$ (Eq. 14) radical production,

$$
\mathrm{CH}_{4}+\frac{1}{4} \mathrm{O}_{2} \rightarrow \mathrm{CH}_{3}+\frac{1}{2} \mathrm{H}_{2} \mathrm{O}
$$

$$
\mathrm{C}_{2} \mathrm{H}_{6}+\frac{1}{4} \mathrm{O}_{2} \rightarrow \mathrm{C}_{2} \mathrm{H}_{5}+\frac{1}{2} \mathrm{H}_{2} \mathrm{O} .
$$

Although Reactions 13 and 14 involve only gas-phase 966 species, they are understood to he surface reactions. 967 Homogeneous recombination of $\mathrm{CH}_{3}$ radicals produces 968 gas-phase $\mathrm{C}_{2} \mathrm{H}_{6}$ according to Eq. 11 .

In addition to the reaction pathways, individual re- 970 action rates need to be established. There is literature ${ }_{971}$ that reports global and partially elementary OCM reac- 972 tion mechanisms for several different catalysts. Global 973 representations of the OCM catalytic kinetics use re- 974 actions that involve only gas-phase species (e.g., Ta- 975 ble 1). The rate expressions are empirical, with details 976 of the catalysts (e.g., specific surface area, bed poros- 977 ity and tortuosity, etc.) subsumed implicitly into the 978 rate expressions. The reaction pathways and functional 979 forms of the rate expressions are presumed to be gen- 980 eral. However, because the rate expressions are fit to 981 particular experiments, and for specific temperature and 982 pressure ranges, the kinetic parameters need to be fine- 983 tuned before applying in other circumstances. Never- 984 theless, with appropriate tuning for particular catalysts 985 and operating conditions, the mechanisms can be used 986 to predict reactor behavior and assist reactor design. Be- 987 cause the gas-phase thermodynamic properties are well ${ }_{988}$ established, the global kinetics can predict exothermic 989 behavior and hence temperature variations within reac- 990 tor catalysts beds.

As an alternative to global mechanisms, there are po- 992 tential benefits to developing elementary-step reaction ${ }_{993}$ mechanisms. Because the elementary-step mechanisms 994 involve surface adsorbates, establishing the thermody- 995 namics, and hence microscopic reversibility, is difficult. 996 Although there is very little literature on elementary- 997 step OCM catalysis, there are certainly benefits to such 998 development. Because they are based on fundamentals, 999 validated elementary-step mechanisms have better pre- 1000 dictive capability than do global reaction mechanisms 1001 with empirical rate expressions.
Table 1: Global reactions in Oxidative Coupling of Methane, OCM [71].

\begin{tabular}{llc}
\hline & Reaction & $\approx \Delta H_{298}^{\circ}(\mathrm{kJ})$ \\
1. & $\mathrm{CH}_{4}+2 \mathrm{O}_{2} \rightarrow \mathrm{CO}_{2}+2 \mathrm{H}_{2} \mathrm{O}$ & -802 \\
2. & $2 \mathrm{CH}_{4}+\frac{1}{2} \mathrm{O}_{2} \rightarrow \mathrm{C}_{2} \mathrm{H}_{6}+\mathrm{H}_{2} \mathrm{O}$ & -177 \\
3. & $\mathrm{CH}_{4}+\mathrm{O}_{2} \rightarrow \mathrm{CO}+\mathrm{H}_{2} \mathrm{O}+\mathrm{H}_{2}$ & -277 \\
4. & $\mathrm{CO}+\frac{1}{2} \mathrm{O}_{2} \rightarrow \mathrm{CO}_{2}$ & -283 \\
5. & $\mathrm{C}_{2} \mathrm{H}_{6}+\frac{1}{2} \mathrm{O}_{2} \rightarrow \mathrm{C}_{2} \mathrm{H}_{4}+\mathrm{H}_{2} \mathrm{O}$ & -105 \\
6. & $\mathrm{C}_{2} \mathrm{H}_{4}+2 \mathrm{O}_{2} \rightarrow 2 \mathrm{CO}+2 \mathrm{H}_{2} \mathrm{O}$ & -757 \\
7. & $\mathrm{C}_{2} \mathrm{H}_{6} \rightarrow \mathrm{C}_{2} \mathrm{H}_{4}+\mathrm{H}_{2}$ & +137 \\
8. & $\mathrm{C}_{2} \mathrm{H}_{4}+2 \mathrm{H}_{2} \mathrm{O} \rightarrow 2 \mathrm{CO}+4 \mathrm{H}_{2}$ & +210 \\
9. & $\mathrm{CO}+\mathrm{H}_{2} \mathrm{O} \rightarrow \mathrm{CO}+\mathrm{H}_{2}$ & -41 \\
10. & $\mathrm{CO}_{2}+\mathrm{H}_{2} \mathrm{O} \rightarrow \mathrm{CO}+\mathrm{H}_{2} \mathrm{O}$ & +41 \\
\hline
\end{tabular}

Although OCM catalysts based on $\mathrm{Li} / \mathrm{MgO}$ have relatively simple atomic structure and are the easiest to understand, elementary reaction mechanisms have yet to be fully developed. Practical catalysts such as $\mathrm{Mn} / \mathrm{Na}_{2} \mathrm{WO}_{4} / \mathrm{SiO}_{2}$ structures are far more complex. In addition to establishing reaction-pathway details, surface thermodynamics need to be established such that thermal balances can be accurately represented. Synergistic combinations of theory and experiment are needed to develop and validate general-purpose reaction mechanisms.

Stansch et al. [71] developed an OCM reaction mechanism for $\mathrm{La}_{2} \mathrm{O}_{3} / \mathrm{CaO}$ catalysts (Table 1 ). The global reactions represent total and partial oxidation as well as water-gas-shift chemistry. Stansch et al. validated their kinetic parameters in the temperature range $700 \leq T \leq$ $955^{\circ} \mathrm{C}$. In subsequent research Daneshpayeh et al. [117] modified the kinetic parameters in Stansch's mechanism to represent $\mathrm{Mn} / \mathrm{Na}_{2} \mathrm{WO}_{4} / \mathrm{SiO}_{2}$ catalysts. Daneshpayeh et al. used the same reaction network as Stansch's model, but modified activation barriers and the reaction-rate orders to fit experimental measurements over a range of temperatures $\left(750 \leq T \leq 875{ }^{\circ} \mathrm{C}\right)$.

Ahari et al. [118] developed an OCM microkinetic reaction mechanism with gas-phase and surface reactions. The nominal values of the pre-exponential factors were derived from collision theory. The activation barriers were estimated according to the Bell-Evans-Polanyi relationship. The rate parameters were fine-tuned based on packed-bed reactor experiments, where the effects of temperature, feed composition (fuel/oxygen) and gashourly space velocity were investigated. An isothermal, one-dimensional, packed-bed reactor model was developed to assist interpreting the measurements and assigning rate parameters. The surface reactions were represented as 11 irreversible steps. The surface adsorbates that were considered are $\mathrm{O}(\mathrm{s}), \mathrm{OH}(\mathrm{s}), \mathrm{CO}(\mathrm{s})$, $\mathrm{CHO}(\mathrm{s}), \mathrm{CH}_{2} \mathrm{O}(\mathrm{s})$ and $\mathrm{CH}_{3} \mathrm{O}(\mathrm{s})$. The reaction mechanism considers gas-phase adsorption on the catalytic 
active sites, adsorbate-adsorbate reactions, and the reaction of gas-phase radicals with surface adsorbates. The detailed gas-phase reactions were represented with 39 reversible steps among 13 species. This reaction mechanism was adapted from the earlier studies of Marin and colleagues [119, 120]. The product gas-phase species included $\mathrm{CO}, \mathrm{CO}_{2}, \mathrm{H}_{2}, \mathrm{H}_{2} \mathrm{O}, \mathrm{C}_{2} \mathrm{H}_{4}$, and $\mathrm{C}_{2} \mathrm{H}_{6}, \mathrm{C}_{3} \mathrm{H}_{6}$ and $\mathrm{C}_{3} \mathrm{H}_{8}$.

Sun et al. [112] proposed a detailed OCM reaction mechanism to represent gas-phase and surface reactions over $\mathrm{Li} / \mathrm{MgO}$ and $\mathrm{Sn} / \mathrm{Li} / \mathrm{MgO}$ catalysts. This mechanism consists of 14 surface reactions and 39 gas-phase reactions. As with the $\mathrm{Mn} / \mathrm{Na}_{2} \mathrm{WO}_{4} / \mathrm{SiO}_{2}$ catalysts, the methane activation proceeds via methyl-radical formation in the gas-phase as well as on the catalyst surface. Methyl radicals recombine to form $\mathrm{C}_{2} \mathrm{H}_{6}$. The desired gas-phase products are $\mathrm{C}_{2} \mathrm{H}_{4}$ and $\mathrm{C}_{2} \mathrm{H}_{6}$, with the undesired oxidation products being $\mathrm{CO}, \mathrm{CO}_{2}$, and $\mathrm{H}_{2} \mathrm{O}$. The surface species include $\mathrm{O}(\mathrm{s}), \mathrm{OH}(\mathrm{s}), \mathrm{H}_{2} \mathrm{O}(\mathrm{s})$, $\mathrm{CH}_{3} \mathrm{O}(\mathrm{s}), \mathrm{CH}_{2} \mathrm{O}(\mathrm{s}), \mathrm{CHO}(\mathrm{s}), \mathrm{CO}(\mathrm{s}), \mathrm{CO}_{2}(\mathrm{~s})$. The reaction mechanism includes the adsorption of gas-phase 1053 species, reaction of gas-phase species (either radical or 1054 stable molecules) with surface adsorbates (Eley-Rideal 1055 steps), or the surface-surface reactions. The model is 1056 validated under isothermal reactor conditions.

To date, there are no published reaction mecha- 1058 nisms for the low-temperature OCM catalysts (i.e., $T<1059$ $700{ }^{\circ} \mathrm{C}$ ). However, there is general agreement that the 1060 methane activation on $\mathrm{La}_{2} \mathrm{O}_{3}$ catalysts relies on $\mathrm{CH}_{3-} 1061$ radical formation mechanisms. The high-temperature 1062 reaction pathway is thought to be different from the low- 1063 temperature pathways. Although the surface can create ${ }_{1064}$ sufficient methyl radicals, the $\mathrm{CH}_{3}$ recombination and ${ }_{1065}$ $\mathrm{C}_{2} \mathrm{H}_{6}$ dehydrogenation steps must occur in gas-phase. 1066 Thus, even for low-temperature processes, it should be 1067 expected that the temperature plays an important role. ${ }_{1068}$

\section{Non-oxidative conversion of methane}

There are two broad approaches to achieve the nonoxidative conversion of methane. Both are catalytic de- 1074 hydrogenation processes, but seek different products. 1075 The first seeks to produce primarily ethylene, which is ${ }_{1076}$ a valuable feedstock for further downstream process- 1077 ing. The second, which is usually called methane de- 1078 hyroaromatization (MDA) seeks to produce benzene. In 1079 principle, both approaches are feasible at high tempera- 1080 tures with sufficiently selective catalysts.

\subsection{Methane to ethylene and ethane}

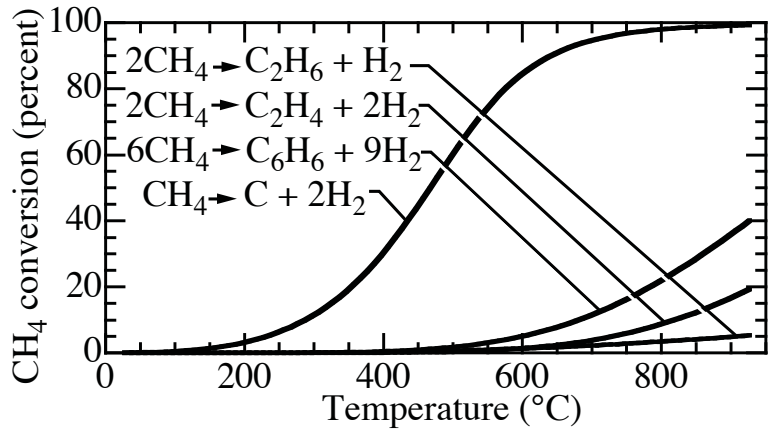

Figure 3: Equilibrium thermodynamics of direct conversion of $\mathrm{CH}_{4}$ under non-oxidative conditions.

The desired production of $\mathrm{C}_{2} \mathrm{H}_{4}$ from $\mathrm{CH}_{4}$ can be represented globally as in Eq. 2 and the $\mathrm{C}_{2} \mathrm{H}_{6}$ formation from methane can be represented as

$$
2 \mathrm{CH}_{4} \rightleftharpoons \mathrm{H}_{2}+\mathrm{C}_{2} \mathrm{H}_{6}, \quad \Delta H_{298}^{\circ} \approx+65 \mathrm{~kJ} .
$$

Unlike OCM, where some $\mathrm{H}_{2}$ is converted to $\mathrm{H}_{2} \mathrm{O}$, the non-oxidative conversion retains $\mathrm{H}_{2}$ as reaction product. Because the chemistry does not involve oxygen or oxygen-containing species, it is theoretically possible to increase the carbon selectivity toward $\mathrm{C}_{2} \mathrm{H}_{4}$ and $\mathrm{C}_{2} \mathrm{H}_{6}$. However, even assuming a perfect catalyst, Fig. 3 shows that equilibrium direct conversion of $\mathrm{C}_{2} \mathrm{H}_{4}$ or $\mathrm{C}_{2} \mathrm{H}_{6}$ is thermodynamically limited and only favored at high temperatures. Figure 3 also shows that graphitic carbon (C) is much more favorable than the reactions to form $\mathrm{C}_{2}$ and benzene. At $500{ }^{\circ} \mathrm{C}$, the equilibrium conversions of $\mathrm{CH}_{4}$ to $\mathrm{C}_{2} \mathrm{H}_{6}$ and $\mathrm{C}_{2} \mathrm{H}_{4}$ are only about $0.6 \%$ and $1 \%$, respectively. The direct conversion of $\mathrm{CH}_{4}$ to $\mathrm{C}_{2}$ is practical only above about $800{ }^{\circ} \mathrm{C}$, with the $\mathrm{C}_{2} \mathrm{H}_{4}$ being significantly greater than $\mathrm{C}_{2} \mathrm{H}_{6}$.

Although the formation of both $\mathrm{C}_{2} \mathrm{H}_{4}$ and $\mathrm{C}_{2} \mathrm{H}_{6}$ occur via methane dehydrogenation pathways, Fig. 4 shows the nature of these two reactions to be quite different. Based on the Gibbs free energy change associated with the global reactions, direct $\mathrm{C}_{2} \mathrm{H}_{4}$ formation (i.e., $2 \mathrm{CH}_{4} \rightleftharpoons \mathrm{C}_{2} \mathrm{H}_{4}+2 \mathrm{H}_{2}$ ) is favorable only at high temperatures. The direct $\mathrm{C}_{2} \mathrm{H}_{6}$ formation (i.e., $2 \mathrm{CH}_{4} \rightleftharpoons \mathrm{C}_{2} \mathrm{H}_{6}+\mathrm{H}_{2}$ ) is always significantly endothermic, with very little temperature dependence. Even at a the high temperature of $900{ }^{\circ} \mathrm{C}$ the direct conversion of $\mathrm{CH}_{4}$ to $\mathrm{C}_{2} \mathrm{H}_{6}$ is only around $4.8 \%$. This suggests that $\mathrm{C}_{2}$ formation may not be direct at practical reactor temperatures.

The practical conversion of $\mathrm{CH}_{4}$ to $\mathrm{C}_{2}$ may be feasible at moderate temperatures via indirect routes. According to Fig. 4, the direct conversion of methane to 


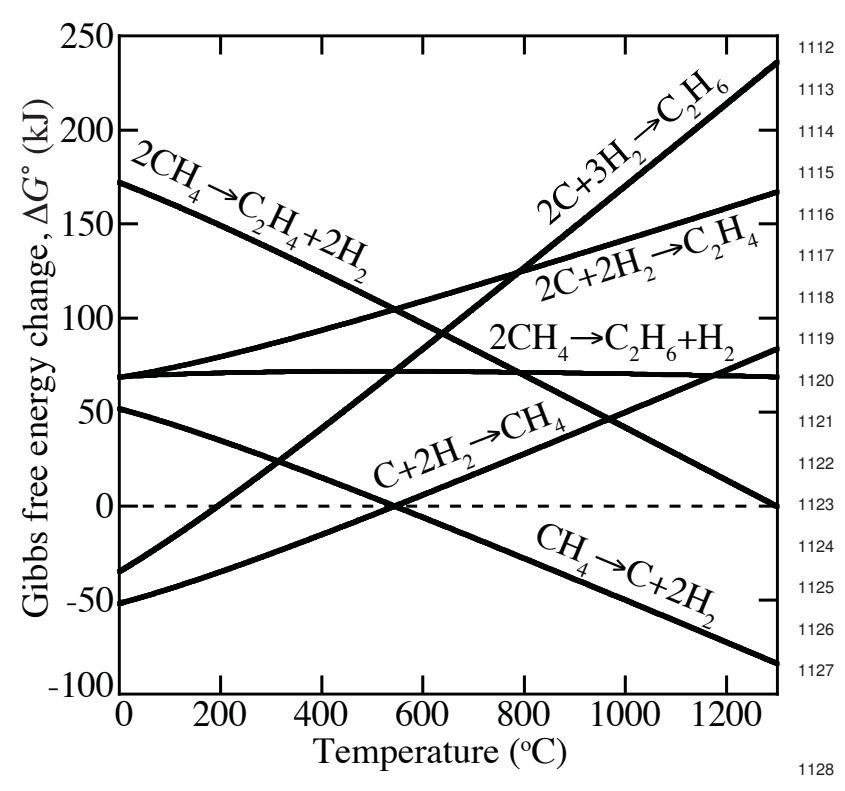

Figure 4: Gibbs free energy change as a function of temperature 1129 at atmospheric pressure for the relevant reactions of methane nonoxidative coupling. This graph was adapted from Garnier et al. [121].

course, such a simplified global representation provides very little insight into the complexities of the process.

As is typical of dehydrogenation processes, the direct conversion of methane to both ethylene and aromatics is thermodynamically limited. Figure 3 shows that even at $700{ }^{\circ} \mathrm{C}$, the equilibrium thermodynamics limits the methane conversion to below $10 \%$ for either ethylene or benzene; the dominant reaction produces carbon. Figure 3 shows that the benzene formation is more favorable than ethylene. Although not shown in Fig. 3, higher aromatic compounds such as naphthalene $\left(\mathrm{C}_{10} \mathrm{H}_{8}\right)$ are thermodynamically more favorable than benzene. Moreover, a wide range of usually undesired aromatic side compounds (e.g., indene, anthracene and higher polyaromatic hydrocarbons) are inevitably produced.

\section{Methane dehydroaromatization (MDA)}

The MDA process was first discovered in 1993 by Wang et al. [128]. The most relevant catalysts are metalloaded (e.g., Mo, W, Cu, Re, V, Ga) bi-functional zeolites [129-132]. Methane is first activated on the metal sites to form small $\mathrm{C}_{2}$ species (typically ethylene) and $\mathrm{H}_{2}$. Aromatization then follows at zeolite acid sites. Among the metal possibilities, Mo is the most active for methane conversion. Benzene selectivity depends on the zeolite cage dimensions, and hence on the zeolite type. Depending on the particular zeolite, the cage dimensions typically range between 0.35 and $0.85 \mathrm{~nm}$. Zeolites with small cage dimensions, close to the atomic diameter of benzene, are most selective for benzene formation [133, 134]. The particular zeolites that are most effective for benzene production include HZSM5 [135-142], HMCM-22 [143-146], HMCM-36 [147], and HMCM-49 [148, 149].

Figure 5 is a three-dimensional representation of the atomic positions within a HZSM-5 zeolite crystal. The hydrogen atoms on the periphery of the large zeolite cage form the Brønsted-acid sites. Catalytic performance and selectivity depends on the cage dimension relative to the characteristic dimensions of reactant or product molecules.

The Mo/zeolite catalysts can be fabricated using alternative preparation methods. In most cases, a wet impregnation is followed by calcination. That is, a Mo precursor (e.g., ammonium molybdate) is first introduced into zeolite powders. Upon calcination, the Mo precursor forms an oxide, $\mathrm{MoO}_{x}$. Another approach is to physically mix $\mathrm{MoO}_{x}$ and zeolite powders. In either case, the catalyst is initially in the form of a $\mathrm{MoO}_{x}$ /zeolite mixture. However, the $\mathrm{MoO}_{x}$ is not stable in reducing envi- 


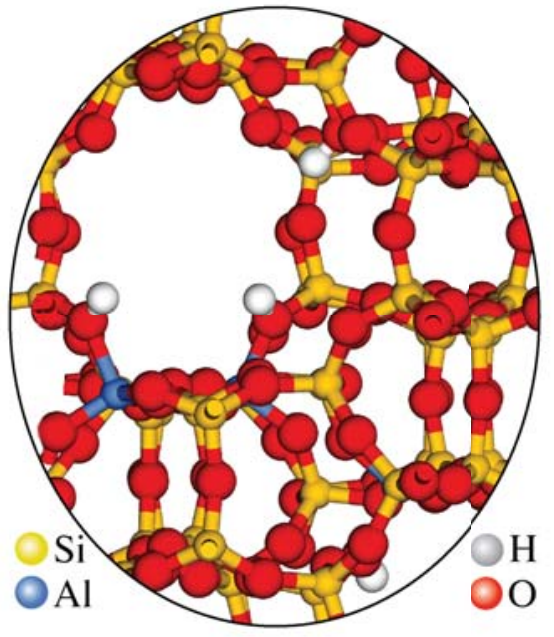

Figure 5: Illustration of a portion of a zeolite crystal (HZSM-5) with a silicon-to-aluminum ratio of 11 . The primary cage is at the upper left of the image. The Brønsted-acid sites are formed by the atomic hydrogens on the periphery of the zeolite cage. ronments. In MDA processes, the $\mathrm{MoO}_{x}$ is transformed ${ }^{1189}$ to a molybdenum-carbide structure.

\subsection{Catalyst and active sites}

Although it is generally established that $\mathrm{CH}_{4}$ is first 1194 activated on $\mathrm{Mo}_{2} \mathrm{C}$ sites, their specific configuration, 1195 oxidation state, interactions with zeolite Brønsted acid 1196 sites, and dimerization kinetics are not yet fully under- 1197 stood. It is well accepted that the molybdenum under- 1198 goes transformation from Molybdenum oxide to a com- 1199 plex carbide when it is exposed to methane. Begin- 1200 ning with freshly synthesized Mo/zeolite catalysts the 1201 Mo is initially in the $\mathrm{Mo}^{6+}$ state. Exposing calcined 1202 Mo/HZSM-5 to $\mathrm{CH}_{4}$ at $700{ }^{\circ} \mathrm{C}$ causes the reduction of 1203 60 to $80 \%$ of the $\mathrm{Mo}^{6+}$ to a molybdenum-carbide struc- ${ }^{1204}$ ture. During the carburization process the molybdenum 1205 incorporation is associated with the Brønsted acid sites. 1206 Thus, as molybdenum is incorporated, the Brønsted acid 1207 sites are replaced by molycarbide structures.

The transition between the oxide and carbide phases 1209 can be represented notionally as $[150,151]$

$$
\mathrm{MoO}_{3} \rightarrow \mathrm{MoO}_{\mathrm{x}} \mathrm{C} \rightarrow \mathrm{Mo}_{2} \mathrm{C} .
$$

The carburization process may be accomplished in- 1214 situ within an MDA reactor or it may be prepared be- 1215 forehand. When the carburization is accomplished in- 1216 situ, the MDA process starts with an induction period ${ }_{1217}$ that may require several hours. During this transient 1218 process the $\mathrm{Mo}_{2} \mathrm{C}$ concentration increases, which also 1219<smiles>CO[Al](C)(C)O[Si](C)(C)O[Si](C)(C)O[Si](C)(C)O[Al](C)(C)C</smiles>

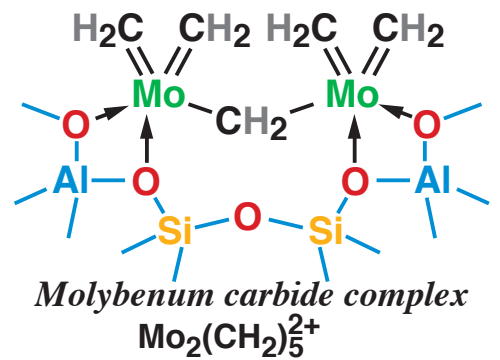

Figure 6: Illustration of a zeolite Brønsted-acid site and a molybdenum-carbide complex at the acid site.

serves to increase the benzene formation rate. During the induction period, the reaction of methane with $\mathrm{MoO}_{x}$ forms $\mathrm{CO}, \mathrm{CO}_{2}$ and $\mathrm{H}_{2} \mathrm{O}$ as products. The carburization time depends on the gas-hourly space velocity and temperature. Under typical MDA reaction conditions (700-800 ${ }^{\circ} \mathrm{C}$ and 750-4500 ml gcat ${ }^{-1} \mathrm{~h}^{-1}$ ) the process is typically completed in one to two hours. In the context of MDA, "completing" the carburization process means that a quasi-steady state is reached in terms of methane conversion and benzene yield. However, not all the molybdenum oxide phases are transformed to the molybdenum carbide, with some $\mathrm{MoO}_{3}$, $\mathrm{MoO}_{x} \mathrm{C}$ and $\mathrm{Mo}_{2} \mathrm{C}$ co-existing.

The distribution between the $\mathrm{MoO}_{3}, \mathrm{MoO}_{x} \mathrm{C}$ and $\mathrm{Mo}_{2} \mathrm{C}$ depends strongly on the zeolite $\mathrm{Si} / \mathrm{Al}$ ratios. At low $\mathrm{Si} / \mathrm{Al}$ ratios the $\mathrm{MoO}_{x}$ phase is stabilized inside the zeolite structure whereas at high $\mathrm{Si} / \mathrm{Al}$ ratios (typically in the range of 25-140), the $\mathrm{MoO}_{x}$ is stabilized outside of the zeolite cages [152]. The surface $\mathrm{MoO}_{3}$ is easily converted to $\mathrm{Mo}_{2} \mathrm{C}$ in a reducing atmosphere (i.e., during carburization). However, the $\mathrm{MoO}_{x}$ that is stabilized within the zeolite cages is less accessible by virtue of mass-transport limitations within small cage channels. Thus, the interior molybdenum-oxides are more difficult to reduce and can remain partially oxidized under MDA reaction conditions [151].

The relative catalytic activities of alternative molybdenum structures for methane activation are not yet established. A number of studies show that $\mathrm{Mo}_{2} \mathrm{C}$ is the active center for methane activation [137, 153-156]. Experimental studies also indicate that molyoxides coexist with the carbides, but their catalytic role is de- 
bated [153, 157-159].

Although the notation $\mathrm{Mo}_{2} \mathrm{C}$ is compact and widely 1273 used, the chemical structures of molycarbides are con- 1274 siderably more complex. The exact carbide structure, ${ }_{1275}$ possibly including oxycarbides $\left(\mathrm{MoO}_{x} \mathrm{C}\right)$, remains un- 1276 certain, and likely depends on the particular zeolite 1277 and the processing conditions. The Mo within the ${ }_{1278}$ zeolite framework is found to be in the form of a 1279 dimer $\left(\mathrm{Mo}_{2} \mathrm{O}_{5}\right)^{2+}$, associating with two Brønsted acid ${ }_{1280}$ sites $[153,160,161]$. Monomeric bidendate $\left(\mathrm{MoO}_{2}\right)^{2+}{ }_{1281}$ with a single Mo atom is anchored into the cage struc- ${ }_{1282}$ ture through oxygen bridges [144]. According to DFT ${ }_{1283}$ simulations $[162,163]$, the particular Mo structure in ${ }_{1284}$ monomer or dimer form within the zeolite framework ${ }_{1285}$ is determined by the zeolite $\mathrm{Si} / \mathrm{Al}$ ratios. A DFT study 1286 by Zhou et al. [164] identified three alternative moly- ${ }_{1287}$ carbide structures with different coordination at the ze- 1288 olite acid sites. For low Si/Al ratios, the linearly 1289 bonded $\mathrm{Mo}$ is either in $\mathrm{Mo}^{5+}$ or $\mathrm{Mo}^{6+}$ states and it is 1290 in dimer form. The monomeric $\mathrm{Mo}^{6+}$ is less stable ${ }_{1291}$ in the $\mathrm{Mo}\left(\mathrm{CH}_{2}\right)_{2}\left(\mathrm{CH}_{3}\right)^{+}$structure that is formed when $\mathrm{Si} / \mathrm{Al}$ ratios are high. The dimeric forms of the moly- ${ }^{1292}$ carbide, which can be represented as $\mathrm{Mo}_{2}\left(\mathrm{CH}_{2}\right)_{5}^{2+}$ or ${ }_{1293}$ $\mathrm{Mo}_{2}\left(\mathrm{CH}_{2}\right)_{4}^{2+}$, are more stable than the monomeric forms ${ }_{1294}$ at low silicon-to-aluminum ratios [164].

The upper image in Fig. 6 schematically illustrates a 1296 zeolite Brønsted acid site before the molybdenum intro- ${ }_{1297}$ duction. The lower image illustrates the molybdenum- 1298 carbide complex in the form of $\mathrm{Mo}_{2}\left(\mathrm{CH}_{2}\right)_{5}^{2+}$ [164]. ${ }_{1299}$

It is generally established that the Mo structure and 1300 its catalytic activity depend on the synthesis method 1301 and the molybdenum loading $[165,160,161]$. The Mo 1302 content in the zeolite can vary between $1 \mathrm{wt} . \%$ and $20{ }_{1303}$ wt.\% [157, 166-168, 151], with the optimum Mo load- 1304 ing depending on the preparation method, carburization 1305 temperature, and reaction conditions $[139,160,161,1306$ 166, 153]. Typically, Mo loading in the range of 4-6 1307 wt.\% delivers best MDA performance.

Lu et al. [168] studied Mo loading effects on HZSM-5 ${ }_{1309}$ zeolites. The catalyst was prepared by wet impregnation 1310 and the Mo loading was varied between 1 and $10 \mathrm{wt} . \% .1311$ They identified three different molybdenum structures: 1312 molybdenum carbide $\left(\mathrm{Mo}_{2} \mathrm{C}\right)$, molybdenum-oxide car- 1313 bide $\left(\mathrm{MoO}_{x} \mathrm{C}\right)$, and molybdenum oxide $\left(\mathrm{MoO}_{3}\right)$. The ${ }_{1314}$ best Mo loadings were found to be between 4 and 61315 wt.\%. Increasing the Mo content further did not in- 1316 crease the benzene selectivity.

$\mathrm{Li}$ et al. [167] prepared a $6 \mathrm{wt} \%$ Mo/HZSM-5 cata- ${ }_{1318}$ lyst. They identified $\left[\mathrm{Mo}_{5} \mathrm{O}_{12}\right]^{6+}$ in the zeolite channel, ${ }_{1319}$ which is incorporated into the zeolite structure by the 1320 replacement of an acid site that is coordinated through 1321 Al. They also reported that $\alpha-\mathrm{MoO}_{3}$ and amorphous 1322
$\mathrm{MoO}_{3}$ are distributed on exterior zeolite surfaces. Furthermore, at very high Mo loadings entrance to the zeolite cages could be blocked by Mo particles.

Chen et al. [157] studied the effects of Mo loadings between 1 and $20 \mathrm{wt} . \%$ on HZSM-5 catalysts in a packed-bed reactor. By measuring the methane conversion and aromatic yield, they showed that increasing Mo content above $10 \mathrm{wt} . \%$ decreased the aromatic yield. The best Mo loading was found to be between 2 and $3 \mathrm{wt} . \%$. The study suggested that both the molybdenum sites and zeolite acid sites were active for methane aromatization. Although $\mathrm{Mo}_{2} \mathrm{C}$ structures were formed within zeolite channels, it was suggested that small crystallites of $\mathrm{MoO}_{3}$ were the active sites for methane dimerization.

Using Density Functional Theory (DFT), Fadeeva et al. [151] studied alternative molybdenum structures in HZSM-5 zeolites. At high Mo loadings, (e.g., 15 wt.\%) $\mathrm{Al}$ was predicted to be extracted from the zeolite framework to form $\mathrm{Al}_{2}\left(\mathrm{MoO}_{4}\right)_{3}$.

\subsection{Catalyst deactivation}

In addition to thermodynamic limitations, rapid or gradual catalyst deactivation represents a significant practical challenge. Even with highly selective catalysts, undesired hydrocarbon products (e.g., $\mathrm{C}_{10} \mathrm{H}_{8}$, $\mathrm{C}_{10+}$ ) are formed, thus limiting the $\mathrm{C}_{6} \mathrm{H}_{6}$ and $\mathrm{C}_{2} \mathrm{H}_{4}$ yield. Furthermore, condensed carbon or polyaromatic hydrocarbons, which are thermodynamically the most stable products of the direct dehydrogenation process, cause severe catalyst deactivation during the MDA process $[39,169]$. Broadly speaking, catalyst-deactivating carbon can take the form of solid carbon (coke) and polyaromatic hydrocarbons (PAH) [170, 171].

Ichikawa and co-workers studied deposit formation in isothermal packed-bed reactors with Mo/zeolite catalysts [170, 172, 173]. After measuring activity as a function of time-on-stream they characterized the deposits using ex-situ Temperature Programmed Oxidation (TPO). At low temperatures the deposits were found to be in the form of graphitic carbon on, or near to, the $\mathrm{Mo}_{2} \mathrm{C}$. The high temperature deposits were in the form of PAH within, or near the entrance of, the zeolite channels. The PAHs diminish the methane aromatization chemistry because they block access to the zeolite channels. As discussed subsequently, the surface deposits can be removed by reaction with oxygenated species. The PAH deposits, especially those within zeolite channels, are more difficult to remove because of transport limitations within the channels. These PAHs are suggested to be the major hydrocarbons that are responsible for catalyst fouling [174, 175]. 


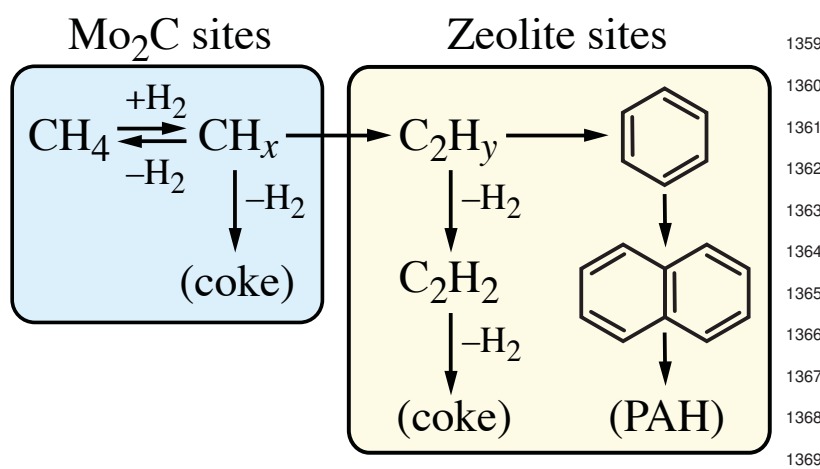

Figure 7: Carbon formation pathways based on the mechanisms pro- ${ }^{1370}$ posed by Zhang and coworkers [176, 177] and Liu et al. [178].

Zhang and co-workers [176, 177] published studies ${ }_{1374}$ investigating deposit formation pathways and chemical ${ }_{1375}$ composition on Mo/HZSM-5 catalysts at $800{ }^{\circ} \mathrm{C}$. They ${ }_{1376}$ used thermogravimetric analysis (TGA), X-ray Pho- ${ }_{1377}$ toelectron Spectroscopy (XPS), and TPO techniques ${ }_{1378}$ to characterize the catalyst-deactivating deposits and ${ }_{1379}$ identify deposit-forming pathways. Figure 7 graphi- ${ }_{1380}$ cally summarizes alternative carbon-deposit pathways. ${ }_{1381}$ Graphitic coke was attributed to $\mathrm{CH}_{4}$ dehydrogenation ${ }_{1382}$ or $\mathrm{C}_{2} \mathrm{H}_{4}$ cracking. The PAH deposits were the result of ${ }_{1383}$ molecular-weight growth and condensation.

By dividing the reactor into three zones, the Zhang ${ }_{1385}$ group was able to identify different deposit character- ${ }_{1386}$ istics along the length of a packed-bed reactor. The ${ }_{1387}$ deposit types along a packed-bed reactor were non- ${ }_{1388}$ uniform and depended greatly on the local hydrogen ${ }_{1389}$ concentration. In the upstream regions, graphite-like ${ }_{1390}$ coke was dominant and it was mainly formed by de- ${ }_{1391}$ hydrogenation of $\mathrm{CH}_{4}$. In the second and third zones (downstream), the main carbon-formation path was via ${ }_{1392}$ $\mathrm{C}_{2} \mathrm{H}_{4}$ cracking on the zeolite. The PAHs were formed ${ }_{1393}$ primarily in the third zone of the reactor. The study ${ }_{1394}$ showed that the overall dominant deposit-formation ${ }_{1395}$ pathway was via $\mathrm{C}_{2} \mathrm{H}_{4}$ cracking.

\subsection{Catalyst regeneration}

Because catalyst deactivation is practically inevitable 1399 under MDA reaction conditions, some catalyst regener- 1400 ation strategy is necessary. In-situ catalyst regeneration 1401 can be accomplished by switching the feed-stream gas 1402 to an oxidant such as $\mathrm{O}_{2}$ or NO [172] or a reducing gas 1403 such as $\mathrm{H}_{2}$ [179-184]. Ex-situ regeneration is also pos- 1404 sible, but often less desirable because the reactors must 1405 be shut down and the catalysts removed.

Oxygen is an effective regeneration gas in the sense 1407 that the carbon deposits can be removed via oxidation 1408 to gas-phase species. However, oxygen regeneration ${ }_{1409}$ is often accompanied by other deleterious processes. The $\mathrm{O}_{2}$ not only removes the deposited carbon, but can also oxidize the active $\mathrm{Mo}_{2} \mathrm{C}$ to inactive or less active $\mathrm{MoO}_{x}$. The molybdenum carburization process is reversible, but a non-productive induction period is required. Additionally, the exothermic carbon oxidation could cause catalyst degradation associated with temperature excursions and local hot spots. Nitric oxide reacts more aggressively with carbon deposits than does oxygen. Thus, alternative oxidants, such as $\mathrm{NO}$ or $\mathrm{O}_{2}-$ NO mixtures, can reduce the oxidation temperatures in the range $330 \leq T \leq 450{ }^{\circ} \mathrm{C}$.

Regeneration based on periodic switching of feed gases is inherently inefficient because of non-productive reactor time. Thus, there are benefits associated with alternative operating conditions that can extend the interval between regeneration cycles. Introducing very low levels of oxidizers (e.g., $\mathrm{O}_{2}, \mathrm{NO}, \mathrm{CO}, \mathrm{CO}_{2}, \mathrm{H}_{2} \mathrm{O}$ ) with the methane feed gas can be effective $[185,186]$. Although hydrogen is a product of dehydrogenation, mixing low levels of $\mathrm{H}_{2}$ with the methane feed can also have beneficial effects on long-time catalyst stability $[158,173]$.

It is interesting to note that in-situ catalystregeneration approaches, such as co-feeding of $\mathrm{CO}$, $\mathrm{CO}_{2}, \mathrm{H}_{2} \mathrm{O}$ and $\mathrm{H}_{2}$ are patented technologies. As recently as 2015, Shell Oil patented an MDA application where mixtures of $\mathrm{CO}, \mathrm{CO}_{2}$, and $\mathrm{H}_{2}$ are premixed with the methane feed to improve the catalyst stability [187]. Exxon Mobil also patented an MDA application where different levels of $\mathrm{CO}, \mathrm{CO}_{2}, \mathrm{H}_{2} \mathrm{O}$, and $\mathrm{H}_{2}$ are co-fed in a fluidized-bed reactor [188-190]. Improved catalytic stability was one of the claims.

\subsubsection{Co-feeding $\mathrm{O}_{2}, \mathrm{CO}$ and $\mathrm{CO}_{2}$}

Tan et al. [158] studied the effects of co-feeding $\mathrm{O}_{2}$, $\mathrm{CO}_{2}$, and $\mathrm{H}_{2}$ on MDA performance in a packed-bed reactor at $770{ }^{\circ} \mathrm{C}$ over a $2 \mathrm{wt} . \% \mathrm{Mo} / \mathrm{HZSM}-5$ catalyst. The results showed that premixing up to $5.3 \% \mathrm{O}_{2}$ and $12.8 \% \mathrm{CO}_{2}$ reduced the catalyst deactivation rate. The catalyst was stable up to $6 \mathrm{~h}$, producing $4 \%$ aromatic yield at $770{ }^{\circ} \mathrm{C}$. However, after the first $6 \mathrm{~h}$, the catalyst deactivated rapidly over the next $4 \mathrm{~h}$ and the process no longer produced aromatic species. Based on XPS analysis, the deactivation was attributed to excess $\mathrm{O}_{2}$ or $\mathrm{CO}_{2}$ that promoted a phase change of molybdenum carbide to less-active molybdenum oxide.

Although high levels of $\mathrm{CO}_{2}$ are detrimental, low levels can play beneficial roles. Rodrigues et al. [191] studied the effect of co-feeding $\mathrm{CO}_{2}$ in a packed-bed reactor over a Mo/HMCM-22 catalyst. The $\mathrm{CO}_{2}$ feed concentration varied between 5.7 and $6.7 \%$. They measured 
the gas-phase $\mathrm{H}_{2}, \mathrm{CH}_{4}, \mathrm{C}_{2} \mathrm{H}_{4}, \mathrm{C}_{2} \mathrm{H}_{6}$, benzene, toluene ${ }_{1454}$ and naphthalene as functions of time-on-stream using ${ }_{1455}$ online gas chromatography coupled with thermal con- ${ }_{1456}$ ductivity (TCD) and flame ionization detectors (FID). 1457 The results showed that $\mathrm{CO}_{2}$ beneficially extended the ${ }_{1458}$ catalyst lifetime. Apparently, the $\mathrm{CO}_{2}$ reacts with sur- 1459 face carbon $[\mathrm{C}]$, cleaning the catalyst surface (s), and ${ }_{1460}$ producing $\mathrm{CO}$. It is likely that the $\mathrm{CO}_{2}$ reacts with any ${ }_{1461}$ deposited coke according to the Bouduard process as ${ }_{1462}$

$$
\mathrm{CO}+(\mathrm{s}) \rightleftharpoons \mathrm{CO}(\mathrm{s}),
$$

$\mathrm{CO}(\mathrm{s})+(\mathrm{s}) \rightleftharpoons \mathrm{C}(\mathrm{s})+\mathrm{O}(\mathrm{s})$,

$$
[\mathrm{C}]+\mathrm{O}(\mathrm{s}) \rightleftharpoons \mathrm{CO}(\mathrm{s}),
$$$$
\mathrm{CO}(\mathrm{s})+\mathrm{O}(\mathrm{s}) \rightleftharpoons \mathrm{CO}_{2}(\mathrm{~s})+(\mathrm{s}),
$$

$$
\mathrm{CO}_{2}(\mathrm{~s}) \rightleftharpoons \mathrm{CO}_{2}+(\mathrm{s}),
$$

$$
\mathrm{CO}_{2}+[\mathrm{C}] \rightleftharpoons 2 \mathrm{CO} \text {. }
$$

Yao et al. [149] studied the promotional role of CO in MDA over a Mo/HMCM-49 catalyst. Using isotopi- ${ }_{1473}$ cally labeled carbon in $\mathrm{CO}$ as ${ }^{13} \mathrm{C}$, they showed that $\mathrm{CO}$ participates in oxidizing the carbonaceous surface species. By measuring the isotopically tagged benzene ${ }^{13} \mathrm{C}_{x} \mathrm{C}_{6-x} \mathrm{H}_{6}(x=0-3)$ as a function of time-on-stream, ${ }^{1475}$ the results revealed complexities associated with the in- ${ }^{1476}$ fluence of CO in MDA. In addition to reaction with ${ }^{1477}$ surface-adsorbed carbon, $\mathrm{CO}$ also participates in the ${ }^{1478}$ benzene formation. The added CO did not affect the ${ }^{1479}$ methane conversion, but improved the catalyst stability. ${ }^{1480}$ This result is consistent with the earlier studies of Liu et ${ }^{1481}$ al. [192] that also used isotopically labeled CO. A sub- ${ }^{1482}$ sequent study by Liu et al. [178] explained the benefi- ${ }^{1483}$ cial role of CO by the reaction of surface-deposited car- ${ }^{1484}$ bon $[\mathrm{C}]$ with the surface oxygen $\mathrm{O}(\mathrm{s})$ as in Eq. 19. Liu ${ }^{1485}$ et al. [178] also reported that co-feeding CO increases ${ }^{1486}$ the benzene and naphthalene formation rates, increases ${ }^{1487}$ methane conversion, and extends the catalyst lifetime.

Liu et al. [192] also studied the effects of co-feeding ${ }^{1489}$ $\mathrm{CO}_{2}$ (10\% or higher) in MDA over a Mo/HZSM-5 cat- ${ }^{1490}$ alyst. Perhaps surprisingly, the process was reported to ${ }^{1491}$ be more sensitive to $\mathrm{CO}_{2}$ in the feed than it was to $\mathrm{CO}{ }^{1492}$ in the feed. Co-feeding only $1.6 \% \mathrm{CO}_{2}$ decreased the ${ }^{1493}$ benzene formation rate, but increased the methane con- ${ }^{1494}$ version. Increasing the feed $\mathrm{CO}_{2}$ concentration above ${ }^{1495}$ $10 \%$ greatly suppressed the aromatic yield. Apparently, ${ }^{1496}$ the $\mathrm{CO}_{2}$ participated in methane dry reforming as

$$
\mathrm{CH}_{4}+\mathrm{CO}_{2} \rightarrow 2 \mathrm{CO}+2 \mathrm{H}_{2}, \quad \Delta H_{298}^{\circ} \approx+246 \mathrm{~kJ} . \text { (23) }{ }^{499}
$$

With high $\mathrm{CO}_{2}$ levels, the reforming reaction path was 1501 thermodynamically favored over the desired MDA path. ${ }_{1502}$

\subsection{2. $\mathrm{H}_{2} \mathrm{O}$ co-feeding}

Co-feeding $\mathrm{H}_{2} \mathrm{O}$ in the MDA reactive gas mixture is experimentally demonstrated to improve the catalyst stability and several research groups have explored the behavior [192-199]. The beneficial role of steam is generally explained by the removal of surface carbon [C] by $\mathrm{H}_{2} \mathrm{O}$ to form $\mathrm{CO}$ and $\mathrm{H}_{2}$, via either the change in zeolite acid site density or by the steam reforming of naphthalene.

Ichikawa and co-workers published a series of papers studying the beneficial role of steam in MDA [192, 193, 173]. According to their studies, the $\mathrm{H}_{2} \mathrm{O}$ can play several, possibly competitive, roles. Steam may promote methane reforming, react with surface carbon, or modify the $\mathrm{Mo}_{2} \mathrm{C}$ structure. Ma et al. [173] studied the co-feeding effects of $\mathrm{H}_{2}$ and/or $\mathrm{H}_{2} \mathrm{O}$ in MDA over Mo/HZSM-5 catalysts at $750{ }^{\circ} \mathrm{C}$ and 3 bar. They reported the principal methane reactions and their Gibbs free energies (evaluated at $750{ }^{\circ} \mathrm{C}$ and 3 bar) as

$$
\begin{aligned}
\mathrm{CH}_{4} & \rightarrow[\mathrm{C}]+2 \mathrm{H}_{2} \quad \Delta G=-22 \mathrm{~kJ}, \\
\mathrm{H}_{2} \mathrm{O}+[\mathrm{C}] & \rightarrow \mathrm{CO}+\mathrm{H}_{2} \quad \Delta G=-11 \mathrm{~kJ}, \\
\mathrm{CH}_{4}+\mathrm{H}_{2} \mathrm{O} & \rightarrow \mathrm{CO}+3 \mathrm{H}_{2} \quad \Delta G=-33 \mathrm{~kJ} .
\end{aligned}
$$

Based on the Gibbs free energy change $(\Delta G=-33$ $\mathrm{kJ}$ ), the steam-reforming path was expected to dominate. Adding less than $1.8 \% \mathrm{H}_{2} \mathrm{O}$ was beneficial in suppressing catalyst deactivation. However, increasing the $\mathrm{H}_{2} \mathrm{O}$ concentration also caused rapid catalyst deactivation, which is likely associated with $\mathrm{Mo}_{2} \mathrm{C}$ oxidation and dealumination of the zeolite. This study also reported synergistic effects of co-feeding $\mathrm{H}_{2}$ and $\mathrm{H}_{2} \mathrm{O}$. The $\mathrm{H}_{2}$ inhibited the degradation of the $\mathrm{Mo}_{2} \mathrm{C}$ complex which can be oxidized by reaction with $\mathrm{H}_{2} \mathrm{O}$ [200]. Using low-level $\mathrm{H}_{2} \mathrm{O}$ co-feed, Ma et al. [173] reported durable catalyst performance in a packed-bed reactor for over 1000 minutes time-on-stream. Improved MDA stability was explained by the suppression of PAH at the zeolite acid sites. Figure 8 reproduces the $\mathrm{Ma}$ et al. [173] benzene formation rates, with different co-feed streams.

Yao et al. [194] also studied the effect of premixing $\mathrm{H}_{2} \mathrm{O}$ in the MDA feed over a Mo/HMCM-49 catalyst in a packed-bed reactor. By introducing $2.9 \% \mathrm{H}_{2} \mathrm{O}$ into the $87.4 \% \mathrm{CH}_{4}$ and $9.7 \% \mathrm{~N}_{2}$ feed stream, they claimed to synergistically combine methane steam reforming and MDA chemistry. Stable catalyst performance was reported for up to $60 \mathrm{~h}$ time-on-stream. These results were explained by the beneficial participation of $\mathrm{H}_{2} \mathrm{O}$ in reforming chemistry, producing $\mathrm{CO}$ and $\mathrm{H}_{2}$. The $\mathrm{CO}$, which is a product of Eq. 25, can further react with the surface deposited carbon [C] according to Eqs. 17-19. 


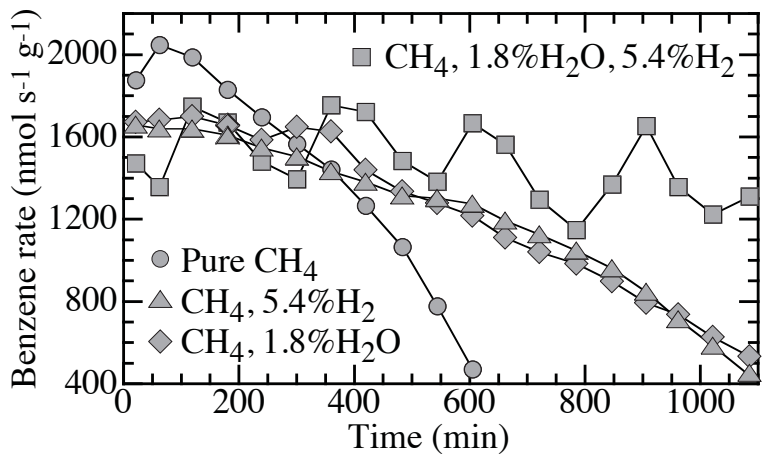

Figure 8: Co-feeding effect of $\mathrm{H}_{2}$ and/or $\mathrm{H}_{2} \mathrm{O}$ in MDA at $750{ }^{\circ} \mathrm{C}, 3$ atm over Mo/HZSM-5 [173].

Liu et al. [195] studied MDA chemistry over a 3 wt.\%

Mo/HZSM-5 catalyst at $730{ }^{\circ} \mathrm{C}$. They reported that up to $2 \% \mathrm{H}_{2} \mathrm{O}$ can improve the catalyst activity and stability. According to their TPO, XPS, and high-resolution transmission electron microscopy (HRTEM) measurements, the improvement of catalytic activity was related to the removal of weakly bound surface carbon prior to its transformation to the graphitic or aromatic carbon that causes catalyst deactivation. They found molybdenum in the form of $\mathrm{Mo}_{2} \mathrm{C}$ and $\mathrm{Mo}_{2} \mathrm{O}_{x} \mathrm{C}_{y}$ after carburization. However, with greater than $2 \% \mathrm{H}_{2} \mathrm{O}$ the carbide ${ }^{1538}$ structures reacted to form oxides, $\mathrm{Mo}_{2} \mathrm{O}-\mathrm{MoO}_{3}$.

Skutil and Taniewski [196] studied the effects of premixing $\mathrm{H}_{2} \mathrm{O}, \mathrm{CO}$, and $\mathrm{CO}_{2}$ in methane feed for an $\mathrm{MDA}{ }^{154}$ process using Mo/HZSM-5 catalysts at $725^{\circ} \mathrm{C}$. They ${ }^{154}$ showed that up to $2 \% \mathrm{H}_{2} \mathrm{O}$ and $2.5 \% \mathrm{CO}_{2}$ increased the catalytic activity, benzene yield, and improved the catalyst stability. However, further increases in $\mathrm{H}_{2} \mathrm{O}(9.5 \%)$ and $\mathrm{CO}_{2}(5$ and $11 \%)$ caused rapid catalyst deactivation. Premixing 8.5\% CO enhanced the catalytic activity and catalyst stability, but slightly decreased the benzene se- ${ }^{1548}$ lectivity.

Several groups studied the role of $\mathrm{H}_{2} \mathrm{O}$ in the context ${ }^{1550}$ of changing the Brønsted-acid site density [197, 141, 198, 199]. According to Ding et al. [197] zeolite deac- ${ }^{1552}$ tivation is caused by the PAH formation. The Brønsted ${ }^{1553}$ acid sites promote cyclization and aromatization. Any ${ }^{1554}$ excess of acid sites tends to promote further aromatiza- ${ }^{1555}$ tion from benzene to naphthalene and higher condens- 1556 able PAHs. Steam reduces the Brønsted acidity, leading ${ }^{1557}$ to significant improvement in benzene selectivity and 1558 catalyst stability.

\subsubsection{Reaction of steam with naphthalene}

Steam can play a significant role in cracking naphtha- 1563 lene, which is the primary precursor leading to deleteri- ${ }^{1564}$

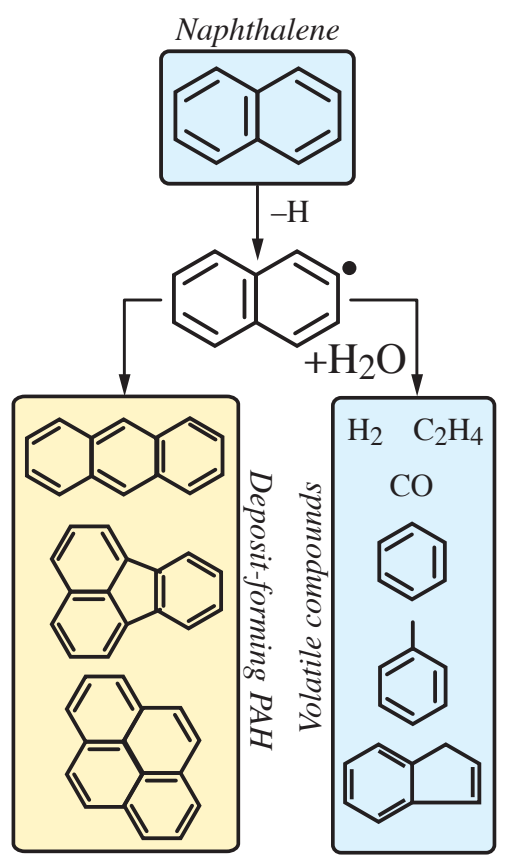

Figure 9: Schematic illustrating possible pathways for the interactions of steam with naphthalene.

ous condensed PAHs. Naphthalene is a gas-phase compound under the MDA reaction conditions, but can react rapidly to form higher polyaromatics (e.g., anthracene, phenanthrene, fluoranthene, pyrene,...), which condense to form solid deposits on the catalyst. These species can block zeolite cage openings, inhibiting transport into and out of the small channels. The result appears as catalyst deactivation.

Low levels of $\mathrm{H}_{2} \mathrm{O}$ can react beneficially with naphthalene, interrupting the pathway to higher PAH. The reaction products (including hydrogen, carbon monoxide, ethylene, benzene,...) also beneficially affect the MDA process. Figure 9 shows two possible reaction pathways for subsequent reaction with naphthalene. Without an oxidant in the reactive stream, molecular weight growth processes pyrolyze naphthalene toward higher aromatics and PAH deposits (left-hand pathway). However with low-level steam addition (right-hand pathway) naphthalene steam-cracking chemistry can impede molecular weight growth and form small aromatics as well as $\mathrm{CO}$ and $\mathrm{H}_{2}$ [201]. Moreover, as discussed previously, steam can react with deposited carbon to assist surface regeneration. Thus, low levels of steam are expected to reduce the catalyst deactivation rate.

Buchireddy et al. [202] studied naphthalene steam cracking in a packed-bed reactor with a mixture of synthesis gas $\left(20 \% \mathrm{CO}, 9 \% \mathrm{CO}_{2}, 20 \% \mathrm{H}_{2}, 3 \% \mathrm{CH}_{4}\right)$, 
$\mathrm{C}_{10} \mathrm{H}_{8}$, and $\mathrm{H}_{2} \mathrm{O}$ at $750{ }^{\circ} \mathrm{C}$ and a steam-to-carbon ra- 1613 tio of 5. They proposed that cracking reactions take 1614 place within the zeolite cage structure at Brønsted acid ${ }_{1615}$ sites. Therefore, higher acidity tends to increase naph- 1616 thalene cracking activity. Because naphthalene must 1617 be transported inside the zeolite cages, the cage size 1618 strongly influences the cracking rate. Zeolites with 1619 larger cages produce higher cracking activity. For ex- 1620 ample, H-ZSM5, which has a characteristic cage dimen- 1621 sion of $55 \mathrm{~nm}$, delivered $19 \%$ naphthalene conversion. 1622 The ZY-30, which has a characteristic cage dimension ${ }_{1623}$ of $80 \mathrm{~nm}$, increased the naphthalene conversion to 33\%. 1624 Buchireddy et al. suggested that the naphthalene crack- 1625 ing produces graphitic carbon $\mathrm{C}(\mathrm{s})$ as well as volatile ${ }_{1626}$ $\mathrm{CO}, \mathrm{CO}_{2}$, and smaller hydrocarbons. The surface car- ${ }_{1627}$ bon reacts further with $\mathrm{CO}_{2}$ (Eq. 22) and $\mathrm{H}_{2} \mathrm{O}$ (Eq. 25) ${ }_{1628}$ to form $\mathrm{CO}$.

Incorporating $\mathrm{Ni}$ into zeolites can significantly 1630 increase the naphthalene conversion up to 98\%. ${ }_{1631}$ Buchireddy et al. [202] explained the high conversion ${ }_{1632}$ by the effect of $\mathrm{Ni}$ in promoting steam and dry reform- ${ }_{1633}$ ing as

$\mathrm{C}_{10} \mathrm{H}_{8}+10 \mathrm{H}_{2} \mathrm{O} \rightleftharpoons 10 \mathrm{CO}+14 \mathrm{H}_{2}, \quad \Delta H^{\circ} \approx+1163 \mathrm{~kJ}^{1635}$ (27) ${ }_{1637}$ $\mathrm{C}_{10} \mathrm{H}_{8}+10 \mathrm{CO}_{2} \rightleftharpoons 20 \mathrm{CO}+4 \mathrm{H}_{2}, \quad \Delta H_{298}^{\circ} \approx+1575 \mathrm{~kJ} .{ }_{1638}$

Buchireddy et al. measured naphthalene conversion, 1639 but did not report the product composition. Thus, the 1640 chemical pathways governing steam-naphthalene inter- 1641 action remain unclear. Nevertheless, based on thermo- 1642 dynamics considerations, steam reforming of naphtha- ${ }_{1643}$ lene should be fast above $700{ }^{\circ} \mathrm{C}$. The Gibbs free en- 1644 ergy change of the naphthalene-steam-reforming reac- ${ }_{1645}$ tion (Eq. 27) is $\Delta G=-66 \mathrm{~kJ}$ at $750{ }^{\circ} \mathrm{C}$.

Naphthalene steam cracking is certainly not lim- ${ }_{1647}$ ited to zeolite catalysts. Devi et al. [201] studied ${ }_{1648}$ naphthalene steam cracking over olivine (Mg-Fe sili- 1649 cate) catalysts and proposed a detailed reaction path- 1650 way, producing gas-phase benzene, toluene, ethylene, ${ }_{1651}$ indene and acetylene. The reaction mechanism also ${ }_{1652}$ involved PAH species, including fluoranthene, an- ${ }_{1653}$ thracene, phenantracene, crysene, and pyrene. These ${ }_{1654}$ higher PAH are also responsible for deactivation under ${ }_{1655}$ MDA conditions [175, 174]. Thus, it is at least possi- 1656 ble that similar molecular-weight-growth pathways are ${ }_{1657}$ active on the Mo/Zeolite catalysts.

Wang et al. [203] proposed a reaction pathway for ${ }_{1659}$ naphthalene steam cracking over $\mathrm{Rh}_{2} \mathrm{O}_{3} / \mathrm{HY}$ zeolite and 1660 Mo-Ni oxide catalysts. In this reaction pathway, naph- 1661 thalene ring opening favors the formation of smaller 1662 alkanes and aromatics. However hydrogenation reac- 1663 tions proceed in parallel with steam cracking, producing very large polyaromatic hydrocarbons (e.g., teralin and decalin) through condensation reactions.

In addition to dominantly catalytic chemistry, gasphase reactions may also play important roles, especially at high temperature. Jess [204] studied homogeneous gas-phase reaction of naphthalene and steam at temperatures between 700 and $1400{ }^{\circ} \mathrm{C}$. Although naphthalene is difficult to activate homogeneously at temperatures below $800{ }^{\circ} \mathrm{C}$, at higher temperatures numerous gas-phase products were measured $\left(\mathrm{CO}, \mathrm{CO}_{2}\right.$, $\mathrm{C}_{2} \mathrm{H}_{2}, \mathrm{C}_{2} \mathrm{H}_{4}, \mathrm{C}_{2} \mathrm{H}_{6}, \mathrm{C}_{6} \mathrm{H}_{6}$ and $\mathrm{C}_{7} \mathrm{H}_{8}, \mathrm{C}_{9} \mathrm{H}_{8}$ and $\mathrm{C}_{9} \mathrm{H}_{10}$ ). These gas-phase species are also products of catalytic naphthalene steam cracking processes [201, 203]. Although gas-phase chemistry may be active, the catalyst certainly affects reaction pathways and the product distribution.

Although low-level steam addition surely has a beneficial influence for MDA processes, there is very limited fundamental understanding of naphthalene-steam chemistry on zeolite-based catalysts. Improved understanding the interaction of naphthalene-steam reactions and the catalyst deactivation mechanisms will likely contribute to improved MDA process technology. Synergistic theoretical and experimental research is certainly needed.

\subsection{Incorporating a second metal into Mo/Zeolite}

Catalyst stability and performance can be varied by incorporating another metal in addition to Mo. Noble metals (i.e., Pt, Pd, Rh, Ru, Ir, Re) [205-207], transition metals (i.e., $\mathrm{Fe}, \mathrm{Cr}, \mathrm{Co}, \mathrm{Ga}, \mathrm{Ni}, \mathrm{Zn}, \mathrm{Ti}, \mathrm{W})[91,208-$ 211] and their combinations [212,213] have been evaluated for MDA applications. Among the noble metals, Pt- and Re-doped Mo/zeolite catalysts showed increased catalytic activity and stability.

Burns et al. [208] studied incorporating transition metals ( $\mathrm{Ga}, \mathrm{Co}, \mathrm{Al}, \mathrm{Fe}$ ) into Mo/Zeolite catalysts using an impregnation technique. Using a packed-bed reactor, measurements were reported for methane conversion as well as hydrogen and benzene formation rates. Catalyst screening revealed that $\mathrm{Ga}, \mathrm{Fe}$, and $\mathrm{Al}$ can all help to improve the catalyst stability. The second metal can change the zeolite catalyst structure via reaction with aluminum to form a secondary metal-aluminum-oxide phase. The second metal also has the effect of modifying the Brønsted acidity. Yet another potential role of the secondary metal is to form mixed molybdenumcontaining phases. The second metal can also affect the initial molybdenum-oxide dispersion.

Although only indirectly related to MDA, Yeh et al. [214] compared Ga- and Pt-incorporated 
metal/ZSM-5 structures in endothermic hexane reform- 1715 ing. The Ga was shown to enhance both the aromatiza- 1716 tion rates and catalyst stability.

Aboul-Gheit et al. [211] studied bimetallic Mo-Fe, ${ }_{1718}$ Mo-Co and M-Ni/HZSM-5 catalysts (equal weights, ${ }_{1719}$ $3 \%$ each) in a packed-bed reactor at $700{ }^{\circ} \mathrm{C}$. The met- 1720 als were incorporated into the catalyst by mechanical 1721 mixing. They measured the catalytic activity in terms 1722 of methane conversion and aromatic yield as functions 1723 of time-on-stream. Based on ex-situ TPO measure- 1724 ments they determined the cumulative coke formation 1725 rate. Unlike Burns et al. [208], Aboul-Gheit et al. [211] 1726 reported that second-metal incorporation increased the 1727 coke and hydrogen formation rates, with the effects be- 1728 ing greatest for $\mathrm{Fe}$, followed by $\mathrm{Co}$ and then Ni. Aboul- 1729 Gheit et al. interpreted the low catalytic activity of Mo 1730 mixed with group-VIII metals $(\mathrm{Fe}, \mathrm{Co}, \mathrm{Ni})$ in terms of ${ }_{1731}$ electronic structure and unfilled d-orbitals. The mixed- ${ }_{1732}$ metal structures influenced the chemisorption behavior, ${ }_{1733}$ strengthening the $\mathrm{CH}_{4}$ adsorption and leading to coke formation.

In addition to the second-metal identity, the loading ${ }_{1735}$ also affects the activity. However, there appear to be no ${ }_{1736}$ general rules for determining the optimal ratios between ${ }_{1737}$ Mo and the second metal. Masiero at al. [215] studied ${ }_{1738}$ effects of the $\mathrm{Mo} / \mathrm{Fe}$ ratio in HZSM-5 catalysts. X-ray ${ }_{1739}$ diffraction (XRD) was used to characterize the catalyst ${ }_{1740}$ phases. The catalytic activity at $700{ }^{\circ} \mathrm{C}$ was reported ${ }_{1741}$ in terms of methane conversion and benzene selectiv- ${ }_{1742}$ ity. Catalyst deactivating deposits were analyzed using ${ }_{1743}$ thermogravimetric analysis (TGA), differential thermal ${ }_{1744}$ analysis (DTA), and temperature-programmed oxida- ${ }_{1745}$ tion (TPO). The study showed that increasing Fe content ${ }_{1746}$ decreased the acid strength and hence decreased arom- ${ }_{1747}$ atization. A Mo/Fe ratio of 4 increased the catalytic ac- ${ }_{1748}$ tivity as well as the stability. In addition to improved ${ }_{1749}$ activity, the Fe formed a second bimetallic $\mathrm{Fe}_{2}\left(\mathrm{MoO}_{4}\right)_{3}$ structure that enhanced the catalytic stability.

A 2015 study by Abdelsayed et al. [91] confirmed that $\mathrm{Fe}$ incorporation increased methane conversion and ${ }^{175}$ catalyst stability. Unlike, Masiero at al. [215], Ab- ${ }^{1751}$ delsayed et al. did not observe any secondary Mo phases. However, they found that carbon nanotubes were formed on the spent catalysts. The carbon nanostructures apparently enhanced reactant and product diffusion and coke resistance.

\subsection{Alternative catalysts}

Although zeolite catalysts with a range of cage sizes 1753 and metal loadings are used, there may be viable al- 1754 ternatives with non-zeolite catalysts. A 2014 discov- 1755 ery by Guo et al. [90] suggested that $\mathrm{Fe}$ with $\mathrm{SiO}_{2}$ sup- 1756 ports is an excellent catalyst for the non-oxidative conversion of methane to ethylene. They reported a 30\% $\mathrm{C}_{2} \mathrm{H}_{4}$ yield at $950{ }^{\circ} \mathrm{C}$ in a packed-bed reactor. The process also yielded significant amounts of aromatics (approximately $23 \%$ ), primarily benzene and naphthalene. The catalyst showed excellent durability over long periods up to $60 \mathrm{~h}$, without the appearance of carbon deposits. The reported very high process temperatures, $1000 \leq T \leq 1200^{\circ} \mathrm{C}$. Typical processes for methane dehydrogenation to ethylene operate in the range of $800 \leq$ $T \leq 900{ }^{\circ} \mathrm{C}$. At $1020^{\circ} \mathrm{C}$, Guo et al. reported methane conversion to be $32 \%$, with steady product selectivities of $52.7 \%$ ethylene, $21.5 \%$ benzene, and $25.8 \%$ naphthalene for $60 \mathrm{~h}$ on stream. Operating in the temperature range $950 \leq T \leq 1090{ }^{\circ} \mathrm{C}$, the product distribution remained almost constant. Although high operating temperature represents a practical technological disadvantage, the performance of $\mathrm{Fe} / \mathrm{SiO}_{2}$ catalysts for $\mathrm{C}_{2} \mathrm{H}_{4}$ or aromatics production merits further investigation.

\subsection{MDA reaction kinetics}

There is relatively little literature on the detailed reaction pathways and associated rates for MDA kinetics on bi-functional Mo/zeolites catalysts. It is reasonably well established that molybdenum-carbide complex is the active center for methane activation. The $\mathrm{Mo}_{2} \mathrm{C}$ is believed to be responsible for activating methane to form small $\mathrm{C}_{2}$ olefins (mainly $\mathrm{C}_{2} \mathrm{H}_{4}$ ) and hydrogen. Describing the methane-activation chemistry on the $\mathrm{Mo}_{2} \mathrm{C}$ probably requires fewer reaction steps than does the subsequent chemistry on the zeolite acid sites. Nevertheless, because of the relatively complex $\mathrm{Mo}_{2} \mathrm{C}$ structure (cf., Fig. 6), establishing the elementary reaction steps is challenging.

Iglesia and co-workers $[216,18]$ proposed a global reaction for the methane activation as

$$
2 \mathrm{CH}_{4} \rightarrow \mathrm{C}_{2} \mathrm{H}_{4}+\mathrm{H}_{2}, \quad \Delta H_{298}^{\circ} \approx+202 \mathrm{~kJ} .
$$

The rate expression for this reaction was assumed to be first-order, being expressed empirically as

$$
r=k p_{\mathrm{CH}_{4}}(1-\gamma),
$$

where $\gamma$ is evaluated as

$$
\gamma=\frac{p_{\mathrm{C}_{2} \mathrm{H}_{4}} p_{\mathrm{H}_{2}}^{2}}{p_{\mathrm{CH}_{4}}} \frac{1}{K},
$$

with $k$ being a rate constant, $p_{i}$ being partial pressures, and $K$ being the equilibrium constant.

As illustrated in Fig. 10, Xing et al. [163, 164] were the first to propose elementary reaction steps to form 


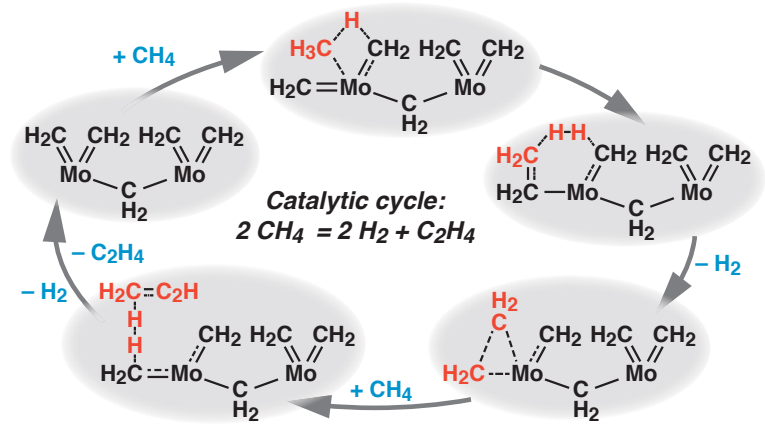

Figure 10: Illustration of a proposed catalytic cycle for methane acti- 1802 vation on the $\mathrm{Mo}_{2} \mathrm{C}$ sites (adapted from Zhou et al. [164]).

$\mathrm{C}_{2} \mathrm{H}_{4}$ on $\mathrm{Mo}_{2} \mathrm{C}$ structures. The cycle begins by methane adsorption, followed by a transition state leading to hydrogen desorption. Methane is again adsorbed, followed by hydrogen and ethylene desorption restoring the catalyst to its original $\mathrm{Mo}_{2} \mathrm{C}$ structure.

Following the methane dimerization on the $\mathrm{Mo}_{2} \mathrm{C}$ aromatization takes place on the zeolite Brønsted acid sites. The aromatization chemistry is complex, involving numerous reaction steps. As is typical of Brønsted acid sites, chemistry proceeds according to chemisorption, desorption, hydride transfer, pyrolytic dehydrogenation/hydrogenation, protolysis, oligomerization, and $\beta$-scission processes.

Iglesia and co-workers $[216,18]$ proposed a threestep lumped kinetics model for MDA on Mo/HZSM-5 catalysts. Following the methane dimerization reaction (Eq. 29) the global aromatization reactions include

$$
3 \mathrm{C}_{2} \mathrm{H}_{4} \rightarrow \mathrm{C}_{6} \mathrm{H}_{6}+3 \mathrm{H}_{2}, \quad \Delta H_{298}^{\circ} \approx-74 \mathrm{~kJ},
$$

$$
\mathrm{C}_{6} \mathrm{H}_{6}+2 \mathrm{C}_{2} \mathrm{H}_{4} \rightarrow \mathrm{C}_{10} \mathrm{H}_{8}+3 \mathrm{H}_{2}, \quad \Delta H_{298}^{\circ} \approx-38 \mathrm{~kJ} \quad{ }_{1825}
$$

Based on the gas-phase chemistry of methane pyrol- 1827 ysis as originally developed by Dean [217], the Igle- ${ }_{1828}$ sia studies also discuss the effects of gas-phase reac- ${ }_{1829}$ tions in MDA. Under the packed-bed conditions stud- 1830 ied, the gas-phase contributions were found to be negli- ${ }_{1831}$ gible [216].

As illustrated in Fig. 11, Wong et al. reported het- ${ }_{1833}$ erogeneous reaction pathways for aromatization chem- 1834 istry on HZSM-5 and HMCM-22 zeolites [218]. The ${ }_{1835}$ methane dimerization kinetics on molybdenum was ex- 1836 plained in a global step following the reaction pathway 1837 proposed by Li et al. [216]. In the Wong et al. study, the 1838 formation of ethylene is followed by aromatization on zeolites Brønsted acid sites. Chemisorption, oligomerization, pyrolysis, hydride transfer and alklylation are the major reaction paths leading to gas-phase products $\mathrm{C}_{2} \mathrm{H}_{4}, \mathrm{C}_{2} \mathrm{H}_{6}, \mathrm{C}_{6} \mathrm{H}_{6}, \mathrm{C}_{7} \mathrm{H}_{8}$ and $\mathrm{C}_{10} \mathrm{H}_{8}$. The reaction pathway also includes gas-phase reaction intermediates (e.g., hexane, cyclohexane) and surface species (e.g., $\left.\mathrm{C}_{2} \mathrm{H}_{5}{ }^{+}, \mathrm{C}_{4} \mathrm{H}_{9}{ }^{+}\right)$. Although they did not report reactionrate expressions, Wong et al. reported activation barriers for each of the reaction families. They also provided the nominal values of pre-exponential factors as evaluated by transition-state theory.

Based on the pathways suggested by Wong et al [218], Karakaya et al. [134] proposed an elementary reaction mechanism for bi-functional Mo/HZSM-5 catalysts. The $\mathrm{C}_{2} \mathrm{H}_{4}$ formation pathway on the $\mathrm{Mo}_{2} \mathrm{C}$ sites was developed according to a DFT study by Zhou et al. [164]. The Karakaya et al. reaction mechanism, which involved 50 elementary reactions, was implemented into a one-dimensional packed-bed computational model. In this reaction mechanism, $\mathrm{C}_{2} \mathrm{H}_{4}$ production over $\mathrm{Mo}_{2} \mathrm{C}$ is close to its equilibrium limit. Using previously published data from packed-bed experiments [219-221], Karakaya et al. fine-tuned and validated the reaction model. However, the model did not include deposit formation and catalyst deactivation behavior.

Despite considerable research on MDA processes, predictive models have yet to be developed to describe the inherently unsteady behavior (i.e., carburization, benzene production, catalyst deactivation, regeneration). Even for more traditional processes (e.g., steam reforming), state-of-the-art surface-reaction models do not include the catalyst deactivation behavior. Yet another problem with most elementary-step surfacekinetics reaction mechanisms is the imposition thermodynamic consistency and microscopic reversibility. Because the thermochemistry of adsorbed species is generally unknown (or at least uncertain), the detailed surface-reaction models usually fail to satisfy the enthalpic and entropic consistency. Although estimating or measuring such thermodynamic properties may be difficult, the properties play a central role in ensuring microscopic reversibility. There is active research devoted to estimating the thermodynamic properties needed to assure microscopic reversibility [222224]. To date, most modeling research on detailed reaction mechanisms has focused on transition-metal catalysts (primarily, Pt, Pd, Rh, and Ni). Clearly, developing and validating predictive models for the bifunctional catalysts used in MDA represent much larger challenges. 


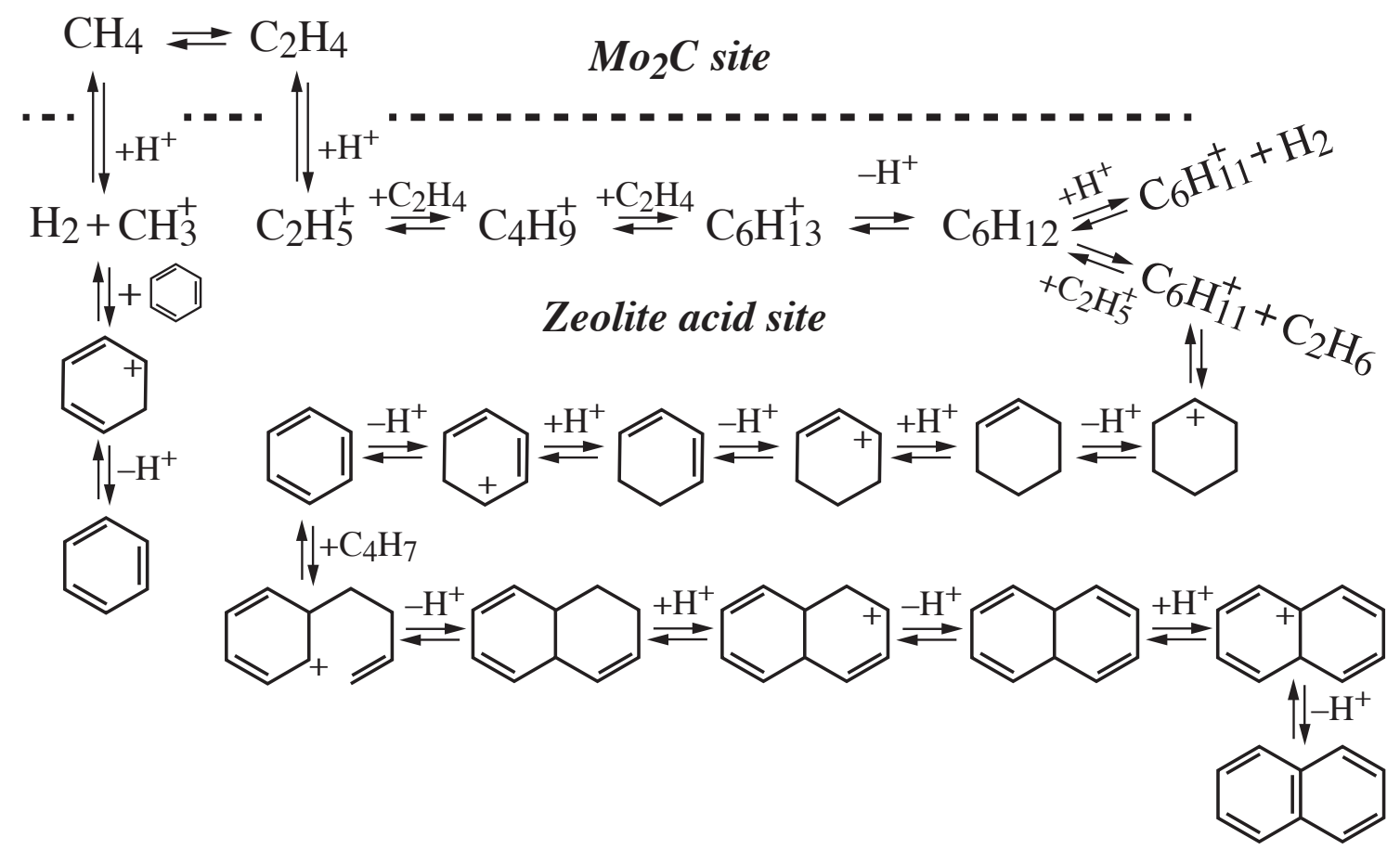

Figure 11: MDA reaction pathway proposed by Wong et al. [218] for a bi-functional Mo/zeolite catalyst.

\section{Reactor technologies}

Although catalysts are central to both oxidative and ${ }_{1867}$ non-oxidative processes, the catalyst is only one factor in controlling the overall process. Considerations such 1868 as catalyst packing, thermal management, reactor oper- 1869 ating conditions, and downstream gas separations also 1870 play critical roles. Turnover rates (e.g., ethylene or ben- 1871 zene produced per unit catalyst area per unit time) con- 1872 tribute greatly to the process efficiency and cost. An 1873 analysis by Hall [225] showed that separating ethylene 1874 from the other effluent gases $\left(\mathrm{CH}_{4}, \mathrm{CO}, \mathrm{C}_{2} \mathrm{H}_{6}\right)$ is a ma- 1875 jor cost-driver. Thus, developing systems with higher 1876 product selectivity increases product yield and also con- 1877 tributes to decreasing overall process cost.

Reactor and process design involves numerous, often 1879 competing, considerations. Generally speaking, cata- 1880 lysts may be deployed in packed beds, washcoat lay- 1881 ers, or in fluidized beds. The catalysts themselves may 1882 take a variety of shapes and sizes, ranging from small 1883 particles to larger pellets. The reactors can take a va- 1884 riety of forms, including shell-and-tube, monolith, or 1885 planar microchannels. A variety of membranes can be ${ }_{1886}$ used, including micro- or nano-porous structures, thin- 1887 film metals (e.g., Pd or Pd alloys), or dense-ceramic ion- 1888 transport materials. The general reactor configuration 1889 (e.g., tubular or planar) is an important design consid- 1890 eration. The following subsections discuss reactor considerations for OCM, MDA, and membrane-assisted reactor design and operation.

\subsection{OCM reactors}

Because OCM processes are highly exothermic $\left(\Delta H_{298}^{\circ}=-281 \mathrm{~kJ}\right)$, careful attention to thermal management can avoid deleterious local hot spots and unsafe operating conditions. Limiting temperature excursions and limiting high-temperature residence time are important considerations in process and reactor design. The $\mathrm{CH}_{4} / \mathrm{O}_{2}$ stoichiometry, especially at the catalyst surfaces, greatly affects the product composition. Operating conditions (e.g., flow rates, operating pressure and temperature) should be established to achieve certain temperature distributions, residence times, and space velocities. Usually, operating conditions that avoid mass-transport limitations at the catalyst surfaces are desirable.

Most laboratory-scale OCM studies are carried out in small packed-bed reactors where catalyst particles (or pellets) are packed within small-diameter (i.e., $\leq$ $20 \mathrm{~mm}$ ) tubes [226]. The temperature is typically controlled by an external furnace. Small tube diameters help to maintain radially uniform temperatures within the bed. As illustrated in Fig. 12, the catalyst particles are held in place by a chemically inert packing material 


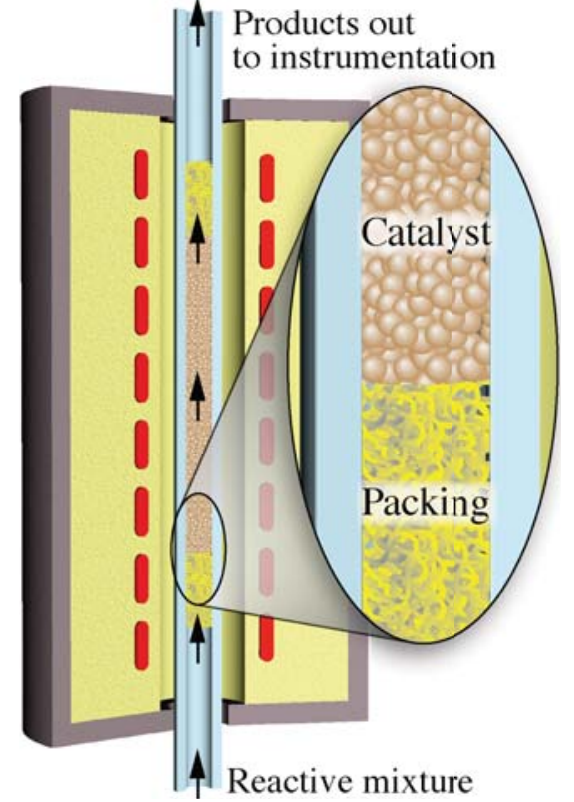

Figure 12: Illustration of a typical laboratory-scale catalytic packed- 1939 bed reactor in a tube furnace.

such as silica wool. Reacting mixtures flow through the ${ }_{1943}$ bed, with product species being measured at the outlet. 1944

Ras and Gomes-Quero [227] developed small-scale 1945 packed-bed OCM reactors operating at temperatures be- 1946 tween 755 and $875{ }^{\circ} \mathrm{C}$. They showed that the small- ${ }_{1947}$ diameter tubular configuration enabled good tempera- 1948 ture control. Alternatively, high-performance heat ex- 1949 changers can be integrated into packed-bed reactors. 1950 A recent patent application from Siluria Technologies 1951 disclosed a packed-bed OCM reactor with integrated ${ }_{1952}$ heat-exchangers that maintain precise temperature con- ${ }^{1953}$ trol [228].

Although the small-diameter tubes reduce radial tem- ${ }^{1955}$ perature gradients, understanding axial temperature gra- 1956 dients and local hot spots is important. Consider a pre- ${ }_{1957}$ mixed $\mathrm{CH}_{4} / \mathrm{O}_{2}$ feed entering into a reactor such as il- 1958 lustrated in Fig. 12. The $\mathrm{O}_{2}$ is consumed rapidly, caus- 1959 ing high local heat-release rates. Senkan and cowork- 1960 ers have measured local temperature increases on the 1961 order of $200{ }^{\circ} \mathrm{C}$ over axial distances of less than 101962 $\mathrm{mm}[99,229]$. The reaction heat is controlled by the 1963 limiting reactant $\mathrm{O}_{2}$. Thus, the methane conversion, re- 1964 action heat, and $\mathrm{C}_{2}$ selectivity depend strongly on the 1965 local $\mathrm{CH}_{4} / \mathrm{O}_{2}$ mixtures.

In practice, OCM processes operate with large ex- 1967 cesses of $\mathrm{CH}_{4}$ (typically, $5 \leq \mathrm{CH}_{4} / \mathrm{O}_{2} \leq 10$ ). Under 1968 $\mathrm{CH}_{4}$-rich conditions, the methane conversion is limited 1969 by the deficient $\mathrm{O}_{2}$ concentration. The desired $\mathrm{C}_{2}$ prod- ${ }_{1970}$ ucts are more stable at low $\mathrm{O}_{2}$ levels, meaning the $\mathrm{C}_{2}$ selectivity is higher at low $\mathrm{O}_{2}$ partial pressures where methane conversion is low. In other words there is a trade-off between the $\mathrm{C}_{2}$ selectivity and yield. High $\mathrm{C}_{2}$ selectivity (e.g., $70 \%$ ) is possible when methane conversion is low (e.g., $\leq 20 \%$ ). Of course, processes seek to achieve high methane conversion and high $\mathrm{C}_{2}$ yield.

Tye et al. citeTMB02 published a model-based study of an OCM packed-bed reactor with a $\mathrm{La}_{2} \mathrm{O}_{3} / \mathrm{CaO}$ catalyst. The results included the effects of feed composition and isothermal operating conditions on conversion, yield, and selectivity. The reaction chemistry was based on the Stansch mechanism [71]. Figure 13 shows a summary of the results. The methane conversion depends strongly on the $\mathrm{CH}_{4} / \mathrm{O}_{2}$ ratio. The $\mathrm{C}_{2}$ selectivity is high when $\mathrm{CH}_{4} / \mathrm{O}_{2}$ ratio is high (e.g., greater than ten). However, due to relatively low $\mathrm{CH}_{4}$ conversion at high $\mathrm{CH}_{4} / \mathrm{O}_{2}$ ratios, the overall $\mathrm{C}_{2}$ yield is low. The $\mathrm{C}_{2}$ selectivity is highest at $875{ }^{\circ} \mathrm{C}$. Due to the increased methyl-radical formation rates and the contributions of gas-phase chemistry at high temperature, increasing temperature from $700{ }^{\circ} \mathrm{C}$ to $875^{\circ}$ increases the $\mathrm{C}_{2}$ yield and selectivity. However, further increasing temperature above $875{ }^{\circ} \mathrm{C}$ causes deep oxidation of $\mathrm{C}_{2}$, decreasing the $\mathrm{C}_{2}$ selectivity. The optimum $\mathrm{C}_{2}$ yield is predicted at $875{ }^{\circ} \mathrm{C}$ and $\mathrm{CH}_{4} / \mathrm{O}_{2}$ ratios around five.

The Tye et al. study also considers the influence of isothermal or adiabatic (non-isothermal) operation. The results show that heat generation and temperature variations have significant influence on $\mathrm{C}_{2}$ yield. The study suggests that feed dilution (e.g., up to $50 \%$ at $750{ }^{\circ} \mathrm{C}$, $\left.\mathrm{CH}_{4} / \mathrm{O}_{2}=4\right)$ can be beneficial. The diluents can smooth the temperature distributions and avoid the local hot spots.

A possible way to control the reaction heat and improve the $\mathrm{C}_{2}$ yield is to distribute the $\mathrm{O}_{2}$ feed axially rather than premixing. One approach is to introduce the $\mathrm{O}_{2}$ via a membrane, such as illustrated in Fig. 1b. Another approach is via discrete $\mathrm{O}_{2}$ injection points with segmented reactors or catalyst beds [229]. When the oxygen is introduced in a distributed manner along the length of the reactor, the local exotherms can be significantly diminished.

Stunkel et al. [230] published a case study considering several alternative OCM reactor designs and processes. These included packed-bed, fluidized-bed, and membrane reactors. In all cases, a $\mathrm{Na}-\mathrm{W}-\mathrm{Mn} / \mathrm{SiO}_{2}$ catalyst was used. Process performance was evaluated in terms of ethylene yield. The study included the effects of operating conditions, including temperature, pressure, reactant stoichiometry, and feed rates. The experiments demonstrated that membrane-coupled 
(a) $\mathrm{X}_{\mathrm{CH} 4, \%}$

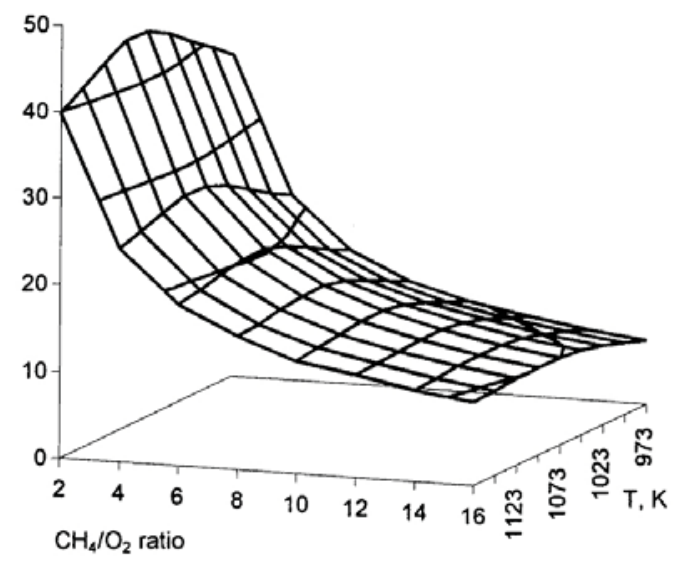

(b) $\mathrm{S}_{\mathrm{C} 2} \%$

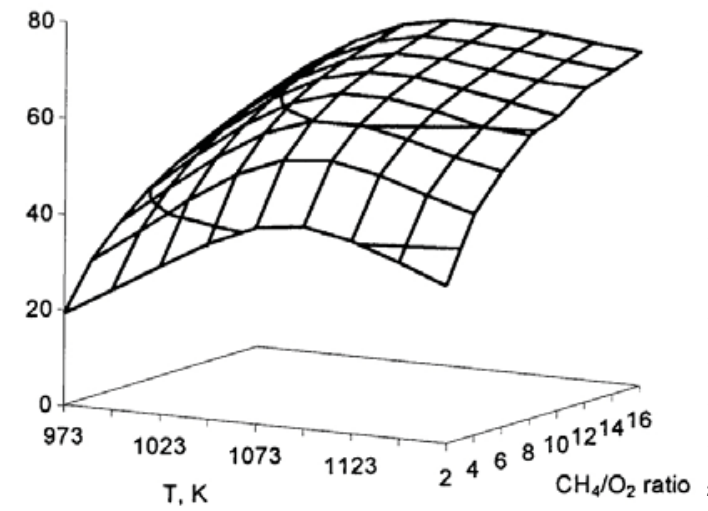

(c) $\mathrm{Y}_{\mathrm{c} 2} \%$

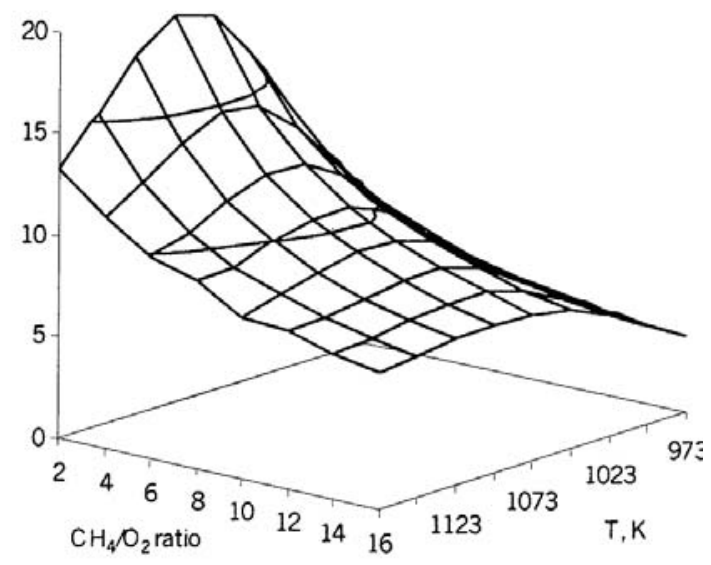

Figure 13: Model-predicted influence of the $\mathrm{CH}_{4} / \mathrm{O}_{2}$ ratio and tem- 2017 perature on OCM methane conversion (a), $\mathrm{C}_{2}$ selectivity (b) and yield 2018 (c). The figure is reproduced from Tye, et al. [78].

$$
\text { teer }
$$

susceptible to local hot spots than were packed-bed reactors. Fluidized-bed reactors had the most uniform temperature disctibutions. The Stunkel et al. [230] economic analysis showed that gas-separation (especially $\mathrm{CO}_{2}$ removal) has a major impact on the overall cost. They concluded that membrane-coupled packed-bed reactors offered the best potential for the industrial scale OCM plants.

Fluidized-bed reactors may offer potentially better thermal management compared to packed-bed reactors. The OCM process depends on both homogeneous and heterogenous chemistry. Methyl radicals are mostly generated on the catalyst surface, with exothermic recombination reactions taking place in the gas-phase. Hence, much of the heat is released in the gas-phase, potentially creating large temperature differences between the gas and the solid catalyst. The formation rates of undesired oxidation products (e.g., $\mathrm{CO}, \mathrm{CO}_{2}$, and $\mathrm{H}_{2} \mathrm{O}$ ) are increased at high gas-phase temperature. The particle motion in fluidized beds tends to diminish temperature variations [231, 89, 232-234]. However, capital and operating costs are usually higher for fluidized-bed reactors, compared to fixed-bed reactors [234].

\subsubsection{Modeling packed-bed OCM reactors}

Models of OCM processes must be concerned with thermal behavior and the closely coupled interactions between temperature and catalytic chemistry. The selectivity between desired $\mathrm{C}_{2}$ products and undesired total-oxidation products depends strongly on temperature. The temperature distribution depends on catalyst activity, flow rates, and feed composition. Local temperature maldistribution or local hot spots can be problematic for a variety of reasons. Reactor and process design can benefit greatly from model-based predictive capabilities that couple thermal and chemical interactions.

The accuracy of the model predictions relies on understanding the catalytic chemistry and the physical transport within catalyst beds. The exothermic nature of the OCM chemistry requires coupling heat and mass transfer effects to predict the overall reactor performance. Models must at least predict the gas-phase composition and temperature profiles as well as the loby Senkan and colleagues [99, 229] measured the axial temperature and gas-phase concentration profiles in a small-diameter OCM packed-bed reactor. Their results revealed very high axial temperature and composition gradients. 
The most straightforward modeling studies are 2051 based on assuming one-dimensional plug-flow behav- 2052 ior within packed catalyst beds [78, 235, 236]. In such 2053 configurations radial heat and mass transports are ne- 2054 glected. Especially for catalysts beds that are packed in 2055 narrow tubes, one-dimensional models are appropriate. 2056 However, as the beds become larger, radial temperature 2057 and composition variations become important. Thus, 2058 two- and three-dimensional models are needed to accu- 2059 rately represent the packed-bed performance [237-239]. 2060 Membranes that deliver radial fluxes into the packed 2061 beds tend to increase radial gradients, and thus increase 2062 the need for multi-dimensional models.

\subsubsection{One-dimensional packed-bed formulation}

Astem of governing equations to represent trans- 2066 port and chemistry within a one-dimensional packed- 2067 bed reactor may be summarized as:

Gas-phase species continuity

$$
\frac{\partial\left(\phi_{\mathrm{g}} \rho_{\mathrm{g}} Y_{k}\right)}{\partial t}+\nabla \cdot \mathbf{j}_{k}=\left(A_{\mathrm{s}} \dot{s}_{k}+\phi_{\mathrm{g}} \dot{\omega}_{k}\right) W_{k}+\frac{P_{\mathrm{B}}}{A_{\mathrm{B}}} \mathbf{j}_{k}^{\mathrm{M}}
$$

Overall gas-phase continuity

$$
\frac{\partial\left(\phi_{\mathrm{g}} \rho_{\mathrm{g}}\right)}{\partial t}+\sum_{k=1}^{K_{\mathrm{g}}} \nabla \cdot \mathbf{j}_{k}=\sum_{k=1}^{K_{\mathrm{g}}} A_{\mathrm{s}} \dot{s}_{k} W_{k}+\frac{P_{\mathrm{B}}}{A_{\mathrm{B}}} \sum_{k=1}^{K_{\mathrm{g}}} \mathbf{j}_{k}^{\mathrm{M}}
$$

Gas-phase energy

$$
\frac{\partial \phi_{\mathrm{g}} \rho_{\mathrm{g}} e}{\partial t}+\nabla \cdot \mathbf{q}_{\mathrm{g}}=-\dot{q}_{\mathrm{conv}}-\dot{q}_{\mathrm{surf}}
$$

Catalyst-phase energy

$$
\frac{\partial}{\partial t}\left(\phi_{\mathrm{s}} \rho_{\mathrm{s}} c_{\mathrm{p}, \mathrm{s}} T_{\mathrm{s}}\right)+\nabla \cdot \mathbf{q}_{\mathrm{s}}=\dot{q}_{\mathrm{conv}}+\dot{q}_{\mathrm{surf}}-\dot{q}_{\mathrm{env}} .
$$

Catalyst surface coverage

$$
\frac{\partial \theta_{k, m}}{\partial t}=\frac{\dot{s}_{k}}{\Gamma_{m}}
$$

Gas-phase flux within catalyst bed

$$
\mathbf{j}_{k}=-\rho_{\mathrm{g}} Y_{k} \frac{B_{\mathrm{g}}}{\mu} \nabla p-D_{k}^{\mathrm{e}} W_{k} \nabla\left[X_{k}\right]
$$

Effective diffusion coefficient

$$
D_{k}^{\mathrm{e}}=\phi_{\mathrm{g}}^{2} D_{k, \mathrm{~m}}+\frac{\phi_{\mathrm{m}}^{2}\left(1+3 \phi_{\mathrm{g}}\right)}{1-\phi_{\mathrm{g}}} D_{k, \mathrm{Kn}},
$$

The independent variables in these equations are time 2099 $t$ and the spatial coordinates. Dependent variables in- 2100 clude gas-phase mass fractions $Y_{k}$, gas-phase density $\rho_{\mathrm{g}},{ }_{2101}$ gas-phase internal energy $e\left(d e=c_{\mathrm{v}, \mathrm{g}} d T_{\mathrm{g}}\right)$, gas-phase temperature $T_{\mathrm{g}}$, solid-phase temperature $T_{\mathrm{s}}$, and catalyst surface coverage $\theta_{k, m}$ ( $k$ is the species index and $m$ is the phase index, with $\Gamma_{m}$ being the phase site density). Axial gas-phase fluxes within the bed are $\mathbf{j}_{k}$, which include pressure-driven convection (superficial velocity is $\left.U=B_{\mathrm{g}} \nabla p / \mu\right)$ and Fickian diffusion. The pressure is represented as $p$ and the gas-phase concentrations as $\left[X_{k}\right]$. The effective diffusion coefficient $D_{k}^{\mathrm{e}}$ considers ordinary and Knudsen diffusion. The parameter $\phi_{\mathrm{m}}$ represents the microscale porosity within catalyst particles.

Gas-phase fluxes through a membrane are represented as $\mathbf{j}_{k}^{\mathrm{M}}$. As discusssed in Section 6, the constitutive relationships governing the membrane fluxes depend on the type of membrane.

The species production rates via catalytic surface chemistry are represented as $\dot{s}_{k}$. Species production rates via gas-phase chemistry are represented as $\dot{\omega}_{k}$. Evaluation of these rates depends on particular reaction mechanisms.

Physical parameters include the gas-phase and solidphase volume fractions $\phi_{\mathrm{g}}$ and $\phi_{\mathrm{s}}$, respectively. The catalyst specific area (catalyst surface area per unit volume) is represented as $A_{\mathrm{s}}$. The parameters $P_{\mathrm{B}}$ and $A_{\mathrm{B}}$ represent the bed perimeter and cross-sectional areas, respectively. The gas-phase dynamic viscosity is $\mu$, the bed permeability is $B_{\mathrm{g}}$, and $W_{k}$ are the gas-phase molecular weights.

The gas internal energy is $e\left(d e=c_{\mathrm{v}, \mathrm{g}} d T_{\mathrm{g}}\right)$. The solid-phase volume fraction is $\phi_{\mathrm{s}}=1-\phi_{\mathrm{g}}$, temperature is $T_{\mathrm{s}}$, the density is $\rho_{\mathrm{s}}$, and heat capacity is $c_{\mathrm{p}, \mathrm{s}}$. Heat fluxes within the gas and solid (catalyst) phases are represented as $\mathbf{q}_{\mathrm{g}}$ and $\mathbf{q}_{\mathrm{s}}$, respectively. Convective heat exchange between phases or the environment are represented as $\dot{q}_{\text {conv }}$ and $\dot{q}_{\text {env }}$. The variable $\dot{q}_{\text {surf }}$ represents the heat associated with adsorption and desorption between the catalyst and gas phases.

In a one-dimensional setting, these equation are usually solvable on typical personal computers. In high dimensions, more computational resources are usually appropriate.

\subsubsection{Modeling OCM membrane reactors}

Several computational studies have addressed the performance of membrane-coupled OCM reactors. Predictive models require knowledge of the chemical kinetics as well as the oxygen transport mechanisms [240, 79-82]. These studies have considerded both one- or two-dimensional reactor models.

One-dimensional models, which necessarily assume radial unifomity, deliver qualitatively accurate predictions of the axial concentration and temperature profiles. 
However, a study by Holst et al. [79] showed the possibility of significant differences between one- and twodimensional models, with the two-dimensional models being able to more accurately represent measured experimental data. Incorporating radial variations in the oxygen composition played a major role in predicting the overall temperature and composition fields.

Koa and Lin [240] modeled a membrane coupled OCM reactor and compared the results with a packedbed reactor without a membrane. The $\mathrm{Li} / \mathrm{MgO}$ catalyst was housed within an inner tube, with oxygen flowing in an outer annular space. The membrane was fabricated from mesoporous alumina. A four-step global reaction mechanism for the catalytic chemistry was taken from Wang and Lin [60]. The oxygen flux through the porous membrane was modeled using a Knudsendiffusion model. One-dimensional plug flow was assumed within the catalyst bed. The model predicted that the membrane-coupled OCM reactor, operating at ${ }^{2154}$ atmospheric pressure and $750{ }^{\circ} \mathrm{C}$, can deliver a maxi- 2155 mum of $30 \% \mathrm{C}_{2}$ yield at $53 \% \mathrm{C}_{2}$ selectivity. The results ${ }^{2156}$ also showed that a co-flow configuration was much bet- ${ }^{2157}$ ter than a counter-flow configuration.

Patcharavorachot et al. [82] developed a one- ${ }^{2159}$ dimensional packed-bed model to study OCM per- ${ }^{2160}$ formance using a dense-ceramic oxide-ion-conducting ${ }^{2161}$ membrane. The $\mathrm{La}_{2} \mathrm{O}_{3} / \mathrm{CaO}$ catalyst was housed in an ${ }^{2162}$ interior tube, with air flowing in the exterior annulus. ${ }^{2163}$ The perovskite membrane $\left(\mathrm{Ba}_{0.5} \mathrm{Sr}_{0.5} \mathrm{Co}_{0.8} \mathrm{Fe}_{0.2} \mathrm{O}_{3-\delta}\right){ }^{2164}$ served to separate oxygen from air as well as to deliver ${ }^{2165}$ oxygen flux onto the catalyst bed. The ten-step catalytic ${ }^{2166}$ chemistry was taken from Stansch et al. [71]. This re- ${ }^{2167}$ action mechanism involved only gas-phase species, and 2168 used empirical rate expressions. The simulations pre- 2169 dicted that the membrane could increase $\mathrm{C}_{2+}$ yield from $7.2 \%$ to $33 \%$ at $830{ }^{\circ} \mathrm{C}$. Operating at $843{ }^{\circ} \mathrm{C}$ with 2170 $\mathrm{CH}_{4} / \mathrm{O}_{2}$ ratio of 0.83 , the model also predicted a maxi- ${ }_{2171}$ mum $\mathrm{C}_{2+}$ yield of $36.5 \%$.

Holst et al. [79] developed one- and two-dimensional 2173 models of packed-bed OCM reactors with oxygen- 2174 permeable membranes. The porous ceramic membranes 2175 were modeled using empirical expressions to represent 2176 the oxygen fluxes. In addition to the catalytic chem- 2177 istry, these models represented axial and radial heat and 2178 mass transfer. Two catalysts were considered. Re- 2179 action kinetics for the $\mathrm{La}_{2} \mathrm{O}_{3} / \mathrm{CaO}$ catalyst were taken 2180 from Stansch et al. [71]. This reaction mechanism con- 2181 sisted of nine global surface reactions and one global 2182 gas-phase reaction. The four-step global heterogeneous 2183 reactions for the $\mathrm{Li} / \mathrm{MgO}$ catalyst were taken from Wang ${ }_{2184}$ and Lin [60], who also considered oxygen-ion transport 2185 membranes. Additionally, four global gas-phase reac- 2186

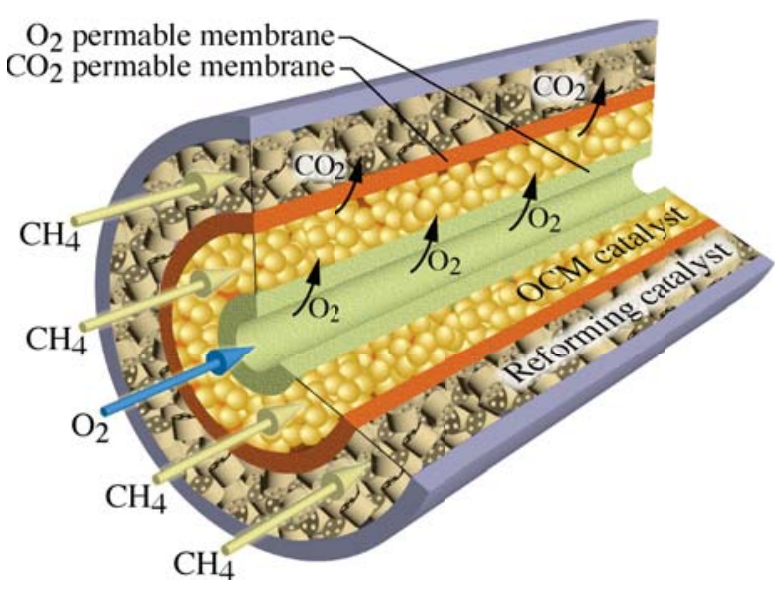

Figure 14: Dual-membrane reactor concept for integrating dry reforming chemistry into an OCM process [241].

tions were taken from Lane and Wolf [104]. The Holst et al. study emphasized the importance of radial concentration gradients that resulted from oxygen flux through membranes

Godini et al. [81] also studied membrane-coupled OCM in a packed-bed reactor, with a specific focus on comparing reactor performance with $\mathrm{La}_{2} \mathrm{O}_{3} / \mathrm{CaO}$ and $\mathrm{Na}_{2} / \mathrm{WO}_{4} / \mathrm{Mn} / \mathrm{SiO}_{2}$ catalysts. The reaction mechanisms for the $\mathrm{La}_{2} \mathrm{O}_{3} / \mathrm{CaO}$ were adopted from Stansch et al. [71]. The reaction mechanisms for the $\mathrm{Na}_{2} / \mathrm{WO}_{4} / \mathrm{Mn} / \mathrm{SiO}_{2}$ were adopted from Daneshpayeh et al. [117]. This mechanism considered ten reaction steps among eight gas-phase species. Similar to the Holst et al. [79] study, the Godini et al. model also emphasized the importance of two-dimensional models that incorporate the effects of radial heat and mass transfer.

\subsubsection{Combined OCM processes}

Godini et al. [241] introduced a reactor concept that integrated dry reforming of methane and OCM reactions. As illustrated in Fig. 14, the reactor was designed in a laboratory-scale co-annular configuration. A porous-alumina membrane is used to introduce air from an inner tube into the annular OCM catalyst bed. The reactant $\mathrm{CH}_{4}$ was introduced into both inner and outer annular catalyst beds. The inner bed housed the OCM catalyst $\left(\mathrm{Mn} / \mathrm{Na}_{2} \mathrm{WO}_{4} \mathrm{SiO}_{2}\right.$ and $\left.\mathrm{La}_{2} \mathrm{O}_{3} / \mathrm{CaO}\right)$ and the outer bed housed a dry-reforming catalyst $\left(\mathrm{Ni} / \mathrm{La} / \mathrm{SiO}_{2}\right)$. Carbon dioxide, produced by the OCM process, is separated via a $\mathrm{CO}_{2}$-permeable membrane and used for dry reforming within the outer catalyst bed.

The OCM process is exothermic, while dry reforming is endothermic. Combining the processes offers opportunities for thermal balancing and control, with the 


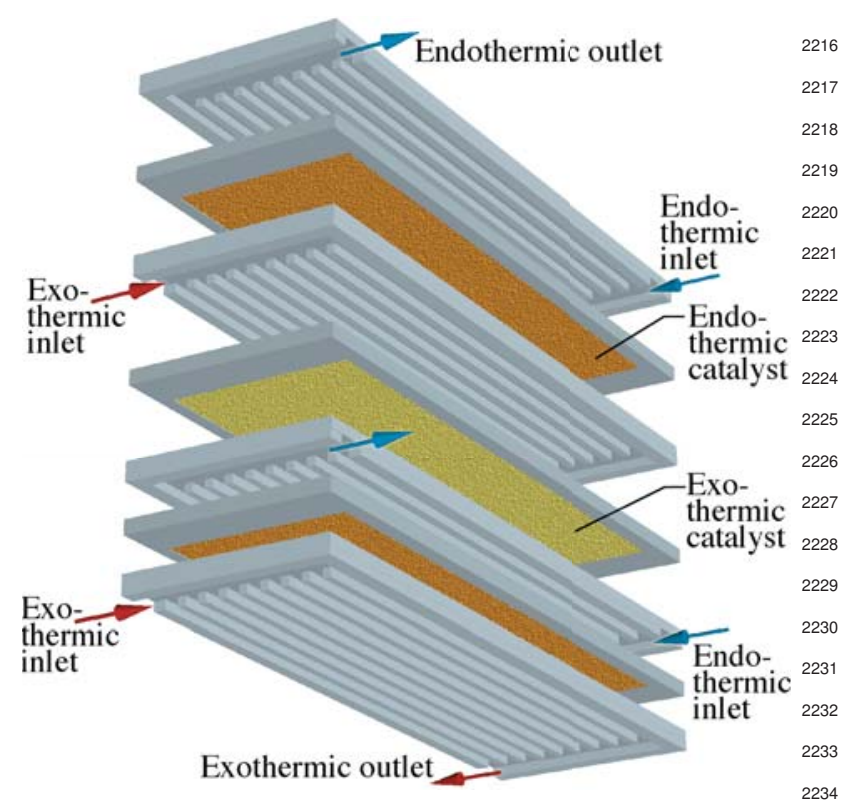

Figure 15: Illustration of a microchannel reactor with alternating lay- ${ }^{2235}$ ers of endothermic and exothermic catalysts.

endothermic dry reforming taking advantage of excess 2239 heat from the OCM process. Moreover, because $\mathrm{CO}_{2}$ is 2240 consumed in dry reforming, there is very little $\mathrm{CO}_{2}$ leav- 2241 ing the catalyst beds (nearly $90 \% \mathrm{CO}_{2}$ is consumed). 2242 Thus, downstream separation costs can be significantly 2243 decreased.

Controlling temperature is often important, espe- 2245 cially for exothermic processes such as OCM. Catalytic 2246 microchannel reactors can be designed to tightly cou- 2247 ple excess heat from an exothermic process to supply 2248 needed heat to a endothermic processes. Figure 15 illus- 2249 trates an exploded view of a generic microchannel con- 2250 figuration [243]. Washcoated catalyst layers are in di- 2251 rect contact with microchannel networks. Depending on 2252 fabrication approach, the "microchannels" have charac- 2253 teristic heights of a fraction of a millimeter [244, 245]. 2254 The thin-layer sandwich construction transfers heat ef- 2255 ficiently between the exothermic and endothermic lay- 2256 ers. There has been considerable research on systems 2257 that use catalytic combustion in the exothermic chan- 2258 nels to supply heat to a reforming process in the en- 2259 dothermic channels. In the present context, the exother- 2260 mic channels could house an OCM process, with the en- 2261 dothermic channels housing a methane-reforming pro- 2262 cess [246, 242].

2263

Although the heat- and mass-transfer within mi- 2264 crochannel reactors is highly efficient, there are chal- 2265 lenges in achieving high-performance results. For ex- 2266 ample, at high temperature, sealing between layers can 2267 be difficult. The operation is passive in the sense that there is no direct control of the flow and temperature uniformity within the channels [247]. Once the microchannel reactor is fabricated and sealed, access to the catalysts is limited. Thus, catalyst replacement is difficult, which can be operationally problematic for processes that are susceptible to carbon deposition and other catalyst deactivation processes.

Thybaut et al. [242] introduced a novel multi-bed reactor concept, integrating OCM and methane dry reforming (DRM) chemistry. As illustrated in Fig. 16, the OCM and methane dry reforming (DRM) chemistry takes place in parallel, using small-scale staged catalytic packed-beds. The two gas streams remain separated, enabling the two processes to operate at different temperatures, pressures, and flow rates. Gas-phase heat exchangers transfer excess heat from the exothermic OCM reaction to the endothermic DRM process. Thybaut et al. designed the microchannel heat exchangers in a cross-flow configuration, but with baffel sections yielding partially counter-flow performance.

The small-scale reactors are insulated, seeking nominally adiabatic performance within individual reactors. Thus, the gas temperature within the exothermic reactors increases and the gas temperature within the endothermic reactors decreases. However, because the reactors are small, the temperature excursions are small. The heat exchangers between stages reduce the temperature of the exothermic stream and increase the temperature of the endothermic stream. Although the temperatures within the reactors vary in a step-wise manner, the temperature steps are small. Thus, staging the smallscale unit processes delivers an approximately continuous result. An advantage of staging is that the smallscale packed-bed reactors can be maintained or replaced as needed. Thybaut et al. suggested that five stages are sufficient to provide good performance (Fig. 16 shows three stages).

Using computational simulation, Tiemersma et al. [248] studied the possibility of designing dualfunction catalysts within single catalyst particles. The inner core of the spherical catalyst particles was a steam-reforming catalyst (e.g., $\mathrm{Pt} / \mathrm{Al}_{2} \mathrm{O}_{3}$ ). The outer shell was an OCM catalyst (e.g., $\mathrm{La}_{2} \mathrm{O}_{3} / \mathrm{CaO}$ ). The two active catalyst regions were separated by a chemically inert annular region. Combining the two catalytic functions within individual particles enabled close thermal and chemical integration of the endothermic steam reforming and the exothermic OCM. Tiemersma et al. [249] went on to explore the possibility of integrating the dual-function catalysts into a co-annular, packed-bed, membrane reactor. Oxygen was introduced 


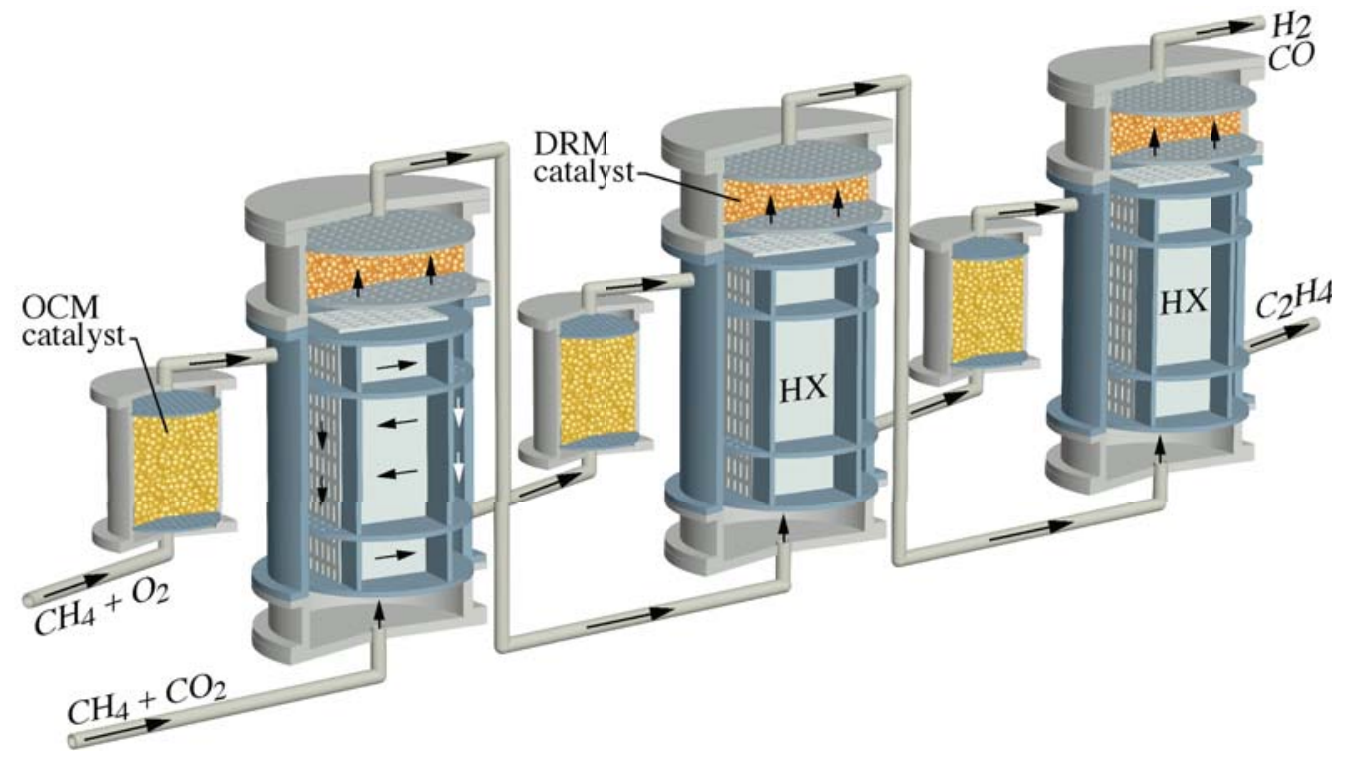

Figure 16: A staged-reactor system that integrates oxidative coupling of methane (OCM) and dry reforming of methane (DRM) [242].

through the central porous-membrane tube and $\mathrm{CH}_{4}$ and ${ }_{2297}$ $\mathrm{H}_{2} \mathrm{O}$ were introduced in the outer shell that housed the 2298 dual-function catalyst. The model-based results showed 2299 a $36 \% \mathrm{C}_{2}$ yield at $866^{\circ} \mathrm{C}$. These approaches suggest in- 2300 teresting advantages of innovative new catalyst and re- 2301 actor concepts.

Figure 17 illustrates a multi-layer membrane-coupled 2303 reformer reactor [250, 251]. Using ceramic ion 2304 transport membranes, this system effectively integrates 2305 air separation with the supply of oxygen to partial- 2306 oxidation (CPOX) catalysts. Air flows within internal 2307 microchannels whose upper and lower walls are formed 2308 as thin oxide-ion membranes. Aspects of the fabrication 2309 technology lead to the relatively complex flow patterns 2310 within the microchannels. The perovskite membrane is 2311 $\mathrm{La}_{1-x} \mathrm{Ca}_{x} \mathrm{FeO}_{3-\delta}$ (LCF), which has the important advan- 2312 tage of being stable in both oxidizing and reducing envi- 2313 ronments. The thin membrane is supported on a porous 2314 ceramic structure, which is also loaded with the partial- 2315 oxidation catalyst. Natural-gas flows across the external 2316 porous catalyst structures. Although this system was de- 2317 signed for syngas $\left(\mathrm{H}_{2}\right.$ and $\left.\mathrm{CO}\right)$ production by partial ox- 2318 idation, the design approach is also applicable for OCM. ${ }_{2319}$ Of course, the OCM catalysts would be different from 2320 the CPOX catalysts. The tight integration of air separa- 2321 tion and catalysis enhances process intensification.

\subsection{MDA reactors}

Most laboratory-scale MDA experiments are carried out in packed-bed reactors [168, 218-221], which are relatively straightforward to build and operate. Small amounts of catalyst (i.e., 0.5-2.0 g) are usually sufficient for catalyst screening experiments. Radially uniform temperature profiles can be achieved by packing the catalysts in small-diameter tubes within furnaces. Although axial temperature can vary, radial temperature variations are usually negligible with packed-bed diameters around $10 \mathrm{~mm}$. Small-diameter packed beds lend themselves to one-dimensional approximations in computational modeling. The experimental-modeling synergy is important in understanding and establishing chemical pathways and evaluating reaction rates.

A few studies consider MDA in fluidized beds. Cook et al. [252] compared the MDA performance in packedbed and fluidized-bed reactors. They used 4 wt.\% Mo/HZSM-5 catalysts. Results showed that at the beginning of the process (up to $2 \mathrm{~h}$ ) the fluidized-bed reactor improved the aromatic yield up to $15 \%$. However, as explained by the increased residence time in fluidizedbed reactors, naphthalene selectivity was preferred over benzene. Also, at longer time-on-stream, deactivation was more severe in their fluidized-bed reactor compared to packed-bed reactor. The relatively rapid fluidizedbed deactivation was attributed to the particle-particle collisions and weak mechanical stability of the catalyst particles.

Gimeno et al. [253] presented a cylindrical catalytic two-zone fluidized-bed reactor. The fluidization was accomplished primarily via mechanical stirring. Methane was introduced axially downward from the top of the 


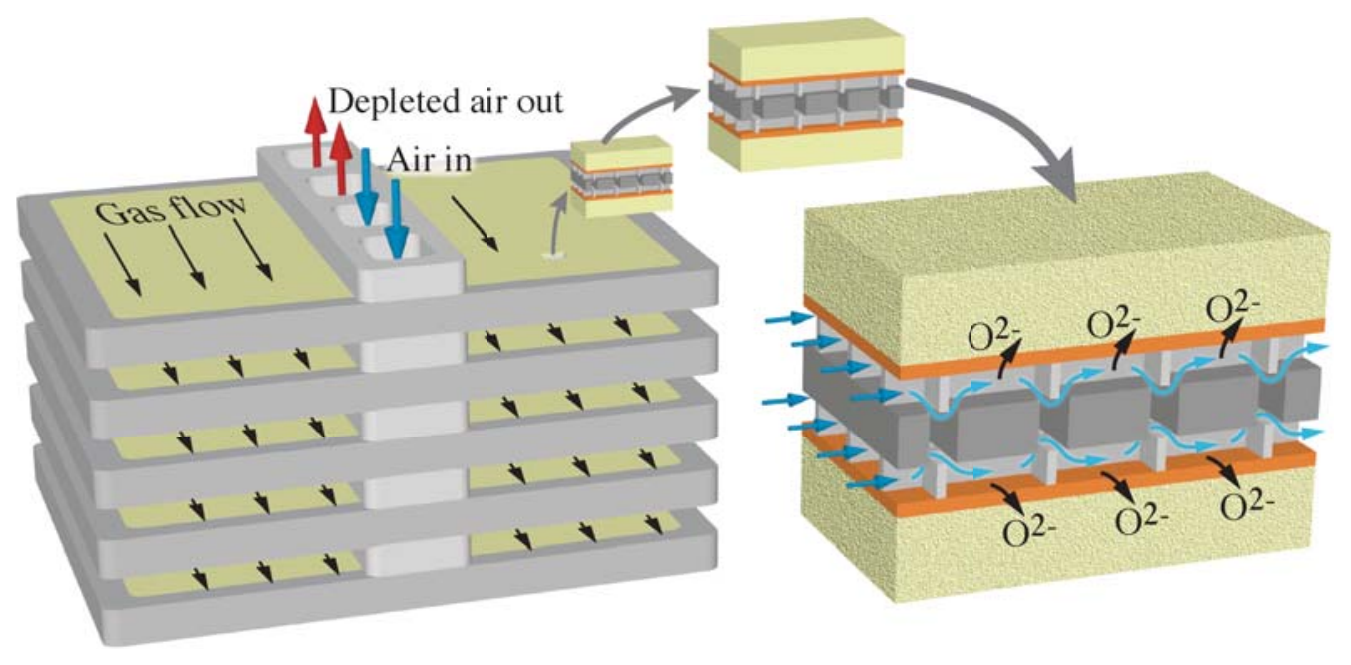

Figure 17: Partial-oxidation reformer integrated with air-separation oxygen-transport membranes [250, 251].

reactor and combinations of $\mathrm{O}_{2}, \mathrm{H}_{2} \mathrm{O}$, and $\mathrm{CO}_{2}$ were in- 2359 troduced axially upward from the bottom of the cylin- 2360 drical reactor. Product gases were extracted radially 2361 outward near the top of the reactor. The catalyst par- 2362 ticles recirculated between the upper and lower zones. 2363 The upper portion of the two-zone reactor was respon- 2364 sible for the MDA chemistry. The lower portion of the 2365 reactor was intended to promote continuous in-situ cat- 2366 alyst regeneration. The concept delivered good catalyst 2367 stability and aromatic yield, with the methane conver- 2368 sion being close to its thermodynamic limit in the tem- 2369 perture range $700 \leq T \leq 800{ }^{\circ} \mathrm{C}$. Benzene, toluene and ${ }_{2370}$ xylenes accounted for $95 \%$ of the aromatic products.

\subsubsection{Modeling MDA reactors}

There are far fewer modeling studies for MDA pro- ${ }^{2374}$ cesses than there are for OCM processes. At least in ${ }^{2375}$ part, the lack of MDA reaction mechanisms impedes ${ }^{2376}$ the development of MDA models. Because of factors ${ }^{2377}$ such as relatively rapid deposit formation and catalyst ${ }^{2378}$ deactivation, MDA processes do not achieve long-term ${ }^{2379}$ steady-state operation. Thus, interpreting the experi- ${ }^{2380}$ ments and establishing relatively simple global reaction ${ }^{2381}$ pathways and rates is difficult. Moreover, because the ${ }^{2382}$ catalyst continuously changes (carburization and deac- ${ }^{2383}$ tivation), the MDA process is inherently transient, mak- ${ }^{2384}$ ing modeling more complex than is the case for nomi- ${ }^{2385}$ nally steady-state processes.

Modeling studies have considered both global re- ${ }^{2387}$ action kinetics developed by Lui et al. [254] and de- ${ }^{2388}$ tailed reaction kinetics proposed by Wong et al. [218] ${ }^{2389}$ and Karakaya et al [134]. The models assume nom- ${ }^{2390}$ inally steady-state operating conditions, with catalyst ${ }^{2391}$ deactivation and PAHs formation chemistry not being included. The models are used to explore the effects of operating conditions (i.e., temperature, weight hourly space velocity) on product yield and selectivity $[218,134]$. Results indicate a strong relationship between naphthalene formation rate, temperature, and residence times. Increasing temperature and residence times generally increase the methane conversion toward equilibrium. However as conversion increases, naphthalene formation is favored over benzene. Seeking to increase both methane conversion and benzene yield, a number of computational studies have investigated the effects of incorporating hydrogen-permeable membranes.

The Iglesia group considered membrane-assisted MDA in tubular reactors [216, 18]. A 4 wt.\% Mo/HZSM-5 catalyst bed was housed within a tube, with the tube walls forming the hydrogen-permeable membrane. The models used a global three-step kinetic model to predict benzene and naphthalene formation rates. The modeling results revealed a strong interaction between the operating conditions, membrane hydrogen fluxes, and benzene formation rates. The results showed that methane conversion increases as a function of hydrogen removal rate. However, benzene selectivity follows a non-linear trend. At low hydrogen removal rate $(\leq 5 \%)$ the benzene yield increases slightly. As the methane conversion further increases by increasing the hydrogen removal rate, the process favors naphthalene. Experimental studies also confirm that increased hydrogen removal rate favors the coke formation and without a significant beneficial effect on benzene yield [254258]. The value of the hydrogen-permeable membrane 
integration relies on developing catalysts with improved 2443 benzene selective and controlling the catalyst deactivat- 2444 ing coke formation.

\subsubsection{Combined MDA processes}

Because catalyst stability and thermodynamic limita- 2448 tions are major concerns in MDA, a number of studies 2449 focus on alternative technologies to improve the single- 2450 pass yield. One such approach is called "one-pot" syn- 2451 thesis, meaning that processes can be tightly integrated 2452 as sequential processes in single reactor. Such pro- 2453 cess intensification can improve performance and re- 2454 duce downstream separation processes.

Samarth et al. [259] combined OCM and MDA chem- 2456 istry in a sequential two-zone packed-bed reactor. The ${ }_{2457}$ first zone contained an OCM catalyst ( $\mathrm{Si} / \mathrm{Sn} / \mathrm{MgO}$ ), fol- 2458 lowed by an MDA catalyst ( 5 wt.\% Ga/HZSM-5). Com- 2459 bining these two processes increased both the OCM and 2460 MDA performance (i.e., conversion, yield, and catalyst 2461 stability). The undesired products of OCM reactions 2462 (i.e., $\mathrm{CO}_{2}, \mathrm{H}_{2} \mathrm{O}$ ) can be beneficial for the MDA chem- 2463 istry.

$\mathrm{Xu}$ and co-workers [260, 261] developed another 2465 two-zone reactor concept. In this case, the first-zone 2466 OCM catalyst was a mixture of 20 wt.\% SrO and 202467 wt. $\% \mathrm{La}_{2} \mathrm{O}_{3} / \mathrm{CaO}$. The second-zone MDA catalyst was 2468 6 wt.\% Mo/HZSM-5. The reactor was operated at at- 2469 mospheric pressure and $730{ }^{\circ} \mathrm{C}$. Under these conditions 2470 the process is primarily one of MDA. However, the low 2471 levels of $\mathrm{CO}_{2}$ and $\mathrm{H}_{2} \mathrm{O}$ produced in the upstream OCM 2472 section served to enhance catalyst stability and increase 2473 benzene yield over $16 \mathrm{~h}$ of time-on-stream [260]. Simi- 2474 lar trends were observed with the MDA catalyst being 62475 wt. $\%$ Mo/MCM-49. In this case, the study reported 5\% 2476 aromatic yield for up to $72 \mathrm{~h}$ time-on-stream [261]. 2477

MDA chemistry has also been used to enhance the 2478 efficiency of coal pyrolysis. Jin et al. [262] designed 2479 and developed a two-zone packed-bed reactor. The 2480 first zone was supplied with methane over a 4 wt.\% 2481 Mo/HZSM-5 catalyst. The coal to be pyrolyzed was 2482 introduced into a catalyst-free second zone. Results 2483 showed that combining MDA with coal pyrolysis ben- 2484 eficially improved the desired tar yield by around $40 \% 2485$ at $700{ }^{\circ} \mathrm{C}$ and $1 \mathrm{~atm}$. The increased tar yield from the 2486 combined process was attributed primarily to the partic- 2487 ipation of free radicals that were formed in the MDA 2488 zone.

Li et al. [263] demonstrated a two-zone reactor in 2490 which the flash pyrolysis of coal was followed by arom- 2491 atization. The pyrolysis took place in an upstream re- 2492 actor zone, followed by MDA chemistry in the second 2493 zone. Methane was a product of the coal pyrolysis. The 2494 study reported that the downstream MDA promoted the aromatization of olefins and alkanes, and the dehydroxylation of phenolic compounds.

Huang et al. [264] demonstrated a combined biofuel pyrolysis and MDA process in a two-stage catalytic reactor. The pyrolysis produces a methane-rich gas stream. Methane-rich gas from the pyrolysis reaction was fed to a second-stage reactor, which housed a packed-bed MDA catalyst (HZSM-5 with 3 wt.\% Mo and $3 \mathrm{wt} . \% \mathrm{Cu}$ ). The $\mathrm{C}_{6}-\mathrm{C}_{12}$ yield was improved compared to the bio-fuel pyrolysis alone. The approach showed the potential of improving the conversion of bio-derived fuels to bio-oils.

Although MDA processes generally require high temperature to activate methane, combining processes can assist in reducing overall process temperatures. For example, Majhi et al. [265] studied combined methanol and methane aromatization over Mo/HZSM-5 and ZnMo/ZSM-5 catalysts. Unlike the endothermic methane aromatization, methanol aromatization is exothermic. By mixing 1.6-2.5\% methanol in the methane feed, the reaction temperature of MDA was decreased to $550 \lesssim$ $T \lesssim 650{ }^{\circ} \mathrm{C}$. Full methanol conversion was reported at temperatures above $500{ }^{\circ} \mathrm{C}$. The $\mathrm{Zn}$ incorporation into the Mo/ZSM-5 catalyst increased methane conversion from $18 \%$ to $22 \%$ at $650{ }^{\circ} \mathrm{C}$. The product composition was mainly $\mathrm{C}_{6} \mathrm{H}_{6}, \mathrm{C}_{7} \mathrm{H}_{8}$, and $\mathrm{C}_{8}$ and $\mathrm{C}_{9+}$ aromatics. Benzene selectivity was around $20-30 \%$, which is relatively low, compared to pure methane aromatization. Gradual catalyst deactivation was observed during $5 \mathrm{~h}$ on stream.

A number of investigations have shown that cofeeding higher hydrocarbons with methane offers the possibility of reducing MDA operating temperatures. Co-aromatization studies have included several hydrocarbons, including ethane [266, 267], propane [268272], butane [273], pentane [274], hexane [275], light gasoline $\left(\mathrm{C}_{5}\right.$ and $\mathrm{C}_{6}$ mixtures $)$ [276], and alkenes (butene, iso-butene, propene) [268]. These studies have used a variety of zeolite catalysts with second-metal incorporation (Ga, Mo, Zn, Mo-Zn, La-Zn, Co-Zn). Although the co-aromatization of methane with higher hydrocarbons increases the methane conversion and aromatic yield, the catalyst deactivation is more rapid compared to MDA alone [267, 269, 277]. Thus, although several studies have been reported, the benefits of coaromatization remain somewhat inconclusive.

Using isotopically labeled ${ }^{13} \mathrm{CH}_{4}$, Luzgin et al. [270, 272] studied the co-aromatization of methane with propane over $\mathrm{Zn}$ - and Mo-containing H-BEA zeolites at $550 \leq T \leq 600{ }^{\circ} \mathrm{C}$. Figure 18 illustrates $\mathrm{CH}_{4}$ reaction pathways with propane co-aromatization. Solid- 


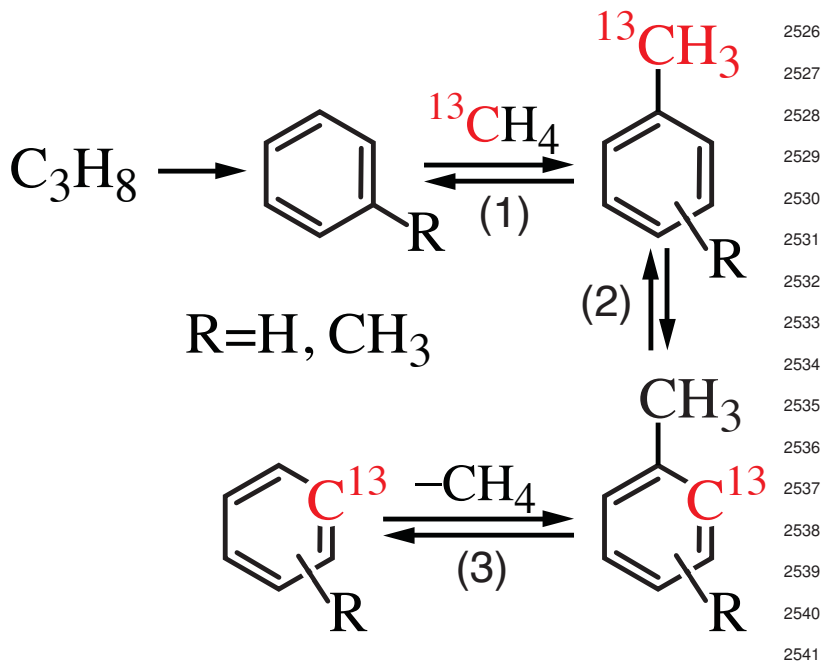

Figure 18: Possible reaction pathway for the co-aromatization of 2542 methane and propane. The ${ }^{13} \mathrm{C}$-labeled methane facilitates under- ${ }_{2543}$ standing the role of methane [270].

state NMR and GC-MS analyses showed that in the 2547 presence of propane, aromatization proceeds primar- 2548 ily via propane conversion to benzene, toluene, or xy- 2549 lene. These reactions are highly favorable due to low 2550 Gibbs free energy changes. The methane consumption 2551 is mainly via methylation reactions.

Despite reports of the benefits associated with hydro- 2553 carbon co-aromatization processes, there is also dissent- 2554 ing literature. A recent study of Bijani et al. [277] ques- 2555 tioned the effectiveness of propane co-aromatization. 2556 Using a thermodynamic analysis, they evaluated the ${ }_{2557}$ effect of temperature $\left(400 \leq T \leq 600{ }^{\circ} \mathrm{C}\right)$, pres- 2558 sure $(1 \leq p \leq 10$ bar), and methane-to-propane ratio 2559 $\left(0 \leq \mathrm{CH}_{4} / \mathrm{C}_{3} \mathrm{H}_{8} \leq 20\right)$. The thermodynamic analy- 2560 sis supported the idea that equilibrium methane conver- 2561 sion could not exceed $1 \%$ when propane is co-fed at 2562 temperatures below $600{ }^{\circ} \mathrm{C}$ and atmospheric pressure. ${ }_{2563}$ Bijani et al. supported their analysis by experimentally studying the effects of temperature, gas-hourly space velocity, and $\mathrm{CH}_{4} / \mathrm{C}_{3} \mathrm{H}_{8}$ ratio over a $\mathrm{Zn} / \mathrm{HZSM}-5$ catalyst in a packed-bed reactor at atmospheric pressure. 2565 They measured the aromatic yield as well as the $\mathrm{CH}_{4} 2566$ and $\mathrm{C}_{3} \mathrm{H}_{8}$ conversion as functions of time-on-stream. ${ }_{2567}$ Higher temperatures enhanced aromatic formation, but 2568 also increased coke formation by pyrolysis of the ther- 2569 modynamically less-stable propane.

The Bijani et al. results are consistent with an ear- 2571 lier study of Naccache et al. [278] who studied co- 2572 aromatization of olefins $\left(\mathrm{C}_{2} \mathrm{H}_{4}\right.$ and $\left.\mathrm{C}_{3} \mathrm{H}_{6}\right)$ over $\mathrm{Ga}_{2573}$ doped MFI. By labeling the carbon in the methane, 2574 Naccache et al. showed that labeled carbon was 2575 not incorporated into the reaction products. Apparently the methane is essentially unreactive during coaromatization.

Another concept for a combined processes involves using $\mathrm{H}_{2}$ from an MDA process in ammonia synthesis. A patent from BASF disclosed a combined MDA and ammonia-synthesis process within the same reactor [279]. The feed gas was a mixture of natural gas $\left(\mathrm{C}_{1}-\mathrm{C}_{6}\right.$ aliphatic hydrocarbons $)$ and nitrogen. The ratio of aliphatic hydrocarbons to nitrogen varied between 1:1 and 20:1. The hydrogen, which is a product of MDA chemistry, was used as a reactant in the ammonia synthesis. By removing the hydrogen in-situ via the ammonia synthesis, the reactor increased methane conversion and benzene yield. A further advantage of the process is that the combination of endothermic MDA and exothermic ammonia synthesis can assist thermal management. The MDA catalyst was an MFI-type zeolite with 0.5-20 wt.\% Mo and 0.02-6 wt.\% Ru. The reported operating temperatures were $400 \leq T \leq 1000{ }^{\circ} \mathrm{C}$ at pressures in the range $0.5 \leq p \leq 100$ bar. The patent discussed implementation in either packed-bed or fluidized bed reactors.

As discussed in Section 1.2, increasing pressure significantly decreases methane conversion. However, increasing pressure increases benzene selectivity while decreasing naphthalene selectivity. In an MDA reactor with a $\mathrm{H}_{2}$-permeable membrane operating at elevated pressures, it is likely that the decreased methane conversion due to the increased pressure can be compensated by shifting the thermodynamic equilibrium via $\mathrm{H}_{2}$ removal. In this case, benzene selectivity can increase and the catalyst is more stable due to the low naphthalene formation rates. Moreover, the benzene turnover rates can be higher due to the increased mass throughputs at increased inlet pressure. A membrane-coupled MDA reactor operating at high pressures offers a potentially valuable approach that merits further study.

\section{Membrane materials and transport}

Hydrogen- and/or oxygen-permeable membranes offer the possibility of improving methane conversion, product selectivity, and yield. Membranes can also contribute to reducing catalyst deactivation and extending productive time-on-stream. Thus, integrating membranes into catalytic reactors may play important roles in developing commercially viable gas-to-liquids technology.

Hydrogen-transport membranes can be used in dehydrogenation processes where the conversion reaction is equilibrium-limited. By removing the excess hydrogen, 
the methane conversion and hence the product yield can 2628 be increased. Consider, for example, direct methane dehydroaromatization (Eq. 1) to produce benzene or direct 2629 conversion of methane to ethylene (Eq. 2); both reac- 2630 tions produce significant amounts of $\mathrm{H}_{2}$.

Permselective membranes can take several physical ${ }_{2632}$ forms, including polymers (e.g., Nafion), thin-film met- 2633 als (e.g., palladium), micro- or nano-porous ceramics, 2634 and ceramic ion-transport membranes (ITM). Because 2635 of the high temperatures needed for methane activation, 2636 polymer membranes are not relevant, and are not con- 2637 sidered here.

Palladium and palladium-alloy membranes have very 2639 good hydrogen permeability, and are frequently used 2640 in hydrogen-separation processes [280]. These mem- 2641 branes operate at elevated temperatures and can be valu- 2642 able for increasing conversion in dehydrogenation pro- 2643 cesses.

Porous membranes can be effective in OCM membrane reactor concepts. However, air separation is not possible through porous structures. Thus, for applica- 2644 tions needing oxygen transport, any air separation must 2645 be accomplished upstream of the membrane reactor. 2646 Very high selectivity can usually not be achieved. Con- 2647 sider an application in which the membrane is intended 2648 to deliver oxygen into a catalyst bed. The porous mem- 2649 brane may allow some undesired diffusion of reactants 2650 and product gases back to the oxygen supply side of the 2651 membrane. However, maintaining high pressure on the 2652 oxygen side helps to avoid the back diffusion. 2653

A range of ceramic ion-transport membranes (ITM) 2654 are well suited to dehydrogenation chemistry and mem- 2655 brane reactors [27, 281]. Broadly speaking, ITM mem- 2656 branes fall into two categories - one promoting proton conduction and the other promoting oxide-ion con- 2657 duction. In both cases, the membranes are based on 2658 heterovalently doped polycrystalline structures. The 2659 so-called protonic ceramics are typically represented 2660 by doped perovskites such as yttrium-doped barium 2661 zirconates (e.g., $\mathrm{BaZr}_{0.9} \mathrm{Y}_{0.1} \mathrm{O}_{3-\delta}$, BZY10). Although ${ }_{2662}$ called protonic ceramics, these materials are mixed con- 2663 ductors that conduct protons, oxide ions, and small po- 2664 larons.

\section{5}

Ceramic materials such as yttria-stablized zirconia 2666 (YSZ) or gadolinia-doped ceria (GDC) are suitable as 2667 oxygen-transport membranes. These materials, which 2668 have a cubic fluorite crystal structure, are widely used 2669 as electrolyte membranes in solid-oxide fuel cells and 2670 electrolyzers. Because the electronic conductivity is 2671 low they can be polarized by applying an electrostatic 2672 potential across the membrane. The electrostatic field 2673 promotes the migration of oxide ions within the mem- 2674 brane, delivering a de-facto oxygen flux.

\subsection{Palladium membranes}

The fact that hydrogen diffuses through Pd has been known since the mid 1800s. In more recent times, various Ag-Pd and Au-Pd alloys have been developed to improve hydrogen fluxes. Membranes, which are typically around one micrometer thick, are usually applied on the outside of porous support tubes. Depending on temperature and hydrogen partial pressure across the membrane, hydrogen fluxes are on the order of $1 \mathrm{~mol} \mathrm{~m}^{-2}$ $\mathrm{s}^{-1}$. Although research is still active, palladium-based membranes are now produced commercially. Reviews by Way and colleagues provide historical and technical perspectives [280, 282].

The effective $\mathrm{H}_{2}$ fluxes may be expressed in the form of Sieverts law as

$$
J_{\mathrm{H}_{2}}=\frac{P}{L}\left(p_{\mathrm{H}_{2}, 1}^{n}-p_{\mathrm{H}_{2}, 2}^{n}\right),
$$

where $P$ represents the permeance $\left(\mathrm{mol} \mathrm{m}^{-2} \mathrm{~s}^{-1} \mathrm{~Pa}^{-n}\right), L$ represents the membrane thickness, $p_{\mathrm{H}_{2}, 1}$ and $p_{\mathrm{H}_{2}, 2}$ represent hydrogen partial pressures $(\mathrm{Pa})$ at the membrane surfaces. The exponent $n$ is ideally $1 / 2$, but membrane defects such as pinholes or microcracks can increase $n$. Any such defects also decrease the hydrogen selectivity.

At the membrane surfaces, molecular hydrogen must react $\left(\mathrm{H}_{2} \leftrightarrows 2 \mathrm{H}\right)$ to form the atomic hydrogen that is transported through the dense Pd membrane. Thus, there is the possibility that the hydrogen transport is rate-limited by surface reaction. However, it is usually assumed that the transport is dominated by bulk-phase diffusion (i.e., Eq. 41).

\subsection{Porous ceramic membranes}

Because of the high temperature needed for OCM of MDA processes, porous membranes are often fabricated from chemically inert ceramic materials such as alumina. Membranes for MDA processes usually demand high selectivity for hydrogen, which is difficult to achieve via porous membranes. Membranes for OCM processes are usually used to distribute oxygen along the length of the catalyst bed. Oxygen selectivity is also a factor, but not as demanding as for hydrogen selectivity in MDA. With a porous membrane in OCM processes, oxygen is usually separated from air prior to entering the reactor. If oxygen is not separated beforehand, then there will be substantial nitrogen dilution in the catalyst bed. Because the porous structure is not selective (or only weakly selective), back diffusion of hydrocarbon species into the oxygen flow can be problematic. This problem is usually minimized or avoided 
by maintaining a high oxygen pressure (e.g., up to 6 bar 2716 is typical) on the $\mathrm{O}_{2}$ feed side [283-285].

The gas flux through porous media depends on the 2718 pore microstructure (porosity, pore dimensions, tortuos- 2719 ity) and membrane thickness. When the pore structure 2720 is relatively open, a pressure-driven Darcy flow repre- 2721 sentation is usually appropriate. When the characteris- 2722 tic pore dimensions are on the same order as the gas- 2723 phase mean-free-path length, multicomponent Knudsen 2724 diffusion becomes dominant. In the intermediate length 2725 scales, multicomponent Fickian and Knudsen diffusion 2726 are both active.

Alternative porous-media transport models have been 2728 developed in the context of representing gas-phase 2729 transport in porous-ceramic electrode structures for 2730 solid-oxide fuel cells [286-288]. The Dusty-Gas 2731 (DGM) formulation provides an effective model for 2732 bridging all the relevant length scales in a single ${ }_{2733}$ model [289]. The steady-state species mass fluxes $\mathbf{j}_{k} 2734$ through a non-reactive porous membrane may be evalu- 2735 ated by solving a mass-conservation problem as

$$
\nabla \cdot \mathbf{j}_{k}=0 .
$$

The DGM is an implicit relationship among the gas- 2739 phase species molar fluxes $\mathbf{J}_{k}$, molar concentrations 2740 $\left[X_{k}\right]$, concentration gradients, and the pressure $p$ gra- 2741 dient as,

$\sum_{\ell \neq k} \frac{\left[X_{\ell}\right] \mathbf{J}_{k}-\left[X_{k}\right] \mathbf{J}_{\ell}}{\left[X_{\mathrm{T}}\right] D_{k \ell}^{\mathrm{e}}}+\frac{\mathbf{J}_{k}}{D_{k, \mathrm{Kn}}^{\mathrm{e}}}=-\nabla\left[X_{k}\right]-\frac{\left[X_{k}\right]}{D_{k, \mathrm{Kn}}^{\mathrm{e}}} \frac{B_{\mathrm{g}}}{\mu} \nabla p,{ }_{2744}^{2743}$

where $\mu$ is the mixture viscosity and $\left[X_{\mathrm{T}}\right]=p / R T$ is ${ }^{2746}$ the total molar concentration. The mass fluxes $\mathbf{j}_{k}$ are ${ }^{2747}$ related to the molar fluxes $\mathbf{J}_{k}$ as $\mathbf{j}_{k}=W_{k} \mathbf{J}_{k}$, where ${ }^{2748}$ $W_{k}$ are molecular weights. $D_{k \ell}^{\mathrm{e}}$ and $D_{k, \mathrm{Kn}}^{\mathrm{e}}$ are the ef- ${ }^{2749}$ fective ordinary and Knudsen diffusion coefficients, re- ${ }^{27}$ spectively. Knudsen diffusion represents molecular diffusion and mass transport assisted by gas-wall collisions. The Knudsen diffusion coefficients depend upon the porous-media microstructure, including porosity $\phi_{\mathrm{g}},{ }^{2754}$ average pore radius $r_{p}$, and tortuosity $\tau_{\mathrm{g}}$. The effective ${ }^{2755}$ binary and Knudsen diffusion coefficients $D_{k \ell}^{\mathrm{e}}$ and $D_{k, \mathrm{Kn}}^{\mathrm{e}}{ }^{2750}$ can be evaluated as

$$
D_{k \ell}^{\mathrm{e}}=\frac{\phi_{\mathrm{g}}}{\tau_{\mathrm{g}}} D_{k \ell}, \quad D_{k, \mathrm{Kn}}^{\mathrm{e}}=\frac{2}{3} \frac{r_{p} \phi_{\mathrm{g}}}{\tau} \sqrt{\frac{8 R T}{\pi W_{k}}} .
$$

The ordinary multicomponent diffusion coefficients $D_{k \ell}$ and the mixture viscosities $\mu$ are determined from kinetic theory [290]. The permeability $B_{\mathrm{g}}$ can be evaluated from the Kozeny-Carman relationship as

$$
B_{\mathrm{g}}=\frac{\phi_{\mathrm{g}}^{3} d_{\mathrm{p}}^{2}}{72 \tau\left(1-\phi_{\mathrm{g}}\right)^{2}},
$$

where $d_{\mathrm{p}}$ is the particle diameter. Equation 45 is based on packed spheres. Although the functional forms remain similar, the permeability relationship can vary depending on the material. Porosity is relatively easy to measure and effective particle diameters and pore radii can be reasonably estimated from microscopic images of the membrane. Permeability is also relatively easy to measure. However, transport depends strongly on tortuosity, which is difficult to measure. Thus, tortuosity is often used as an empirical parameter that is adjusted to fit flux measurements. Details about the DGM and the computational implementation have been reported by Zhu et al. [287].

High temperature and humid oxidizing environments can limit the choice of materials that are suitable for OCM membranes. Pore-modified alumina is often used for OCM processes [98, 291, 292]. Readily available porous alumina can have a pore structure that is too open and permits oxygen fluxes that are too high. Silica $\left(\mathrm{SiO}_{2}\right)$ or silicon oxy-carbide $(\mathrm{SiOC})$ can be deposited within the pores, restricting the flux [291, 292, 285].

Zeolites are used for separations, and in principle could be used as hydrogen-selective membranes [293296]. However, the selectivity is not high. Zeolite pore diameters are generally in the range of $0.3-1.3$ $\mathrm{nm}$. However, the effective diameters of light gases and $\mathrm{H}_{2}$ are similar, with the effective diameter of $\mathrm{H}_{2}$ being $0.289 \mathrm{~nm}$. The effective diameters of $\mathrm{CO}_{2}, \mathrm{CO}$, and $\mathrm{CH}_{4}$ are $0.33 \mathrm{~nm}, 0.376 \mathrm{~nm}, 0.38 \mathrm{~nm}$, respectively. Thus to achieve good selectivity the zeolite cage size would need to be very closely controlled. Recent advances in zeolite technology have enabled the modification of cage sizes without changing the framework and cage structure [297, 294, 298, 295]. Zeolites membranes have been investigated for applications in water-gas-shift processes [299] and hydrocarbon dehydrogenation processes below $550{ }^{\circ} \mathrm{C}$ (e.g., isobutane, cyclohexane) $[300,301]$. To date, zeolite membranes have apparently not been used in MDA processes. Nevertheless, with continued development of zeolite materials, new zeolites may offer opportunities for smallchannel zeolites as alternatives to dense ion-transport membranes.

\subsection{Oxide-ion conducting membranes}

Materials such as yttria-stablized zirconia conduct oxide ions $\mathrm{O}^{2-}$ via a hopping mechanism within the doped crystal structure. The heterovalent doping creates lattice vacancies, which enable oxide-ion mobility. The ionic conductivity is typically represented as

$$
\sigma=\sigma^{\circ} \frac{1}{T} \exp \left(-\frac{E_{\mathrm{a}}}{R T}\right) .
$$


For YSZ, $\sigma_{0} \approx 3.6 \times 10^{5} \mathrm{~S} \cdot \mathrm{K} / \mathrm{cm}$ and $E_{\mathrm{a}} \approx 8 \times 10^{4} \mathrm{~J} 2809$ $\mathrm{mol}^{-1}$ [302]. The oxide-ion flux is dominated by mi- 2810 gration (i.e., driven by electrostatic-potential gradients) as

$$
J_{\mathrm{O}^{2-}}=-\frac{\sigma}{z_{k} F} \nabla \Phi,
$$

where $z_{k}=-2$ is the charge on $\mathrm{O}^{2-}, F$ is the Faraday ${ }^{2812}$ constant, and $\Phi$ is the electrostatic potential. The gas- ${ }^{2813}$ phase molecular oxygen must react at one membrane 2814 surface to incorporate the ion into the membrane lattice and release the $\mathrm{O}_{2}(\mathrm{~g})$ back to the gas phase on the opposite side of the membrane. The incorporation process can be represented globally as

$$
\mathrm{O}_{2}(\mathrm{~g})+4 \mathrm{e}^{-}(\mathrm{ed}) \rightleftharpoons 2 \mathrm{O}^{2-}(\mathrm{el}),
$$

where $\mathrm{e}^{-}$(ed) represents electrons within the electrode and $\mathrm{O}^{2-}(\mathrm{el})$ represents the ion within the electrolyte membrane. Thus, a so-called triple-phase boundary is needed where gas, electrode, and electrolyte are coincident. The oxide-ion transport depends on the establish- 2819 ment of an electrostatic potential, and thus an external ${ }_{2820}$ circuit to provide electrons. There is very little trans- 2821 port associated with oxygen partial-pressure variations 2822 across the membrane alone.

\subsection{Mixed ionic-electronic conductors, MIEC}

Mixed-conducting materials such as $\mathrm{BaZr}_{0.9} \mathrm{Y}_{0.1} \mathrm{O}_{3-\delta} 2826$ (BZY10) or $\mathrm{La}_{1-x} \mathrm{Ca}_{x} \mathrm{FeO}_{3-\delta}$ (LCF) behave differently 2827 from materials such as YSZ. Depending on the partic- 2828 ular material, the membrane may perform dominantly 2829 as a proton conductor or as an oxygen-ion conductor. ${ }^{2830}$ Also, depending on the material, any electronic conduction may be dominantly "n-type" (i.e., electrons) or "p- ${ }_{2831}$ type" (i.e., electron holes).

When the gas-phase composition varies across the membrane, the electrochemical-potential gradient ${ }^{2832}$ serves to drive charged defects through the membrane.

The result is apparent gas transport through the mem- 2833 brane. At each gas-membrane interface gases must re- 2834 act to form the defects that can be transported through 2835 the membrane. Depending on the material and the op- 2836 erating conditions, these defect-incorporation reactions ${ }_{2837}$ may be equilibrated or they may be kinetically limited. ${ }^{2838}$ The defect fluxes within the membrane depend on con- 2839 centration and electrostatic-potential gradients. Math- 2840 ematically, the defect fluxes are governed by Nernst- 2841 Planck-Poisson theory [303-306].

Assuming dilute behavior (i.e., minimal defect-defect ${ }_{2843}$ interactions), the charged-defect fluxes through MIEC 2844 doped-perovskite materials are governed by the NernstPlanck relationship as

$$
\mathbf{J}_{k}=-D_{k}\left(\nabla\left[X_{k}\right]+\frac{z_{k} F}{R T}\left[X_{k}\right] \nabla \Phi\right),
$$

where $D_{k}$ are defect diffusion coefficients. Defect transport is generally understood to occur via an activated hopping mechanism. The defect diffusion coefficients are typically represented in Arrhenius form as

$$
D_{k}=D_{k}^{\circ} \exp \left(-\frac{E_{k}}{R T}\right),
$$

where $D_{k}^{\circ}$ are pre-exponential constants and $E_{k}$ are activation energies. The Nernst-Einstein equation relates the total conductivity $\sigma$ to the charged-defect diffusion coefficients as

$$
\sigma=\sum_{k} \frac{z_{k}^{2} F^{2}}{R T}\left[X_{k}\right] D_{k} .
$$

The MIEC materials typically have several chargecarrying defects. For example, in Kröger-Vink notation, the three mobile defects in BZY are oxygen vacancies $\mathrm{V}_{\mathrm{O}}^{\bullet}$, protons $\mathrm{OH}_{\mathrm{O}}^{\bullet}$, and small polarons $\mathrm{O}_{\mathrm{O}}^{\bullet}$ [19]. The superscripts designate the electronic charge associated with the defects. The "•" indicates a positive charge and the "" indicates a negative charge.

\subsubsection{Protonic ceramic membranes}

Consider $\mathrm{BaZr}_{0.9} \mathrm{Y}_{0.1} \mathrm{O}_{3-\delta}$ (BZY10) as a representative proton-conducting ceramic membrane. Incorporation chemistry can be represented with three reactions as

$$
\begin{gathered}
\frac{1}{2} \mathrm{H}_{2}+\mathrm{O}_{\mathrm{O}}^{\bullet} \rightleftharpoons \mathrm{OH}_{\mathrm{O}}^{\bullet}, \\
\frac{1}{2} \mathrm{O}_{2}+\mathrm{O}_{\mathrm{O}}^{\times}+\mathrm{V}_{\mathrm{O}}^{\bullet \bullet} \rightleftharpoons 2 \mathrm{O}_{\mathrm{O}}^{\bullet}, \\
\mathrm{H}_{2} \mathrm{O}+\mathrm{V}_{\mathrm{O}}^{\bullet \bullet}+\mathrm{O}_{\mathrm{O}}^{\times} \rightleftharpoons 2 \mathrm{OH}_{\mathrm{O}}^{\bullet} .
\end{gathered}
$$

The nomenclature $\mathrm{O}_{\mathrm{O}}^{\times}$indicates a charge-neutral oxygen at the oxygen lattice site. In a departure with earlier studies [305, 307], Zhu et al. [19] represent the electronic charge carrier as a small polaron $\mathrm{O}_{\mathrm{O}}^{\bullet}$ associated with the oxygen site, rather than an electron hole $\mathrm{h}^{\bullet}$.

The gas-surface chemistry may be equilibrated or may be kinetically rate-limited [306]. In either case, the Nernst-Planck model needs equilibrium constants to establish boundary conditions and in rate-limited circumstances to maintain microscopic reversibility. The equilibrium constants can be evaluated in terms of the reaction thermodynamics (i.e., Gibbs free energy changes). 


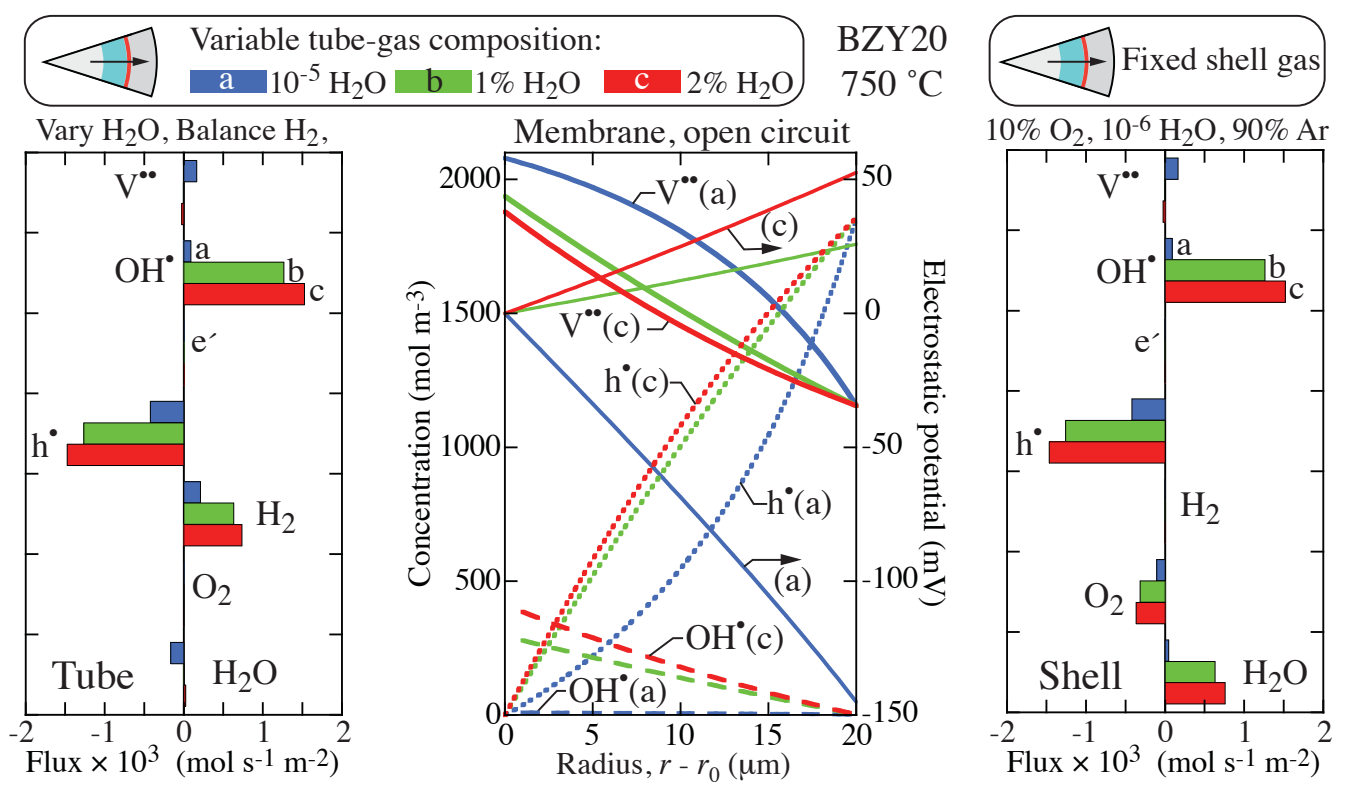

Figure 19: Composite representation of model-based predictions with the tube side gas being dominantly $\mathrm{H}_{2}$, but with varying $\mathrm{H}_{2} \mathrm{O}$ levels. The shell-side molar composition is fixed at $10 \% \mathrm{O}_{2}, 10^{-6} \mathrm{H}_{2} \mathrm{O}$, and $90 \%$ Ar. The left-hand panel shows defect fluxes and gas-phase fluxes evaluated at the inner radius of the membrane (i.e., the tube side). A positive flux means radially outward. The center panel shows radial profiles of the defect concentrations and the electrostatic potential. The right-hand panel shows defect fluxes and gas-phase fluxes evaluated at the outer radius of the membrane (i.e., the shell side). The colors indicate the shell-side $\mathrm{O}_{2}$ composition. The solid lines represent vacancy concentration, the short dashed lines represent hole concentration, and the long dashed lines represent proton concentration (the proton profiles for the $10 \%$ and $20 \% \mathrm{O}_{2}$ cases are overlapping). Additional solid lines, plotted with respect to the secondary $y$-axis, represent the electrostatic potential profile across the membrane. This figure is reproduced from Kee, et al. [305].

Although sometimes difficult to obtain, thermodynamic 2864 properties can be established experimentally [19].

The Nernst-Planck fluxes must be constrained by site 2866 balances and charge neutrality, with details depending ${ }_{2867}$ on the particular membrane material. For BZY10, the number of oxygen sites in a pervoskite lattice (per formula unit) must be maintained as 3 . Thus,

$$
\left[\mathrm{V}_{\mathrm{O}}^{\bullet \bullet}\right]_{\mathrm{L}}+\left[\mathrm{OH}_{\mathrm{O}}^{\bullet}\right]_{\mathrm{L}}+\left[\mathrm{O}_{\mathrm{O}}^{\bullet}\right]_{\mathrm{L}}+\left[\mathrm{O}_{\mathrm{O}}^{\times}\right]_{\mathrm{L}}=3 .
$$

Charge neutrality requires that

$$
2\left[\mathrm{~V}_{\mathrm{O}}^{\bullet \bullet}\right]_{\mathrm{L}}+\left[\mathrm{OH}_{\mathrm{O}}^{\bullet}\right]_{\mathrm{L}}+\left[\mathrm{O}_{\mathrm{O}}^{\bullet}\right]_{\mathrm{L}}-\left[\mathrm{Y}_{\mathrm{Zr}}^{\prime}\right]_{\mathrm{L}}=0 .
$$

Considering BZY10 $\left(\mathrm{BaZr}_{0.9} \mathrm{Y}_{0.1} \mathrm{O}_{3-\delta}\right)$, the yttrium ${ }_{2873}^{2872}$ doping concentration is $10 \%$, in which case $\left[\mathrm{Y}_{\mathrm{Zr}}^{\prime}\right]_{\mathrm{L}}=2874$ 0.1 .

An interesting aspect of mixed-conducting mem- 2876 branes is so-called "uphill diffusion" [308-310]. That is 2877 to say, the apparent transport of some gas-phase species 2878 may be proportional to the partial pressure gradient 2879 across the membrane (i.e., not proportional to the usual 2880 negative partial-pressure gradient as in Fick's law). For 2881 example, the apparent flux of water vapor may be in 2882 the direction from low partial pressure on one side of 2883 the membrane to high partial pressure on the other side. However, all the charged-defect transport must be proportional to the negative gradient in electrochemical potential,

$$
\mathbf{J}_{\mathbf{k}}=-\frac{D_{k}}{R T}\left[X_{k}\right] \nabla \tilde{\mu}_{k} .
$$

The defect electrochemical potentials may be expressed as

$$
\tilde{\mu}_{k}=\mu_{k}^{\circ}+R T \ln \left[X_{k}\right]+z_{k} F \Phi,
$$

where $\mu_{k}^{\circ}$ are the standard-state chemical potentials. The Nernst-Planck flux (Eq. 49) follows directly from these relationships [305]. Because of the role played by the internal electrostatic-potential gradient, the apparent gas-phase transport can sometimes appear to be going in a direction opposite from what would be expected by Fickian diffusion.

To illustrate aspects of proton-conducting membrane behavior, Fig. 19 shows a representative modelpredicted result [305]. In this case a tubular $20 \mu \mathrm{m}$ thick membrane is positioned on a $10 \mathrm{~mm}$ diameter support. The inside of the tube is dominantly $\mathrm{H}_{2}$, but with varying low levels of $\mathrm{H}_{2} \mathrm{O}$. The outside of the tube has a gas atmosphere of $90 \% \mathrm{Ar}$ and $10 \% \mathrm{O}_{2}$ and trace steam. 


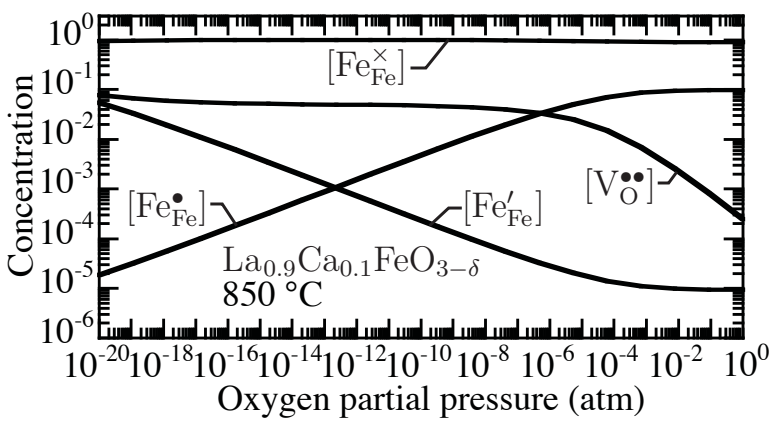

Figure 20: Predicted defect concentrations (formula units) for $\mathrm{La}_{1-x} \mathrm{Sr}_{x} \mathrm{Ca}_{1-y} \mathrm{Fe}_{y} \mathrm{O}_{3-\delta}$ at $850{ }^{\circ} \mathrm{C}$.

The right- and left-hand panels show defect fluxes and effective gas-phase fluxes at the membrane surfaces. The effective gas-phase fluxes are in the range of $10^{-3} 2919$ $\mathrm{mol} \mathrm{s}{ }^{-1} \mathrm{~m}^{-2}$. Under the operating conditions shown, gas-phase $\mathrm{H}_{2}$ leave the central tube but, because of reaction with oxygen, emerges from the membrane exterior as $\mathrm{H}_{2} \mathrm{O}$. The central panel illustrates defect profiles as well as electrostatic potential profiles. Note that internal electrostatic potential variations on the order of 2923 $100 \mathrm{mV}$ are needed to preserve charge neutrality. Of course, details of the defect transport and apparent gasphase fluxes depend on operating conditions. Sanders, et al. [310] developed maps that explore large ranges of ${ }^{294}$ operating space.

\subsubsection{Oxygen-ion transport membranes}

Consider the behavior of $\mathrm{La}_{1-x} \mathrm{Ca}_{x} \mathrm{FeO}_{3-\delta}$ (LCF) as ${ }^{2920}$ an MIEC oxide-ion conducting membrane. This material is important for application in hydrocarbon membrane reactors because, unlike many other MIEC oxide- ${ }_{2927}$ ion conductors, it is stable in both oxidizing and reduc- ${ }_{2928}$ ing environments [311-316].

Because LCF does not have the ability to incorporate 2930 protons, the incorporation chemistry is different from ${ }_{2931}$ materials such as BZY10. As reported by Geary and ${ }_{2932}$ Adler [317], the incorporation and disproportionation ${ }_{2933}$ chemistry can be represented in Kröger-Vink notation ${ }_{2934}$ as

$$
\frac{1}{2} \mathrm{O}_{2}+\mathrm{V}^{\bullet \bullet}+2 \mathrm{Fe}_{\mathrm{Fe}}^{\times} \rightleftharpoons \mathrm{O}_{\mathrm{O}}^{\times}+2 \mathrm{Fe}_{\mathrm{Fe}}^{\bullet} .
$$

$$
2 \mathrm{Fe}_{\mathrm{Fe}}^{\times} \rightleftharpoons \mathrm{Fe}_{\mathrm{Fe}}^{\prime}+\mathrm{Fe}_{\mathrm{Fe}}^{\bullet},
$$

The B-site Fe in this material can be simultaneously 2940 present in three oxidation states, $\mathrm{Fe}^{2+}, \mathrm{Fe}^{3+}$, and $\mathrm{Fe}^{4+}$. 2941 Thus, at the surface and within the bulk, Eq. 60 repre- 2942 sents the interactions between three Fe oxidation states. 2943 Geary and Adler [317] reported thermodynamic proper- 2944

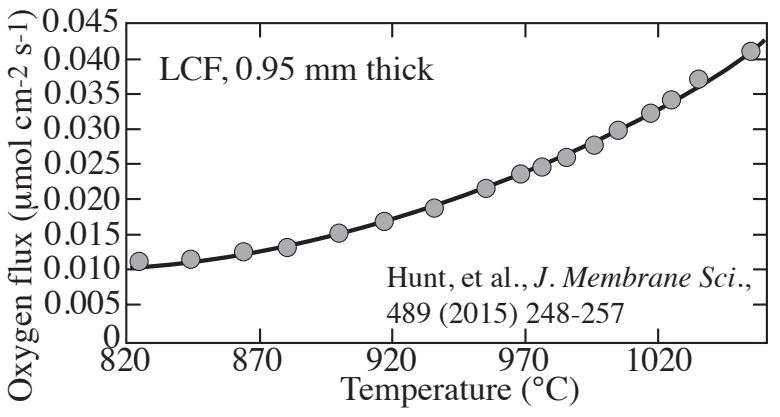

Figure 21: Measured $\mathrm{O}_{2}$ flux through an $\mathrm{La}_{0.9} \mathrm{Ca}_{0.1} \mathrm{FeO}_{3-\delta}$ membrane that is $0.95 \mathrm{~mm}$ thick. The figure is reproduced from Hunt, et al. [316].

ties from which the equilibrium constants can be evaluated.

As is the case with the BZY10, the equilibrium composition must be constrained by site and charge balances. For the LCF materials, the charge balance (electroneutrality) requires that

$$
\left[\mathrm{Ca}_{\mathrm{La}}^{\prime}\right]_{\mathrm{L}}+\left[\mathrm{Fe}_{\mathrm{Fe}}^{\prime}\right]_{\mathrm{L}}=\left[\mathrm{Fe}_{\mathrm{Fe}}^{\bullet}\right]_{\mathrm{L}}+2\left[\mathrm{~V}_{\mathrm{O}}^{\bullet \bullet}\right]_{\mathrm{L}} .
$$

The iron site balance requires that

$$
\left[\mathrm{Fe}_{\mathrm{Fe}}^{\bullet}\right]_{\mathrm{L}}+\left[\mathrm{Fe}_{\mathrm{Fe}}^{\times}\right]_{\mathrm{L}}+\left[\mathrm{Fe}_{\mathrm{Fe}}^{\prime}\right]_{\mathrm{L}}=1
$$

The oxygen site balance requires that

$$
\left[\mathrm{O}_{\mathrm{O}}^{\times}\right]_{\mathrm{L}}=3-\left[\mathrm{V}_{\mathrm{O}}^{\bullet \bullet}\right]_{\mathrm{L}} .
$$

For $\mathrm{La}_{0.9} \mathrm{Ca}_{0.1} \mathrm{FeO}_{3-\delta}$, it may be assumed that $\left[\mathrm{Ca}_{\mathrm{La}}^{\prime}\right]$ is fixed by the doping level as

$$
\left[\mathrm{Ca}_{\mathrm{La}}^{\prime}\right]_{\mathrm{L}}=0.1 .
$$

Also, the "non-stoichiometry" is assumed to be $\delta=$ $\left[\mathrm{V}_{\mathrm{O}}^{\bullet \bullet}\right]_{\mathrm{L}}$.

Using the thermodynamics reported by Geary and Adler [317], Fig. 20 shows the defect concentrations (formula units) as functions of oxygen partial pressure and at $850{ }^{\circ} \mathrm{C}$. At very low $p_{\mathrm{O}_{2}}$, the vacancies (i.e., $\delta$ ) approach the Ca doping concentration. Also at very low $p_{\mathrm{O}_{2}}$ the $\left[\mathrm{Fe}_{\mathrm{Fe}}^{\cdot}\right]$ concentration becomes negligible small, but the $\left[\mathrm{Fe}_{\mathrm{Fe}}^{\prime}\right]_{\mathrm{L}}$ concentration approaches that of the vacancies. At high $p_{\mathrm{O}_{2}}$ the $\left[\mathrm{Fe}_{\mathrm{Fe}}^{\bullet}\right] \mathrm{L}$ concentration is the dominant charge-carrying defect. The reduced $\left[\mathrm{Fe}_{\mathrm{Fe}}^{\prime}\right]_{\mathrm{L}}$ and oxidized $\left[\mathrm{Fe}_{\mathrm{Fe}}^{\bullet}\right]_{\mathrm{L}}$ defects behave as small polarons.

Figure 21 shows measured oxygen fluxes through a $0.95-\mathrm{mm}$ thick $\mathrm{La}_{0.9} \mathrm{Ca}_{0.1} \mathrm{FeO}_{3-\delta}$ membrane as a function of temperature. These fluxes were measured in a stagnation-flow reactor configuration [316]. The paper also reports a range of other measurements, considering membrane thickness and sweep-gas flow rates. 
Table 2: Representative membrane materials

\begin{tabular}{|c|c|c|c|c|}
\hline Material & $\begin{array}{c}\text { Mobile } \\
\text { Species/defects }\end{array}$ & $\begin{array}{l}\text { Electronic } \\
\text { conduction }\end{array}$ & $\begin{array}{l}\text { Effective } \\
\text { gas }\end{array}$ & $\begin{array}{l}\text { Flux } \\
\text { law }\end{array}$ \\
\hline $\begin{array}{l}\text { Lanthanum ferrite } \\
\quad \mathrm{La}_{1-x} \mathrm{Ca}_{x} \mathrm{FeO}_{3-\delta}, \mathrm{LCF}\end{array}$ & $\mathrm{V}_{\mathrm{O}}^{\bullet \bullet}, \mathrm{Fe}_{\mathrm{Fe}}^{\bullet}, \mathrm{Fe}_{\mathrm{Fe}}^{\prime}$ & Yes & $\mathrm{O}_{2}$ & Nernst-Planck \\
\hline $\begin{array}{l}\text { Doped barium zirconate } \\
\qquad \mathrm{BaZr}_{0.9} \mathrm{Y}_{0.1} \mathrm{O}_{3-\delta}, \mathrm{BZY} 10\end{array}$ & $\mathrm{~V}_{\mathrm{O}}^{\bullet \bullet}, \mathrm{OH}_{\mathrm{O}}^{\bullet}, \mathrm{O}_{\mathrm{O}}^{\bullet}$ & Low & $\mathrm{H}_{2}, \mathrm{O}_{2}, \mathrm{H}_{2} \mathrm{O}$ & Nernst-Planck \\
\hline $\begin{array}{l}\text { Doped ceria } \\
\qquad \mathrm{Ce}_{0.9} \mathrm{Gd}_{0.1} \mathrm{O}_{2-\delta}, \mathrm{GDC} 10, \mathrm{LCF}\end{array}$ & $\mathrm{V}_{\mathrm{O}}^{\bullet \bullet}, \mathrm{Ce}_{\mathrm{Ce}}^{\prime}$ & Low & $\mathrm{O}_{2}$ & Nernst-Planck \\
\hline $\begin{array}{l}\text { Yttria-stabilized zirconia } \\
\qquad\left(\mathrm{Y}_{2} \mathrm{O}_{3}\right)_{0.08}\left(\mathrm{ZrO}_{2}\right)_{0.92}, \mathrm{YSZ}\end{array}$ & $\mathrm{O}^{2-}$ & No & $\mathrm{O}_{2}$ & Migration \\
\hline $\begin{array}{l}\text { Meso-porous alumina } \\
\qquad \mathrm{Al}_{2} \mathrm{O}_{3}\end{array}$ & Gases & No & All & Dusty gas \\
\hline $\begin{array}{l}\text { Palladium and alloys } \\
\text { Pd and Pd alloys }\end{array}$ & $\mathrm{H}$ & Yes & $\mathrm{H}_{2}$ & Sieverts law \\
\hline
\end{tabular}

\subsubsection{Ion-transport membrane conductivity}

The electrical conductivity is an important measure of charged-defect mobility within ion transport membranes. Although ITMs are generally all polycrystalline oxides, their properties vary greatly. Kreuer's 2003 review of proton-conducting ceramics showed that conductivity varies by orders of magnitude as functions of material composition and temperature, with doped barium cerates and barium zirconates having the highest conductivities [318].

Figure 22 illustrates measured conductivities for two perovskite materials that are relevant for membrane reactors [19, 319]. The BZY10 is primarily a proton conductor that is suitable for MDA processes. The $\left(\mathrm{La}_{0.8} \mathrm{Ca}_{0.2}\right)_{0.95} \mathrm{FeO}_{3-\delta}$ (LCF) is primarily an oxide-ion conductor that is suitable for OCM processes. There is a great difference in functional behaviors between these two materials. The BZY10 conductivity is approximately four orders of magnitude smaller than that of the LCF. The BZY10 conductivity is a strong function of oxygen partial pressure in the oxidizing environments, but nearly constant in reducing environments. The LCF conductivity shows relatively weak pressure and temperature dependence. The high conductivity of the LCF is primarily the result of high electronic conductivity relative to the oxide-ion conductivity. By contrast, the BZY10 has low electronic conductivity, with the total conductivity being dominated by the partial conductivities of protons and oxide ions.

The electronic conductivity has important implica- 2981 tions in membrane technology. Because materials such 2982 as YSZ or BZY have low electronic conductivity, they can be polarized to establish an electrostatic-potential field within the membrane. The field then can be used to promote ion transport (cf., Eq. 49).
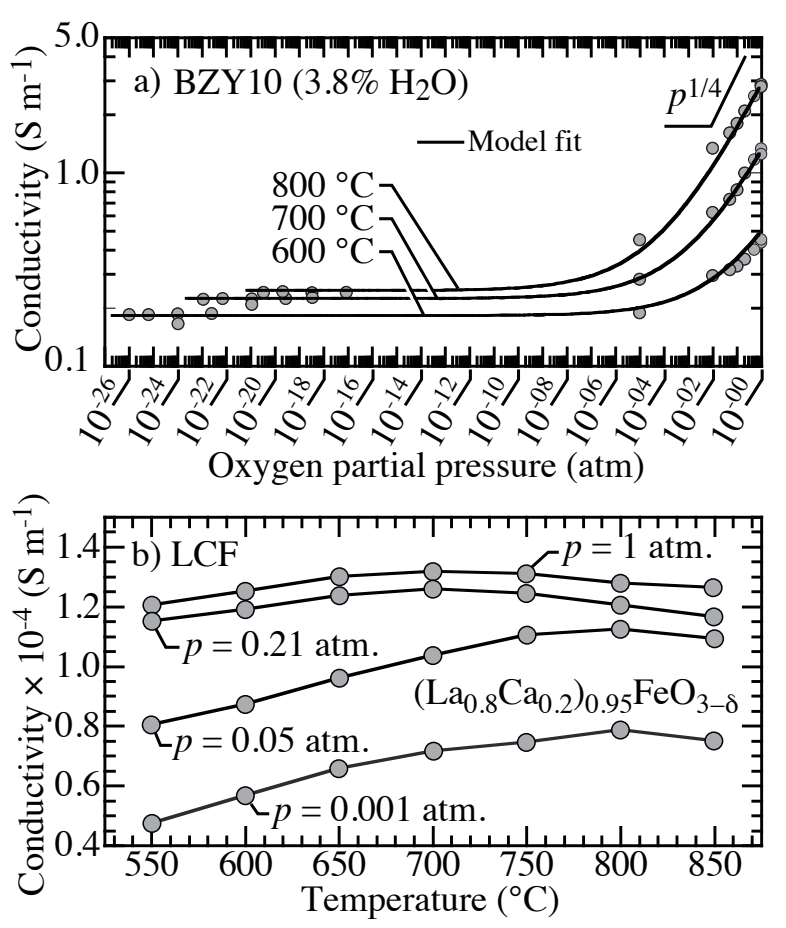

Figure 22: Measured total conductivities for a proton-conducting BZY10 and an oxide-ion conducting LCF. The BZY10 conductivities were reported by Zhu et al. [19] and the LCF conductivities were reported by Yoon et al. [319].

\subsubsection{Nernst-Planck-Poisson model}

The spatial and temporal variations in defect concentrations are governed by conservation equations as

$$
\frac{\partial\left[X_{k}\right]}{\partial t}+\nabla \cdot \mathbf{J}_{k}=0
$$

where $\left[X_{k}\right]$ are defect concentrations and $\mathbf{J}_{k}$ are the Nernst-Planck defect fluxes (Eq. 49). The electrostaticpotential profiles $\Phi$ are determined by solving the Gauss 
equation,

$$
\nabla \cdot\left(\varepsilon_{\mathrm{r}} \varepsilon_{\mathrm{o}} \nabla \Phi\right)=-\rho_{\mathrm{e}}=-F \sum_{k=1}^{K} z_{k}\left[X_{k}\right] .
$$

The relative and vacuum permittivities are represented as $\varepsilon_{\mathrm{r}}$ and $\varepsilon_{\mathrm{O}}$, respectively. The local charge density is ${ }_{3037}$ represented as $\rho_{\mathrm{e}}$.

Imposing strict charge neutrality is a widely practiced ${ }_{3030}^{3030}$ alternative to solving the Gauss equation. Although ${ }_{3040}$ slightly less accurate, imposing charge neutrality is usually easier to implement computationally. Charge neu- ${ }_{3042}$ trality means that $\rho_{\mathrm{e}}=0$. However, interestingly, it does ${ }_{3043}^{3042}$ not follow that

$$
\nabla \cdot\left(\varepsilon_{\mathrm{r}} \varepsilon_{\mathrm{O}} \nabla \Phi\right)=0 .
$$

Based on small-parameter-expansion analysis, Bazant 3047 and colleagues have shown that second-order (i.e., very 3048 small) variations in the charge density cause leading- 3049 order (i.e., large) variations in the electrostatic poten- 3050 tial [320, 321].

Equations 65 and 66 form a coupled system of nonlinear partial differential equations that can be solved computationally. The solution depends on initial and boundary conditions. The boundary conditions de- 3053 pend upon the defect-incorporation chemistry at the ${ }_{3054}$ gas-membrane interfaces, which establish the boundary 3055 defect concentrations. The boundary conditions for the ${ }_{3056}$ electrostatic potentials depend on circumstances such 3057 as if the membrane is polarized by an external circuit. 3058 The governing equations and boundary conditions are 3059 further constrained by imposition of site balances and 3060 electroneutrality, the details depending on the particular ${ }_{3061}$ materials.

Details of the Nernst-Planck-Poisson (NPP) model ${ }_{3063}$ and the computational solution can be found else- 3064 where [19, 304-307, 320-324].

\subsection{Ion-catalyst interactions}

If a catalyst is placed directly onto an ion-conducting 3068 membrane, then there is the possibility that the catalytic 3069 chemistry may be influenced by electrochemistry. In 3070 a great many papers, Vayenas and colleagues, as well 3071 as others, developed theory and discussed processes that are labeled as "non-faradaic electrochemical modification of catalytic activity" (NEMCA) or "electro- 3072 chemical promotion of catalysis" (EPOC) [325-330].

Early research by Gür and Huggins considered NO de- 3073 composition in a solid-state electrochemical cell [331]. 3074 Electrochemical promotion is based on the idea that 3075 ionic species emerging from a mixed-conducting elec- 3076 trolyte membrane are catalytically more reactive than 3077 the equivalent charge-neutral species in the gas phase. Thus, in addition to effective and selective gas transport to and from the catalysts, ion-conducting membranes may offer additional benefits in enhancing the catalytic behavior.

A comprehensive review paper in 2000 by Stoukides [332] discussed NEMCA effects for a wide range of processes, including methane CPOX, $\mathrm{OCM}, \mathrm{CO}$ and $\mathrm{H}_{2}$ oxidation, $\mathrm{NO}_{x}$ decomposition, alkane and alkene oxidation, oxidation and decomposition of sulfur oxides, methanol oxidation, oxidation and dehyrogenation of aromatics, oxidation, decomposition and synthesis of ammonia. An earlier review by Eng and Stoukides [333] considered NEMCA effects for methane partial oxidation to $\mathrm{CO}$ and $\mathrm{H}_{2}$, discussing interactions with solid-oxide fuel cells. This paper also discussed NEMCA effects for OCM processes. A later review by Vayanes et al. [334] discussed the concepts of electrocatalysis, electrochemical promotion, and metal-support interactions for methanol and ethylene oxidation processes.

\subsection{Membrane summary characteristics}

Table 2 summarizes some of the salient characteristics of alternative membranes, especially as they may affect membrane-reactor applications.

Despite their potential benefits, all the membrane approaches must deal with some practical difficulties. For example, at high operating temperatures sealing can be very challenging. Especially in the cases of ceramic membranes, a ceramic-metal seal is usually needed. A range of glass based seals have been developed and used in fuel-cell applications, but long-term leak-free reliability remains elusive. In the case of thin-film membranes (e.g., palladium or ion-conducting ceramics) the fabrication of large-area defect-free materials is difficult. Even small pinholes or micro-cracks can significantly degrade membrane performance. Beyond the initial defect-free fabrication, the thin membranes (typically on the order of tens of microns) must remain mechanically, chemically, and thermally stable on their underlying support structures.

\section{Membrane reactor technology}

As noted in the foregoing discussion, membranes can potentially play important roles in the spatially distributed introduction of oxygen or the removal of hydrogen to improve the process performance [335]. However, the close integration of membranes and catalysts 


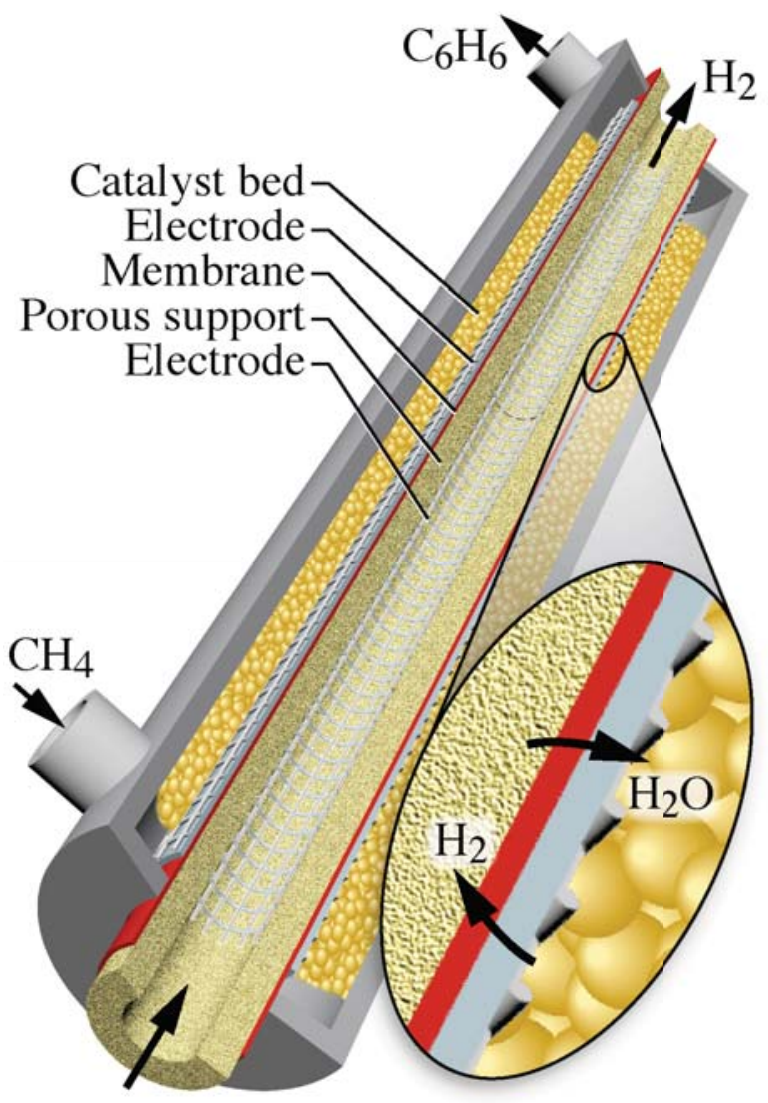
Figure 23: Illustration of an annular packed-bed reactor with a polar- 3103 ized ion-conducting membrane. in different reactor configurations remains an active re- 3107 search topic. This is especially the case for mixed- 3108 conducting and ion-transport membranes. In addition 3109 to simply shifting reaction equilibrium, membranes that 3110 can achieve spatially varying fluxes can beneficially af- 3111 fect the interactions between chemistry and transport 3112 within a catalyst bed.

Membrane reactors for direct methane conversion 3114 processes are typically implemented in a co-annular 3115 configuration with packed-bed catalysts. As illustrated 3116 in Figs. 1 or 23, the catalyst bed is in the annular space 3117 and the sweep gas flows through an inner tube. The ${ }_{3118}$ tube is usually fabricated as a porous support with a thin 3119 membrane applied to the outside of the tube. However, 3120 reactors can also be configured with the catalyst bed be- 3121 ing housed within the interior tube and the sweep gas ${ }_{3122}$ flowing through the annular region.

Figure 23 illustrates a co-annular membrane reac- ${ }_{3124}$ tor in which the membrane may be electrically polar- 3125 ized. In this case, electrodes must be attached to both 3126

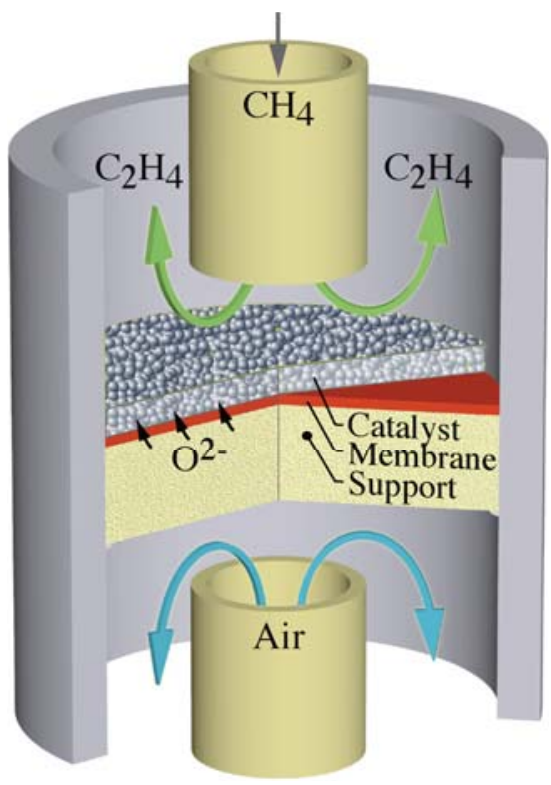

Figure 24: Button-cell, stagnation-flow, reactor design with membrane-coupled OCM process [336].

sides of the membrane. Assuming that the membrane is dominantly an ion conductor with minimal electronic conductivity (e.g., BZY10), an external power source can be used to impose an electrostatic-potential gradient within the membrane [324]. As is evident from the form of the Nernst-Planck flux (Eq. 49), the ion fluxes can be increased by increasing the electrostatic-potential gradient $\nabla \Phi$.

Although the mixed-conducting ceramics are ionic conductors, the ion conductivities are usually low, which is manifested as a high ionic resistance. Thus, polarization can be a significant operational cost (i.e., buying electricity) associated with using the external power source to drive ions through the membrane. Moreover, because electrode design and attachment can be difficult and complex, there can be significant capital cost. Nevertheless, depending on the process, improvements in flux rates and process control may offset the cost and complexity.

If electrodes (such as in Fig. 23) are configured with segmented electrical connections, then it may be possible to control the axial profiles of ion fluxes through the membrane. The opportunity to control fluxes by electrical polarization is only possible with ion-conducting membranes. Metal membranes such as palladium, which are electrical conductors, cannot be polarized. Similarly, membranes fabricated from insulating materials, such as ceramic nano-filtration membranes, offer no benefits from polarization. 
As illustrated with the expanded balloon in Fig. 23, it 3176 is possible with mixed ionic-electronic ceramic (MIEC) 3177 membranes, to have protons being transported in one di- 3178 rection and oxide ions being transported in the other di- 3179 rection [310]. Thus, for membrane-assisted MDA pro- 3180 cesses it is possible to have the benefits of hydrogen flux ${ }_{3181}$ from the catalyst bed and steam flux into the catalyst ${ }_{3182}$ bed. Polarized membranes can be helpful in realizing 3183 this circumstance.

Membrane reactors typically incorporate the catalysts 3185 as packed-beds. However, the catalyst could also be washcoated onto a membrane or the support structure. ${ }^{3186}$ Such washcoated catalysts can be found in laboratory- 3187 scale experiments [337, 338, 284]. Washcoated mono- 3188 liths are common in many industrial processes and in 3189 applications such as automotive catalytic converters. 3190

At the laboratory scale, membrane reactors can also 3191 be configured in a stagnation-flow configuration [336, 3192 $339,312,313]$. In these configurations, such as shown 3193 in Fig. 24, the membrane takes the form of a disk. 3194 The catalyst may be either washcoated on the mem- 3195 brane or packed with the catalyst particles above the ${ }_{3196}$ membrane. Such reactors can also be polarized. In 3197 this case, the experimental setup is very much the 3198 same as is common for so-called button-cell fuel-cell 3199 experiments. Figure 24 shows an oxygen-transport ${ }_{3200}$ membrane as might be used in converting methane to 3201 ethylene via a membrane-assisted OCM process. Al- 3202 though stagnation-flow reactors are especially valuable $з 203$ in studying reaction chemistry and membrane proper- 3204 ties, upscaling to commercially viable reactors is usu- 3205 ally impractical.

\section{Hydrogen-membrane assisted processes}

Although hydrogen-permeable membranes can play 3211 significant beneficial roles in dehydrogenation pro- 3212 cesses, there are potentially deleterious competing ef- 3213 fects. For example, as $\mathrm{H}_{2}$ is removed from hydrocar- 3214 bon streams, there is significant propensity for catalyst- 3215 deactivating carbon deposits. Additionally, even though 3216 conversion of the parent fuel (e.g., $\mathrm{CH}_{4}$ ) may increase, 3217 the product selectivity may shift toward less desired 3218 products. In MDA, as $\mathrm{H}_{2}$ is removed, the product selec- ${ }_{3219}$ tivity shifts toward naphthalene (and higher PAH) and 3220 away from the desired benzene. Thus, simply increasing ${ }_{3221}$ $\mathrm{H}_{2}$ flux through the membrane is not always desirable. 3222 Because they can also transport oxygen defects, mem- ${ }_{3223}$ branes such as the perovskite protonic ceramics may of- 3224 fer advantages compared to membranes that are purely 3225 hydrogen selective (e.g., palladium).
In principle, hydrogen membranes can be used to assist direct conversion of methane to ethylene under nonoxidizing environments (i.e., Eq. 2). However, although conversion may increase, removing the excess $\mathrm{H}_{2}$ can cause severe catalyst deactivation. The high temperatures needed for the direct conversion to ethylene promote more carbon deposits than is the case for MDA process that operate at relatively lower temperature (cf., Fig 3). Hence, the use of hydrogen membranes in nonoxidizing environments is usually impractical.

\subsection{Pd-based $\mathrm{H}_{2}$ membranes}

Larachi and co-workers studied membrane-coupled MDA processes using $\mathrm{Pd}$-alloy membranes with porous stainless-steel supports [255-257]. These studies used packed-bed catalysts in a shell-and-tube configuration at temperatures between $500-700{ }^{\circ} \mathrm{C}$. The HZSM-5 catalysts used 3 wt.\% Mo and 0.5 wt.\% Ru. Although $\mathrm{H}_{2}$ removal via the membrane nearly doubled the $\mathrm{C}_{6} \mathrm{H}_{6}$ yield, the carbon deposits caused severe catalyst deactivation [255]. In a subsequent publication, this group showed that the carbon deposits are in the form of both graphitic carbon and polyaromatic hydrocarbons. The catalyst could be regenerated by flowing hydrogen. However, although the short-term $\mathrm{C}_{6}$ yield could be increased using the membrane, the productive time-onstream decreased [256].

Wang et al. [340] used a Pd-Ag membrane coupled with an MDA packed-bed reactor with a Re/HZSM-5 catalyst. The temperature and gas-hourly space velocities were relatively low $\left(T=585{ }^{\circ} \mathrm{C}, 120 \leq \mathrm{GHSV} \leq\right.$ 1440). Although the membrane increased methane conversion by as much as to $50 \%$, the maximum methane conversion was still low at less than $7.5 \%$.

Kinage et al. [341] coupled a Pd membrane disk in a packed-bed reactor loaded with 3 wt.\% Mo/ZSM-5 catalyst operated at $610{ }^{\circ} \mathrm{C}$. The results showed that the hydrogen-permeable membrane increased methane conversion as well as the aromatic (benzene, toluene, and naphthalene) yield. However, they also reported that carbon deposits on the Pd membrane significantly decreased the hydrogen flux through the membrane.

A study by Natesakhawat et al. [258] reported the results of membrane-coupled MDA reaction in an annular packed-bed reactor with a 4 wt.\% Mo/HZSM-5 catalyst. Using a $125 \mu \mathrm{m}$ thick Pd membrane and operating at $700{ }^{\circ} \mathrm{C}$, they reported severe catalyst deactivation rates with or without the membrane. The coke also deposited on the Pd membrane, significantly decreasing the hydrogen transport rate. At the reaction conditions studied, the membrane lost $75 \%$ of the initial $\mathrm{H}_{2}$ permeability. Nevertheless, the results showed that the membrane 
could increase the $\mathrm{C}_{6} \mathrm{H}_{6}$ yield by up to $360 \%$, but with 3278 a very low overall yield below $2 \%$. They reported that 3279 the membrane efficiency was strongly effected by gas- 3280 hourly space velocities within the catalyst bed.

\subsection{Protonic-ceramic membranes}

Beginning in 1998, Iglesia and co-workers stud- 3284 ied membrane coupled MDA proceses [342, 216, 18, 3225 254]. Liu et al. [254] coupled a dense thin-film ${ }_{3286}$ $\mathrm{SrCe}_{0.95} \mathrm{Yb}_{0.05} \mathrm{O}_{3-\delta}$ proton-conducting membrane with ${ }_{3287}$ a Mo/H-ZSM-5 catalyst in a packed-bed reactor. The ${ }_{3288}$ study showed that at temperatures below $677{ }^{\circ} \mathrm{C}$ the 3289 hydrogen membrane removed less than $7 \%$ of the cat- 3290 alytically produced $\mathrm{H}_{2}$, but did significantly increase 3291 the $\mathrm{CH}_{4}$ conversion. As the temperature increased to 3292 $720{ }^{\circ} \mathrm{C}$, the hydrogen removal increased to approxi- ${ }^{3293}$ mately $16 \%$. At the higher temperature the methane ${ }_{3294}$ conversion rate increased modestly, but also increased 3295 the yield of undesired $\mathrm{C}_{12+}$ hydrocarbons. The catalyst ${ }_{3296}$ deactivation rate also increased at higher temperatures. 3297 Co-feeding $2 \% \mathrm{CO}_{2}$ enhanced the catalytic stability and ${ }_{3298}$ beneficially reduced the $\mathrm{C}_{12+}$ formation rate.

The Iglesia group developed a membrane-coupled 3300 packed-bed model to predict reactor performance, in- 3301 cluding the effect of hydrogen removal on methane con- 3302 version as well as benzene and naphthalene selectiv- 3303 ity $[216,18]$. The model showed that methane conver- 3304 sion can be increased as the hydrogen permeation frac- 3305 tion increases. However, the effect on product distribu- 3306 tion is non-linear. In an MDA system, the production 3307 of undesired naphthalene competes with desired ben- $з 308$ zene yield. Thermodynamic considerations show that 3309 removing hydrogen shifts the product selectivity toward ${ }_{3310}$ naphthalene. However, kinetics and transport consid- 3311 erations show that there are useful tradeoffs between 3312 the hydrogen removal rate (i.e., membrane flux), resi- 3313 dence time in the catalyst bed, and the benzene yield. 3314 At long residence times the MDA process is kineti- 3315 cally controlled, favoring naphthalene formation. In the 3316 kinetically limited regime, the hydrogen removal rate 3317 should be low. As the residence time decreases the pro- 3318 cess is increasingly mass-transport controlled, allowing ${ }_{3319}$ more hydrogen permeation and favoring selectivity to- 3320 ward benzene [18].

In addition to MDA processes, hydrogen mem- 3322 branes can play roles in non-oxidative conver- 3323 sion of methane to ethylene. Woldman and 3324 Sokolovskii [343] developed an electrochemical button 3325 cell using a proton-conducting electrolyte membrane 3326 made of $\mathrm{SrO}\left(\mathrm{CeO}_{2}\right)_{0.95}\left(\mathrm{YbO}_{1.5}\right)_{0.05}(\mathrm{SCY})$. The elec- ${ }_{3327}$ trolyte membrane could be polarized using an external power supply. Methane was supplied to the anode side and nitrogen on the cathode side of the membrane. Even without polarization, and operating at $800{ }^{\circ} \mathrm{C}$, the cell produced ethane and ethylene. Upon polarization the $\mathrm{C}_{2}$ yield increased greatly. Apparently the SCY electrolyte membrane also acted as the catalyst. When steam was mixed with the methane feed, the $\mathrm{C}_{2}$ yield increased. No evidence of carbon deposits was reported. However, in all cases the $\mathrm{C}_{2}$ yields were impractically low at less than $0.01 \%$.

Langguth et al. [344] also studied the use of $\mathrm{SrCe}_{0.95} \mathrm{Yb}_{0.05} \mathrm{O}_{3-\delta}$ (SCYO) as a high-temperature proton-conducting membrane in an electrochemical button cell. Methane (and moist methane) was supplied on the anode side with air supplied on the cathode side. The system did produce ethane and ethylene, but also produced $\mathrm{CO}$ and $\mathrm{CO}_{2}$. The $\mathrm{SCYO}$ membrane is a mixed conductor. Thus, hydrogen can be removed from methane side, but oxygen also enters the methane side. Water vapor was found to decrease the $\mathrm{C}_{2}$ yield because of competitive reforming chemistry.

Liu et al. [27] incorporated a $\mathrm{SrCe}_{0.95} \mathrm{Yb}_{0.05} \mathrm{O}_{3-\delta}$ ( $\mathrm{SCYb})$ mixed-conducting perovskite into a hollowfiber membrane reactor. Methane was introduced into the central tube of a co-annular reactor, with air flowing in the outer annular space. No other catalysts were used. The methane conversion was attributed to electrochemical reactions at the membrane surfaces. In addition to the experiments, the paper also reported a model that represented the proton and electron hole transport within the membrane and the electrochemical methane conversion chemistry at the membrane surfaces. The results showed that the membrane increased the methane conversion as well as the $\mathrm{C}_{2} \mathrm{H}_{4} / \mathrm{C}_{2} \mathrm{H}_{6}$ ratio in the product stream.

With or without membranes, MDA processes are not yet commercially viable. Nevertheless, there appears to be some industrial interest. BASF recently patented an MDA application using a ceramic-protonic conducting membrane [345]. The membrane hydrogen flux could be driven entirely by $\mathrm{H}_{2}$ partial-pressure differences across the membrane or the flux could be increased by electrically polarizing the membrane. By introducing oxygen in the sweep gas, $\mathrm{H}_{2}$ entering the sweep stream is rapidly converted to $\mathrm{H}_{2} \mathrm{O}$, thus decreasing the $\mathrm{H}_{2}$ partial pressure in the sweep and maintaining a large $\mathrm{H}_{2}$ gradient across the membrane. Ceramatec, Inc. recently submitted a patent application describing a protonicceramic membrane coupled with an MDA reactor [346]. This application used a Re/ZSM-5 catalyst and operated in the temperature range $700 \leq T \leq 900{ }^{\circ} \mathrm{C}$ [347]. 


\section{Oxygen-membrane assisted processes}

Oxygen-permeable membranes are most relevant for 3379 OCM processes. As expressed globally by Eq. 3, 3380 OCM processes are intended to produce ethylene from 3381 methane. Membrane assisted OCM reactors can po- 3882 tentially improve thermal management and product se- 3883 lectivity. When oxygen is premixed into the methane 3384 feed stream, controlling local temperature excursions 3385 associated with the exothermic oxidation chemistry can 3386 be difficult. Thus, because the chemistry is highly ${ }_{3387}$ temperature-sensitive, controlling the product selectiv- 3388 ity and unwanted production of total-oxidation products 3389 $\mathrm{CO}_{2}$ and $\mathrm{H}_{2} \mathrm{O}$ can be challenging.

By spatially distributing the introduction of the lim- 3391 iting reactant $\mathrm{O}_{2}$ via a membrane, the process temper- 3392 ature, and hence the product selectivity, can be con- 3993 trolled. In 1985 Otsuka et al. first introduced the idea of 3394 using oxygen-permeable membranes to improve OCM 3395 processes [348]. In these studies the catalysts were $\mathrm{Ag} 3396$ and $\mathrm{Ag}-\mathrm{Bi}_{2} \mathrm{O}_{3}$. The $\mathrm{O}_{2}$ was electrochemically pumped 3397 through a dense ceramic yttria-stabilized zirconia mem- 3398 brane at $700{ }^{\circ} \mathrm{C}$. The membrane reactor was configured 3399 in a co-annular arrangement where the membrane was 3400 supported on the tube side (similar to the configuration 3401 shown in Fig. 23). They demonstrated that membrane- 3402 coupled packed-bed reactor increased the $\mathrm{C}_{2}$ yield and 3403 the selectivity compared to a typical packed-bed reactor 3404 with premixed $\mathrm{O}_{2}$ (e.g., Fig. 12).

In a typical co-annular OCM packed-bed reactor, the 3406 pressure drop along the length of the catalyst bed can be 3407 significant. Thus, the local pressure drop across mem- 3408 brane can vary, leading to local variations in the oxygen 3409 flux into the catalyst bed. Locally high oxygen concen- 3410 trations can lead to deleterious local hot spots and full 3411 oxidation.

\subsection{Ion-transport membranes for OCM}

Oxygen-permeable ITM membranes are usually 3416 doped-perovskite polycrystalline ceramics, such as 3417 $\mathrm{La}_{x} \mathrm{Sr}_{1-x} \mathrm{Co}_{y} \mathrm{Fe}_{1-y} \mathrm{O}_{3-\delta} \quad$ (LSCF) or $\mathrm{La}_{x} \mathrm{Ca}_{1-x} \mathrm{FeO}_{3-\delta}{ }_{3418}$ (LCF). The oxide-ion conductivity of these materials 3419 is highly activated, with practical oxygen fluxes re- 3420 quiring temperatures of $700{ }^{\circ} \mathrm{C}$ and higher. An addi- ${ }_{3421}$ tional, and possibly valuable, attribute of the oxygen- 3422 transport membranes is that they can serve a dual pur- 3423 pose of in-situ air separation as well as controlled oxy- 3424 gen dosing into the reactor. However, material sta- 3425 bility in reducing environments is a practical limita- 3426 tion for many oxide-ion conducting membranes. The ${ }_{3427}$ $\mathrm{La}_{x} \mathrm{Ca}_{1-x} \mathrm{FeO}_{3-\delta}$ perovskites are stable in both oxidiz- ${ }_{3428}$ ing and reducing environments and have good oxide-ion conductivity [311, 312, 314, 317, 313, 315].

To achieve needed fluxes, ceramic ITM membranes usually need to be very thin, often in the range a few tens of micrometers. Thus, they needed to be supported on some sort of much thicker porous ceramic structure, such as a porous tube. The mechanical strength and structural stability of such thin oxygen-permeable ITM membranes can be problematic.

Thin hollow-fiber membranes provide a structure with good mechanical stability [349-353, 337]. The hollow-fiber structures are fabricated using an immersion induced phase inversion technique [350]. As shown in Fig. 25, tapered radial microchannels are open to the tube's inner surface [337].

Othman et al. [337] developed a Catalytic Hollow Fiber Membrane MicroReactor (CHFMMR) for OCM applications. The hollow-fiber tube is fabricated from $\mathrm{La}_{0.6} \mathrm{Sr}_{0.4} \mathrm{Fe}_{0.8} \mathrm{Co}_{0.2} \mathrm{O}_{3-\delta}$ (LSCF), which is an oxide-ion conducting perovskite. The outer surface of the tube forms a thin dense LSCF membrane. A thin layer of the OCM catalyst composed of $\mathrm{Bi}_{1.5} \mathrm{Y}_{0.3} \mathrm{Sm}_{0.2} \mathrm{O}_{3-\delta}$ (BYS) is washcoated onto the interior radial microchannels. The reactor is fabricated in a co-annular configuration, where air flows in the outer annulus and methane is introduced into the tube interior. The LSCF membrane separates air and delivers oxygen to high-surface-area BYS catalyst. The design also provides good heat and mass transfer between the gas and solid phases. The CHFMMR reactor delivers good performance, reported as $39 \% \mathrm{C}_{2+}$ yield and $79 \% \mathrm{C}_{2+}$ selectivity at $900{ }^{\circ} \mathrm{C}$.

$\mathrm{Zhu}$ et al. [354] developed a mixed-conducting multichannel hollow fiber membrane (MCMHF) using $\mathrm{SrFe}_{0.8} \mathrm{Nb}_{0.2} \mathrm{O}_{3-\delta}$ (SFN). The "multi-channel" nomenclature means that there are four axial interior channels within each rod of the SFN. This structure enables high oxygen fluxes $\left(0.38 \mathrm{ml} \mathrm{cm} \mathrm{min}^{-1} \mathrm{~cm}^{-2}\right.$ at $\left.800{ }^{\circ} \mathrm{C}\right)$ in $\mathrm{CO}_{2}$-rich environments, and exhibits good thermal and mechanical stability. The intended application was for oxyfuel combustion, not membrane reactors. Nevertheless, such an approach may be useful for OCM processes.

Bhatia et al. [284] measured the performance of two different membrane-assisted OCM reactor configurations. The reactors were all implemented in a co-annular configuration. The so-called catalytic membrane reactor (CMR) used a mixed-conducting perovskite membrane $\left(\mathrm{Ba}_{0.5} \mathrm{Ce}_{0.4} \mathrm{Gd}_{0.1} \mathrm{Co}_{0.8} \mathrm{Fe}_{0.2} \mathrm{O}_{3-\delta}\right.$, BCGCF) supported on a porous ceramic tube. The $\mathrm{Na}-\mathrm{W}-\mathrm{Mn} / \mathrm{SiO}_{2}$ catalyst was coated on the inner surface of the membrane tube. The so-called packed-bed membrane reactor (PBMR) used a packed-bed catalyst instead of the thin catalyst 

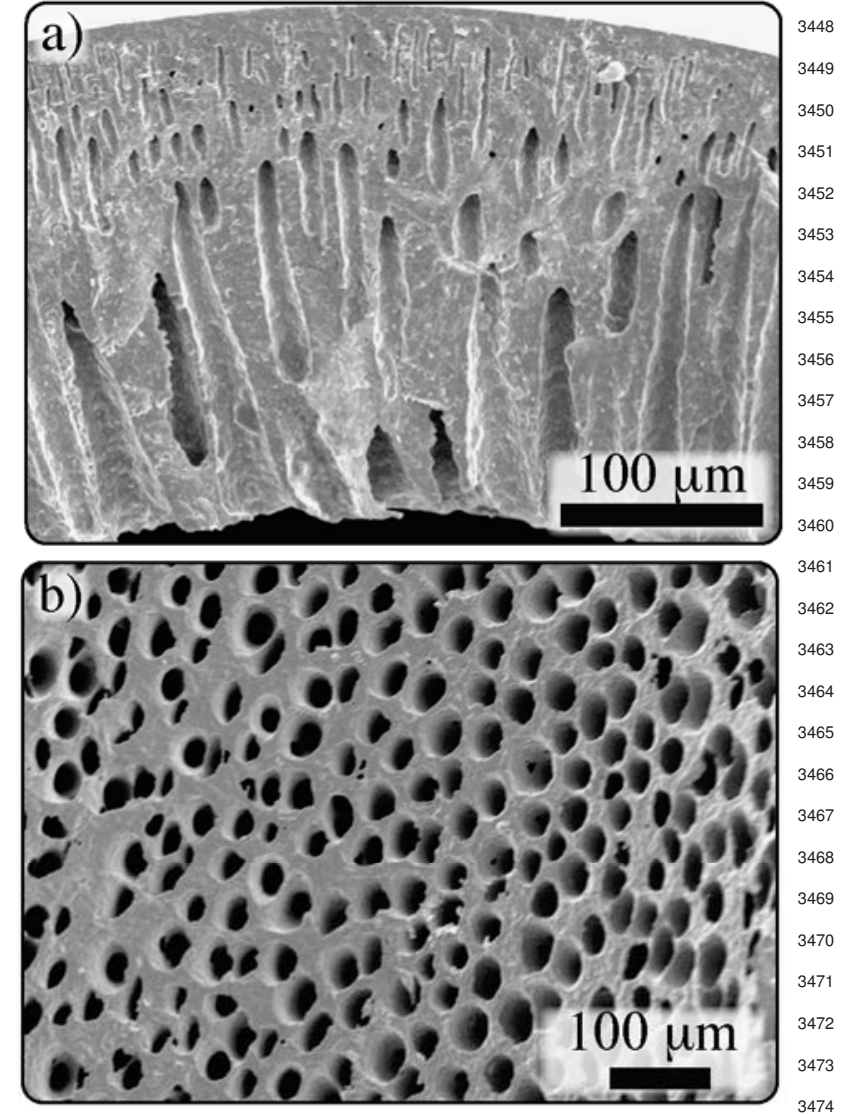

Figure 25: Two microscopic images of the CHFMMR hollow-fiber tube, prior to catalyst introduction [337]. a) Tube cross-section, b) Tube inner surface.

coating that was used in the CMR approach. Compared to the PBMR, the CMR approach achieved significantly better methane conversion, $\mathrm{C}_{2+}$ selectivity, and $\mathrm{C}_{2+}$ yield. The study suggested that reducing pressure drop through the catalyst bed could improve performance of the PBMR. In both cases, with the membrane delivering distributed oxygen flux to the catalyst, the membrane-assisted processes have the potential to ${ }_{3488}$ deliver better results than can be achieved with a typical ${ }_{3488}$ packed-bed reactor.

\subsection{Porous membranes for OCM}

3489

Micro- and nano-porous membranes have the po- 3490 tential advantage of producing higher oxygen fluxes 3491 than dense ion-transport membranes. Moreover, 3492 fluxes through porous membranes are less temperature- 3493 dependent than are the fluxes through ITMs. However, 3494 the selectivity for oxygen flux is lower than it is for ${ }_{3495}$ dense ion transport membranes. The oxygen fluxes are 3496 proportional to the oxygen partial-pressure differences ${ }_{3497}$ across the membrane. Because of its chemical and thermal stability, porous alumina is a often a material of choice. The pore microstructure can be modified to achieve desired oxygen fluxes.

Lafarga et al. [291] used a porous $\mathrm{Al}_{2} \mathrm{O}_{3}$ membrane for distributing the oxygen into an OCM processes. The reactor was a co-annular configuration, with the oxygen flowing in the annular space and a packed-bed catalyst within the central tube. Experiments were conducted at $800^{\circ} \mathrm{C}$ and the oxygen pressure in the annular space was 6 bar. The high pressure was used to impede back diffusion of hydrocarbons onto the annular oxygen flow. The membrane itself was composed of a support structure and a much-less-permeable thin membrane The support layer was approximately $1.5 \mathrm{~mm}$ thick with an average pore size of $10 \mu \mathrm{m}$. The separation layer was approximately $10 \mu \mathrm{m}$ thick with an average pore size of approximately $200 \mathrm{~nm}$. OCM processes need low oxygen fluxes to achieve high performance. To reduce the membrane permeability even further, silica was deposited within the pores. In a related subsequent study, Coronas et al. [292], used the silica-modified porous membrane and reported greater than $40 \% \mathrm{C}_{2}$ yield at $750{ }^{\circ} \mathrm{C}$ with a $\mathrm{Li} / \mathrm{MgO}$ catalyst. No deactivation was reported over $34 \mathrm{~h}$ of time on stream. More recently, Godini et al. [285] implemented a silicon-oxycarbide-modifed $\mathrm{Al}_{2} \mathrm{O}_{3}$ porous membrane in an OCM packed-bed reactor and reported high temperature stability up to 1000 ${ }^{\circ} \mathrm{C}$. Measured results using a $\mathrm{Mn}-\mathrm{Na}_{2} \mathrm{WO}_{4}$ catalyst with varying $\mathrm{CH}_{4} / \mathrm{O}_{2}$ ratios showed $18.5 \% \mathrm{C}_{2}$ yield and good temperature uniformity.

Based on plug-flow models, Kiatkittipong et al. [283] compared OCM reactors with and without membranes. The membrane-assisted reactors were all co-annular packed-bed configurations. The membrane structures included porous-alumina, oxide-ion-conducting perovskite $\left(\mathrm{La}_{0.4} \mathrm{Sr}_{0.6} \mathrm{Ga}_{0.4} \mathrm{Fe}_{0.6} \mathrm{O}_{3-\delta}\right)$, and electrically polarized yttria-stabilized zirconia (YSZ). The study explored pros and cons of the alternative reaction configurations, but did not reach unambiguous conclusions about the best approach.

\subsection{Oxygen membranes for MDA}

Although most MDA research considers hydrogenpermeable membranes, there is also some interest in oxygen-transport membranes. Caro and coworkers [32] studied the incorporation of a $20 \mu \mathrm{m}$ thick $\mathrm{Ba}_{0.5} \mathrm{Sr}_{0.5} \mathrm{Ca}_{0.8} \mathrm{Fe}_{0.2} \mathrm{O}_{3-\sigma}$ perovskite as an oxygenconducting membrane. The process was implemented in a packed-bed reactor at $750{ }^{\circ} \mathrm{C}$ and 1 bar with a 6 wt. $\% \mathrm{Mo} / \mathrm{H}-\mathrm{ZSM}-5$ catalyst. The desired global reac- 
tion can be represented as

$$
6 \mathrm{CH}_{4}+\frac{9}{2} \mathrm{O}_{2} \rightarrow 9 \mathrm{H}_{2} \mathrm{O}+\mathrm{C}_{6} \mathrm{H}_{6}, \quad \Delta H_{298}^{\circ} \approx-1644 \mathrm{~kJ} \text {. }
$$

Compared to premixing $\mathrm{O}_{2}$ with $\mathrm{CH}_{4}$, feeding the oxygen through a membrane increases methane conversion, aromatic selectivity, and catalyst durability [32]. The increased methane conversion can be explained by hydrogen removal via oxidation to produce $\mathrm{H}_{2} \mathrm{O}$ at the membrane-catalyst interface. Low concentrations of water play a beneficial role on catalyst stability [192, 193, 173]. However, there is still catalyst deactivation owing to carbon deposits. In the Caro et al. experiments, the methane-to-oxygen ratio in the reaction zone was not fully controlled. Thus any excess oxygen may have caused a $\mathrm{Mo}_{2} \mathrm{C}$ to oxycarbide $\left(\mathrm{MoO}_{x} \mathrm{C}_{y}\right)$ phase change, which would also contribute to catalyst deactivation.

\section{Summary and outlook}

The direct conversion of natural gas to fuels and ${ }_{3566}$ chemicals has the potential to be much more efficient 3567 than first reforming to produce intermediate synthesis 3568 gas. Assuming a hydrocarbon product is desired, there 3569 is an inherent inefficiency associated with first mak- 3570 ing an oxidation product (i.e., carbon monoxide) and 3571 then reducing to produce final product. However, direct 3572 routes such as oxidative coupling of methane (OCM) 3573 and methane dehydroaromatization (MDA) are far less 3574 mature than commercially practiced processes such as 3575 reforming followed by Fischer-Tropsch synthesis. 3576

Although far less mature than traditional routes via 3577 methane reforming, there is certainly promise for OCM, 3578 MDA, and related processes. However, there are 3579 significant challenges that must be overcome before 3580 laboratory-scale demonstrations can be scaled to com- 3581 mercially viable processes. Broadly speaking, these 3582 challenges include finding ways to improve catalyst per- ${ }_{3583}$ formance, mitigate of catalyst deactivation, reduce coke 3584 and carbon deposits. In addition to designing and de- 3585 veloping new catalysts, innovative reactor and process 3586 design are surely needed.

Any process that involves the dehydrogenation of methane to produce hydrocarbons faces at least two challenges. One is that hydrogen accumulation tends 3588 to limit conversion. Another is that carbon and pol- 3589 yaromatic hydrocarbon deposits are thermodynamically 3590 favored over desired gas-phase phase products such as 3591 small olefins (e.g., ethylene) or small aromatics (e.g., 3592 benzene). Hydrogen-permeable membranes promote 3593 increased conversion, but tend to exacerbate catalystdeactivating deposits.

The two most-studied direct methane-conversion processes have two different objectives. The MDA process seeks to produce benzene and the OCM process seeks to produce ethylene. The OCM process is probably closer to commercial practice than is the MDA process. The low oxygen levels in OCM tend to mitigate, but not eliminate, the carbon-deposition problems. Compared to benzene, ethylene is probably a more flexible product in terms of further downstream processing.

It is reasonable to expect that commercially viable implementation of both OCM and MDA will use some sort of membrane. The oxygen-transport membranes are generally more mature, and several alternative membrane technologies are available. The perovskite mixedconducting protonic ceramics that could be used for MDA offer the interesting possibility of simultaneous hydrogen removal from the catalyst and low levels of steam introduction onto the catalyst bed. Nevertheless, these membranes are less well developed than are the ceramic oxide-ion membranes.

Both the OCM and MDA processes can use a range of catalysts. To date, the most successful OCM catalysts are in the family of $\mathrm{Na}-\mathrm{W}-\mathrm{Mn} / \mathrm{SiO}_{2}$. The most successful MDA catalysts are bifunctional Mo/zeolites. However, there is continuing active research on improving catalyst selectivity and yield for numerous catalysts and catalyst combinations.

Commercially viable direct conversion will likely depend on process intensification. Thus, innovative reactor and process design and development is important. Integrating thermal control with catalytic chemistry is certainly important. The innovative development and use of membranes will likely assist process improvement.

As evidenced by 350 papers and patents cited in this review, it is clear that there is significant and current interest in direct methane conversion. At the same time, it is also evident that there is not yet any direct-conversion process that has been scaled to viable commercial practice. Substantial advances in catalyst performance and reactor technology are needed.

\section{Acknowledgements}

This work was supported by the Air Force Office of Scientific Research (FA9550-12-1-0495), the Office of Naval Research (N00014-08-1-0539), and CoorsTek, Inc. During the course of this study, we gratefully acknowledge fruitful discussions with Profs. Raul Lobo and Dion Vlachos (University of Delaware). We also 
acknowledge the frequent and insightful discussions 3655 with Profs. Huayang Zhu, Sandrine Ricote, Greg Jack- 3656 son, Ryan O'Hayre, Brian Trewyn, Douglas Way, and ${ }_{3658}^{365}$ Anthony Dean (CSM) and Drs. Grover Coors and Jim ${ }_{3659}^{3658}$ Steppan (CoorsTek, Membrane Sciences).

\section{References}

[1] T.M. Gür. Critical review of carbon conversion in "Carbon Cells". Chem. Rev., 113:6179-6206, 2013.

[2] S. McIntosh and R.J. Gorte. Direct hydrocarbon solid oxide 3667 fuel cells. Chem Rev, 104:4845-4865,2004. 3668

[3] N.Ya. Usachev, V.V. Kharlamov, E.P. Belanova, T.S. ${ }^{3669}$ Starostina, and I.M. Krukovskii. Oxidative processing of light ${ }^{3670}$ alkanes: State-of-the art and prospects. Russ. J. Gen. Chem., ${ }^{3671}$ 79:1252-1263, 2009.

[4] U. Zavyalova, M. Geske, R. Horn, G. Weinberg, W. Frand- ${ }^{3673}$ sen, M. Schuster, and R. Schlogl. Morphology and microstruc- ${ }^{3674}$ ture of $\mathrm{Li} / \mathrm{MgO}$ catalysts for the oxidative coupling of methane. ${ }^{3675}$ ChemCatchem, 3:949-959, 2011.

[5] K. Takanabe. Catalytic conversion of methane: Carbon dioxide ${ }^{3677}$ reforming and oxidative coupling. J. Jpn. Petrol. Inst, 5:1-12, ${ }^{3678}$ 2012. 3679

[6] S. Ma, X. Guo, L. Zhao, S. Scott, and X. Bao. Recent progress 3680 in methane dehydroaromatization: From laboratory curiosities ${ }^{3681}$ to promising technology. J. Energy Chem., 22:1-20, 2013. 3682

[7] P. Tang, Q. Zhu, Z. Wu, and D. Ma. Methane activation: The ${ }^{3683}$ past and future. J. Energy Environ. Sci., 7:2580-2591, 2014 36

[8] R. Horn and R. Schlogl. Methane activation by heterogeneous 3685 catalysts. Catal. Lett., 145:23-29, 2015.

[9] J.J. Spivey and G. Hutchings. Catalytic aromatization of ${ }^{3687}$ methane. Chem. Soc. Rev., 43:792-803, 2014.

[10] E.F. Lutz. Shell higher olefin process. J. Chem. Edu., 63:202- ${ }^{3689}$ 203, 1986.

[11] M. Lallemand, A. Finiels, F. Fajula, and F. Hulea. Catalytic ${ }^{369}$ oligomerization of ethylene over Ni-containing dealuminated ${ }^{3692}$ Y zeolites. Appl. Cat. A. Gen., 301:196-201, 2006.

[12] D.A. Wood, C. Nwaoha, and B.F. Towler. Gas-to-liquids (gtl): ${ }^{3694}$ A review of an industry offering several routes for monetizing ${ }^{3695}$ natural gas. J. Nat. Gas Sci. and Eng., 9:196-208, 2012.

[13] Oxidative coupling of methane. ${ }^{3697}$ http://siluria.com/Technology/OxidativeCouplingofMethane, ${ }^{3698}$ Accessed: 2015-04-27.

[14] Oxidative coupling of methane followed by oligomerization 3700 to liquids: Towards sustainable production of high quality fu- ${ }^{3701}$ els and petrochemicals. http://www.ocmol.eu/news2.html, Ac- ${ }^{3702}$ cessed: 2015-06-10.

[15] C. Marcilly. Present status and future trends in catalysis for ${ }^{3704}$ refining and petrochemicals. J. Catal., 216:47-62, 2003.

[16] C. Karakaya, P.J. Weddle, J.M. Blasi, D.R. Diercks, and ${ }^{3706}$ R.J. Kee. Modeling reaction-diffusion processes within cat- ${ }^{3707}$ alyst washcoats: I. Microscale processes based on three- ${ }^{3708}$ dimensional reconstructions. Chem. Eng. Sci., 145:299-307, ${ }^{3709}$ 2016.

[17] J.M. Blasi, P.J. Weddle, C. Karakaya, D.R. Diercks, and R.J. ${ }^{3711}$ Kee. Modeling reaction-diffusion processes within catalyst ${ }^{3712}$ washcoats: II. Macroscale processes informed by microscale ${ }^{3713}$ simulations. Chem. Eng. Sci., 145:308-316, 2016.

[18] W. Li, R.W. Borry, and E. Iglesia. Design and optimization of ${ }^{3715}$ catalysts and membrane reactors for the non-oxidative conver- ${ }^{3716}$ sion of methane. Chem. Eng. Sci., 57:4595-4604, 2002.

[19] H. Zhu, S. Ricote, W.G. Coors, and R.J. Kee. Interpret- ${ }^{3718}$ ing equilibrium-conductivity and conductivity-relaxation mea- ${ }^{3719}$ surements to establish thermodynamic and transport properties for multiple charged defect conducting ceramics. Faraday Discuss., 182:49-74, 2015.

[20] H. Zhu and R.J. Kee. Membrane polarization in mixedconducting ceramic fuel cells and electrolyzers. Intl. J. Hydrogen Energy, 41:2931-2943, 2016.

[21] T.V. Choudhary, E. Aksoylu, and D.W. Goodman. Nonoxidative activation of methane. Catal. Rev. Sci. Eng., 45:151-203, 2003.

[22] S. Majhi, P. Mohanty, H. Wang, and K.K. Pant. Direct conversion of natural gas to higher hydrocarbons: A review. J. Energy Chem., 22:543-554, 2013

[23] N.A. Mamonov, E.V. Fadeeva, D.A. Grigoriev, M.N. Mikhailov, L.M. Kustov, and S.A. Alkhimov. Metal/zeolite catalysts of methane dehydroaromatization. Russ. Chem. Rev., 82:567-585, 2013.

[24] U. Zavyalova, M. Holena, R. Schloegl, and M. Baerns. Statistical analysis of past catalytic data on oxidative methane coupling for new insights into the composition of highperformance catalysts. ChemCatChem., 3:1935-1947, 2011.

[25] S. Arndt, G. Laugel, S. Levchenko, R. Horn, M. Baerns, M. Scheffler, R. Schlögl, and R. Schomäcker. A critical assessment of $\mathrm{Li} / \mathrm{MgO}$-based catalysts for the oxidative coupling of methane. Catal. Rev. Sci. Eng., 53:424-514, 2011.

[26] S. Liu, X. Tan, K. Li, and R. Hughes. Methane coupling using catalytic membrane reactors. Catal. Rev. Sci. Eng., 43:147198, 2001.

[27] Y. Liu, X. Tan, and K. Li. Non-oxidative methane coupling in a $\mathrm{SrCe}_{0.95} \mathrm{Yb}_{0.05} \mathrm{O}_{3-\alpha}$ hollow fiber membrane reactor. Ind. Eng. Chem. Res., 45:3782-3790, 2006

[28] J. Sunarso, S. Baumann, J.M. Serra, W.A. Meulenberg, S. Liu, Y.S. Lin, and J.C. Diniz da Costa. Mixed ionic-electronic conducting (MIEC) ceramic-based membranes for oxygen separation. J. Membr. Sci., 320:13-41, 2008.

[29] K. Zhang, J. Sunarso, Z.P. Shao, W. Zhou, C.H. Sun, S.B. Wang, and S.M. Liu. Research progress and materials selection guidelines on mixed conducting perovskite-type ceramic membranes for oxygen production. RSC Adv, 1:1661-1676, 2011.

[30] Y. Wei, W. Yang, J. Caro, and H. Wang. Dense ceramic oxygen permeable membranes and catalytic membrane reactors. Chem. Eng. J., 220:185-203, 2013.

[31] Q. Liao, Y. Chen, Y.Y. Wei, L.Y. Zhou, and H.H. Wang. Performance of U-shaped $\mathrm{BaCo}_{0.7} \mathrm{Fe}_{0.2} \mathrm{Ta}_{0.1} \mathrm{O}_{3-\delta}$. Chem. Eng. J., 237:146-152, 2014

[32] Z. Cao, H. Jiang, H. Luo, S. Baumann, W. A. Meulenberg, J. Assmann, L. Mleczko, Y. Liu, and J. Caro. Natural gas to fuels and chemicals: Improved methane aromatization in an oxygen-permiable membrane reactor. Angew. Chem. Int. Ed., 52:13794-13797, 2013

[33] J. Caro. Catalytic membrane reactors - Lab curiosity or key enabling technology. Chem. Ing. Tech., 86:1901-1905, 2014.

[34] G.E. Keller and M.M. Bhasin. Synthesis of ethylene via oxidative coupling of methane. J. Catal., 73:9-19, 1982.

[35] N.Y. Usachev, V.V. Kharlamov, E.P. Belanova, and T.S. Starostina. Oxidative processing of light alkanes: State-of-theart and prospects. Russ. J. Gen. Chem., 79:1252-1263, 2009.

[36] C. Hammond, S. Conrad, and I. Hermans. Oxidative methane upgrading. ChemSusChem, 5:1668-1686, 2012.

[37] E. V. Kondratenko, M. Schlter, M. Baerns, D. Linke, and M. Holena. Developing catalytic materials for the oxidative coupling of methane through statistical analysis of literature data. Catal. Sci. Technol., 5:1668-1677, 2015.

[38] S.C. Reyes, E. Iglesia, and C.P. Kelkar. Kinetic-transport models of bimodal reaction sequences-I. Homogeneous and het- 
erogeneous pathways in oxidative coupling of methane. Chem. 3785 Eng. Sci., 48:2643-2661, 1993.

[39] J.H. Lunsford. Catalytic conversion of methane to more useful 3787 chemicals and fuels: A challenge for the 21st century. Catal. 3788 Today, 63:165-174, 2000.

[40] T. Ito, J.-X. Wang, C.-H. Lin, and J.H. Lunsford. Oxidative 3790 dimerization of methane over a lithium-promoted magnesium 3791 oxide catalyst. J. Am. Chem. Soc., 107:5062-5068, 1985.

[41] N. A. S. Amin and S. E. Pheng. Influence of process vari- 3793 ables and optimization of ethylene yield in oxidative coupling 3794 of methane over Li/MgO catalyst. Chem. Eng. J, 116:187-195, 3795 2006.

3796

[42] S. Arndt, U. Simon, S. Heitz, A. Berthold, B. Beck, O. Go- 3797 erke, J. D. Epping, T. Otremba, Y. Aksu, E. Irran, G. Laugel, 3798 M. Driess, H. Schubert, and R. Schomaecker. Li-doped MgO 3799 from different preparative routes for the oxidative coupling of 3800 methane. Top. Catal., 54:1266-1285, 2011.

[43] P. Myrach, N. Nilius, S.V. Levchenko, A. Gonchar, T. Risse, 3802 K.-P. Dinse, L.A. Boatner, W. Frandsen, R. Horn, H.-J. Freund, 3803 R. Schlogl, and M. Scheffer. Temperature-dependent morphol- 3804 ogy, magnetic and optical properties of Li-doped $\mathrm{MgO}$. Chem- 3805 CatChem, 2:854-862, 2010.

[44] D.J. Driscoll, W. Martir, J.X. Wang, and J.H. Lunsford. For- 3807 mation of gas-phase methyl radicals over MgO. J. Am. Chem. 3808 Soc., 107:58-63, 1985.

[45] X.D. Peng, D.A. Richards, and P.C. Stair. Surface composition 3810 and reactivity of lithium-doped magnesium oxide catalysts for 3811 oxidative coupling of methane. J. Catal., 121:99-109, 1990. 3812

[46] K. Kwapien, J. Paier, J. Sauer, M. Geske, U. Zavyalova, 3813 R. Horn, P. Schwach, A. Trunschke, and R. Schlogl. Sites 3814 for methane activation on lithium-doped magnesium oxide sur- 3815 faces. Angew. Chem. Int. Ed., 53:8774-8778, 2014.

3816

[47] L. Tang, D. Yamaguchi, L. Wong, N. Burke, and Ken Chi- 3817 ang. The promoting effect of ceria on $\mathrm{Li} / \mathrm{MgO}$ catalysts for the 3818 oxidative coupling of methane. Catal. Today, 178:172-180, 3819 2011.

[48] U. Simona, S. Arndt, T. Otremba, T. Schlingmann, O. Görke, 3821 K.-P. Dinsec, R. Schomäcker, and H. Schubert. Li/MgO with 3822 spin sensors as catalyst for the oxidative coupling of methane. 3823 Catal. Comm, 18:132-136, 2012.

[49] A. Vatani, E. Jabbari, M. Askarieh, and M. A. Torangi. Kinetic 3825 modeling of oxidative coupling of methane over $\mathrm{Li} / \mathrm{MgO}$ cat- 3826 alyst by genetic algorithm. J. Nat. Gas Sci. Eng, 20:347-356, 3827 2014.

[50] S. Arndt, T. Otremba, U. Simon, M. Yildiz, H. Schubert, and 3829 R. Schomacher. $\mathrm{Mn}-\mathrm{Na}_{2} \mathrm{WO}_{4} / \mathrm{SiO}_{2}$ as a catalyst for the oxida- 3830 tive coupling of methane. What is really known? Appl. Catal. 3831 A, 425:53-61, 2012.

3832

[51] X. Fang, S. Li, J. Lin, J. Gu, and D. Yang. Production of $\mathrm{C}_{2} \mathrm{H}_{4} 3833$ through oxidative coupling of $\mathrm{CH}_{4}$ over W-Mn catalysts. J. 3834 Mol. Catal. (China), 6:427-433, 1992.

[52] R. Koirala, R. Büchel, S.E. Pratsinis, and A. Baiker. Oxidative 3836 coupling of methane on flame-made $\mathrm{Mn}-\mathrm{Na}_{2} \mathrm{WO}_{4} / \mathrm{SiO}_{2}$ : In- 3837 fluence of catalyst composition and reaction conditions. Appl. 3838 Catal. A, 484:97-107, 2014.

[53] H.R. Godini, A. Gili, O. Gorke, S. Arndt, U. Simon, 3840 A. Thomas, R. Schomacher, and G. Wozny. Sol-gel method for 3841 synthesis of $\mathrm{Mn}-\mathrm{Na}_{2} \mathrm{WO}_{4} / \mathrm{SiO}_{2}$ catalyst for methane oxidative 3842 coupling. Catal. Today, 236:12-22, 2014.

[54] H. Liu, X. Wang, D. Yang, R. Gao, Z. Wang, and J. Yang. 3844 Scale up and stability test for oxidative coupling of methane 3845 over $\mathrm{Na}_{2} \mathrm{WO}_{4}-\mathrm{Mn} / \mathrm{SiO}_{2}$ catalyst in a $200 \mathrm{~mL}$ fixed-bed reactor. 3846 J. Nat. Gas. Chem., 17:59-63, 2008.

[55] T.W. Elkins and H.E. Hagelin-Weaver. Characterization of 3848 $\mathrm{Mn} / \mathrm{Na}_{2} \mathrm{WO}_{4} / \mathrm{SiO}_{2}$ and $\mathrm{Mn} / \mathrm{Na}_{2} \mathrm{WO}_{4} / \mathrm{MgO}$ catalysts for the ox- 3849 idative coupling of methane. Appl. Catal. A., 497:96-106, 2015 .

[56] N. Hiyoshi and T. Ikeda. Oxidative coupling of methane over alkali chloride $\mathrm{MnNa}_{2} \mathrm{WO}_{4} / \mathrm{SiO}_{2}$ catalysts: Promoting effect of molten alkali chloride. Fuel Process. Technol., 133:29-34, 2015.

[57] R. Koirala, R. Buchel, S.E. Pratsinis, and A. Baiker. Oxidative coupling of methane on flame-made $\mathrm{Mn}-\mathrm{Na}_{2} \mathrm{WO}_{4} / \mathrm{SiO}_{2}$ : Influence of catalyst composition and reaction conditions. Appl. Catal. A., 484:97-107, 2015.

[58] A. Palermo, J.P Holgado Vaquez, A.F. Lee, M.S. Tikhov, and R.M. Lambert. Critical influence of the amorphous silica-to-cristobalite phase transition on the performance of $\mathrm{Mn} / \mathrm{Na}_{2} \mathrm{WO}_{4} / \mathrm{SiO}_{2}$ catalysts for the oxidative coupling of methane. J. Catal., 177:259-266, 1998.

[59] D. Wang, M.P. Rosynek, and J.H. Lunsford. Oxidative coupling of methane over oxide-supported sodium-manganese catalysts. J. Catal., 155:390-402, 1995.

[60] J. Wu and S. Li. The role of distorded $\mathrm{WO}_{4}$ in the oxidative coupling of methane on supported tungsten oxide catalysts. $J$. Phys. Chem., 99:4566-4568, 1995.

[61] Z.C. Jiang, C.J. Yu, X.P. Fang, S.B. Li, and H.L. Wang. Oxide/support interaction and surface reconstruction in the sodium tungstate $\left(\mathrm{Na}_{2} \mathrm{WO}_{4}\right)$ /silica system. J. Phys. Chem., 97:12870-12875, 1993.

[62] A. Polermo, J.P.H. Vazquez, and R.M. Lambert. New efficient catalysts for oxidative coupling of methane. Catal. Lett., 68:191-196, 2000.

[63] S. Ji, T. Xiao, S. Li, C. Xu, R. Hou, K.S. Coleman, and M.L.H. Green. The relationship between the structure and the performance of $\mathrm{Na}-\mathrm{W}-\mathrm{Mn} / \mathrm{SiO}_{2}$ catalysts for the oxidative coupling of methane. Appl. Catal. A., 225:271-284, 2002.

[64] S. Ji, T. Xiao, S. Li, L. Chou, B. Zhang, C. Xu, R. Hou, A.P.E. York, and M.L.H. Green. Surface $\mathrm{WO}_{4}$ tetrahedron: the essence of the oxidative coupling of methane over Mn-W$\mathrm{Mn} / \mathrm{SiO}_{2}$. J. Catal., 220:47-56, 2003.

[65] A.D. Dedov, G.D. Nipan, S.D. Loktev, A.A. Tyunyaev, V.A. Ketsko, K.V. Parkhomenko, and I.I. Moiseev. Oxidative coupling of methane: Influence of the phase composition of silicabased catalysts. Appl. Catal. A., 406:1-12, 2011.

[66] J. Wu, S. Li, J. Niu, and X. Fang. Mechanistic study of oxidative coupling of methane over $\mathrm{Mn}_{2} \mathrm{O}_{3}-\mathrm{Na}_{2} \mathrm{SiO}_{2}$. Appl. Catal. A., 124:9-18, 1994.

[67] S. Mahmodi, M. R. Ehsani, and S. M. Ghoreishi. Effect of promoter in the oxidative coupling of methane over synthesized $\mathrm{Mn} / \mathrm{SiO}_{2}$ nanocatalysts via incipient wetness impregnation. $J$. Ind. Eng. Chem., 16:923-938, 2010.

[68] J.M. Ha, D.J. Suh, J.W. Choi, Y.H. Yoon, G.S. Yang, and W. Jeon. Catalyst for oxidative coupling of methane for preparing the same and method for oxidative coupling reaction of methane using the same. U.S. Patent 2013/0178680 A1, 2013.

[69] S. Zarrinpashne, R. Ahmedi, and S. M. Zekordi. Catalytic direct converison of methane to ethane and ethlylene. U.S. Patent 7902113B2, 2011

[70] K.D. Champbell, H. Zhang, and J.H. Lunsford. Methane activation by the lanthanide oxides. J. Phys. Chem., 92:750-753, 1988.

[71] Z. Stansch, L. Mleczko, and M. Baerns. Comprehensive kinetics of oxidative coupling of methane ove the $\mathrm{La}_{2} \mathrm{O}_{3} / \mathrm{CaO}$ catalyst. Ind. Eng. Chem. Res., 36:2568-2579, 1997.

[72] V.R. Choudhary, S.A.R. Mulla, and V.H. Rane. Surface basicity and acidity of alkaline earth-promotted $\mathrm{La}_{2} \mathrm{O}_{3}$ catalysts and their performance in oxidative coupling of methane. J. Chem. Technol. Biotechnol., 72:125-130, 1998.

[73] J.M. DeBoy and R.F. Hicks. Kinetics of the oxidative coupling 
of methane over 1 wt. \% Sr/La $\mathrm{La}_{3}$. J. Catal., 113:517-527, 3915 1988.

[74] M.T. Xu and J.H. Lunsford. Effect of temperature on methyl 3917 radical generation over $\mathrm{Sr} / \mathrm{La}_{2} \mathrm{O}_{3}$ catalysts. Catal. Lett., 3918 11:295-300, 1991

[75] Y. Feng, J. Niiranen, and D. Gutman. Kinetic studies of the 3920 catalytic oxidation of methane. 1. Methyl radical production 3921 on $1 \% \mathrm{Sr} / \mathrm{La}_{2} \mathrm{O}_{3}$. J. Phys. Chem., 95:6558-6563, 1991.

[76] S. Becker and M. Baerns. Oxidative coupling and surface prop- 3923 erties on catalytic performance. J. Catal., 128:512-519, 1991. 3924

[77] V.H. Rane, S.T. Chaudhari, and V.R. Choudhary. Oxidative 3925 coupling of methane over La-promoted $\mathrm{CaO}$ catalysts: Influ- 3926 ence of precursors and catalyst preparation method. J. Nat. 3927 Gas Chem., 19:25-30, 2010.

[78] C.T. Tye, A.R. Mohamed, and S. Bhatia. Modeling of catalytic 3929 reactor for oxidative coupling of methane using $\mathrm{La}_{2} \mathrm{O}_{3} / \mathrm{CaO} 3930$ catalyst. Chem. Eng. J., 87:49-59, 2002.

179] N. Holst, S. Jaso, H.R Godini, S. Gloser, H. Arellano-Garcia, G. Wozny, and J. Steinbach. Two-dimensional model for oxid- 3933 taive coupling of methane in a packed-bed membrane reactor. 3934 Chem. Eng. Technol., 35:294-301, 2012.

[80] H.R. Godini, S. Jaso, S. Xiao, H. Arellano-Garcia, M. Omid- 3936 khah, and G. Wozny. Methane oxidative coupling: Synthesis of 3937 membrane reactor networks. Ind. Eng. Chem. Res., 51:7747- 3938 7761, 2012.

[81] H.R. Godini, S. Xiao, M. Kim, N. Holst, S. Jaso, O. Gorke, 3940 J. Steinbach, and G. Wozny. Experimental and model-based 3941 analysis of membrane reactor performance for methane oxida- 3942 tive coupling: Effect of radial heat and mass transfer. Ind. J. 3943 Eng. Chem., 20:1993-2002, 2014.

[82] Y. Patcharavorachot, S. Tiraset, W. Wiyaratn, S. Assabumrun- 3945 grat, and A. Arpornwichanop. Using membrane reactor for 3946 oxidative coupling of methane: simulation and optimization. 3947 Clean Techn. Environ. Policy, 16:1295-1306, 2014.

[83] I. Tezcan and A.K. Avci. Parametric investigation of oxida- 3949 tive coupling of methane in a heat-exchange integrated mi- 3950 crochannel reactor. J Chem. Technol. Biotechnol., 90:1827- 3951 1838,2015

[84] T. Baidya, N. van Vegten, R. Verel, Y. Jiang, M. Yullikov, 3953 T. Kohn, G. Jeschke, and A. Baiker. $\mathrm{SrOAl}_{2} \mathrm{O}_{3}$ mixed ox- 3954 ides: A promising class of catalysts for oxidative coupling of 3955 methane. J. Catal., 281:251-253, 2011.

[85] R.P. Taylor and G.L. Schrader. Lanthanum catalysts for $\mathrm{CH}_{4} 3957$ oxidative coupling-A comparison of theb reactivity of phases. 3958 Ind. Eng. Chem. Res., 30:1016-1023, 1991.

[86] T.L. Van, M. Che, J.M. Tatibouet, and M. Kermarec. Intrared 3960 study of formation and stability of $\mathrm{La}_{2} \mathrm{O}_{2} \mathrm{CO}_{3}$ during the ox- 3961 idative coupling of methane on $\mathrm{La}_{2} \mathrm{O}_{3}$. J. Catal., 142:18-26, 3962 1993.

[87] Y.Sekine, K. Tanaka, M. Matsukaba, and E. Kikuchi. Oxida- 3964 tive coupling of methane on $\mathrm{Fe}$-doped $\mathrm{La}_{2} \mathrm{O}_{3}$ catalyst. Energy 3965 Fuels, 23:613-616, 2009.

[88] D. Lazarov, V. Rives, R. Klissurska, I. Mitov, and D. Klis- 3967 surki. $\mathrm{Fe}_{2} \mathrm{O}_{3} / \mathrm{LiCl}$ catalyst for methane activation. Mater. Lett., 3968 27:129-133, 1996.

[89] D.R. Van Der Vaart. Oxidative coupling catalyst. U.S. Patent 3970 5321185, 1998.

[90] X. Guo, G. Fang, G. Li, H. Ma, H. Fan, L. Yu, C. Ma, X. Wu, 3972 D. Deng, M. Wei, D. Tan, R. Si, S. Zhang, J. Li, L. Sun, 3973 Z. Tang, X. Pan, and X. Bao. Direct, nonoxidative conver- 3974 sion of methane to ethylene, aromatics, and hydrogen. Science, 3975 344:616-619, 2014.

[91] V. Abdelsayed, D. Shekhawat, and M.W. Smith. Effect of Fe 3977 and $\mathrm{Zn}$ promoters on Mo/HZSM-5 catalyst for methane dehy- 3978 droaromatization. Fuel, 139:401-410, 2015.
[92] J.A. Roos ad A.G. Baker, H. Bosch, J.G. van Ommen, and J.R.H. Ross. Selective oxidation of methane to ethane and ethylene over various oxide catalyst. Catal. Today, 1:133-145, 1987.

[93] A.V. Annapragada and E. Gulari. Fe-O-P catalysts for methane utilization-catalyst development and identification. J. Catal., 123:130-146, 1990 .

[94] B. Liu and Z. Huang. Study of forced oscillation operation for oxidative coupling of methane on Fe-P-O catalyst. Chin. J. Catal., 20:16-19, 1999.

[95] P. Huang, Y. Zhao, J. Zhang, Y. Zhu, and Y. Sun. Exploiting shape effects of $\mathrm{La}_{2} \mathrm{O}_{3}$ nanocatalysts for oxidative coupling of methane reaction. Nanoscale, 5:10844-10848, 2013.

[96] J. Song, Y. Sun, R. Ba, S. Huang, Y. Zhao, J. Zhang, Y. Sun, and Y. Zhu. Monodisperse $\mathrm{SrLa}_{2} \mathrm{O}_{3}$ hybrid nanofibers for oxidative coupling of methane to synthesize $\mathrm{C}_{2}$ hydrocarbons. Nanoscale, 7:2260-2264, 2015.

[97] Y.H. Hou, W.C. Han, W.S. Xia, and H.L. Wan. Structure sensitivity of $\mathrm{La}_{2} \mathrm{O}_{2} \mathrm{CO}_{3}$ catalysts in the oxidative coupling of methane. ACS. Catal., 5:1663-1674, 2015.

[98] B. Fallah and C. Falamaki. A new nano-(2 $\left.\mathrm{Li}_{2} \mathrm{O} / \mathrm{MgO}\right)$ catalyst/porous alpha-alumina composite for the oxidative coupling of methane reaction. AIChE J., 56:717-728, 2010.

[99] D. Noon, A. Subsai, and S. Senkan. Oxidative coupling of methane by nanofiber catalysts. ChemCatChem, 5:146-149, 2013

[100] A.G. Dedov, A.S. Loktev, , I.I. Moiseev, A. Aboukais, J.-F. Lamonier, and I.N. Filimonpov. Oxidative coupling of methane catalyzed by rare earth oxides: Unexpected synergistic effect of the oxide mixtures. Appl. Cat. A., 245:209-220, 2003.

[101] W.P. Schammel, J. Wolfennarger, M. Ajinkya, J. McCarty, J.M. Cizeron, S. Weinberger, J.D. Edwards, D. Sheridan, E.C. Scher, and J. McCormick. Oxidative coupling of methane systems and methods. U.S. Patent 2014/0107385 A1, 2014.

[102] A. Tkachenko, J. Gamoras, D. Karshtedt, G. Nyce, and F.R. Zurcher. Method for oxidative coupling of methane in the presence of nanowire catalyst. EP 2853521 A1, 2015.

[103] S. Chinta, J. Thorman, J. Butler, J. Hunter, and T. Rives. Process for the oxidative coupling of methane. U.S. Patent 8912381 B2, 2014.

[104] G.S. Lane and E.E. Wolf. Methane utilization by oxidative coupling: I. a study of reactions in the gas phase during the cofeeding of methane and oxygen. J. Catal., 113:144-163, 1988.

[105] K. Otsuka, Y. Uragami, and M. Hatano. The oxidative coupling of methane in the presence and absence of catalyst. Catal. Today, 13:291-300, 1992.

[106] B. Beck, V. Fleisher, S. Arndt, M. G. Hevia, A. Urakawa, P. Hugo, and R. Schomacher. Oxidative coupling of methaneA complex surface/gas-phase mechanism with strong impact on the reaction engineering. Catal. Today, 228:212-218, 2014.

[107] K.D. Champbell and J.H. Lunsford. Contribution of gas-phase radical coupling in the catalytic oxidation of methane. J. Phys. Chem., 92:5792-5796, 1988.

[108] Y.D. Tong, M.P. Rosynek, and J.H. Lunsford. Secondary reactions of methyl radicals with lanthanide oxides-their role in the selective oxidation of methane. J. Phys. Chem., 93:2896-2898, 1989

[109] L. Luo, X. Tang, W. Wang an Y. Wang, S. Sun, F. Qui, and W. Huang. Methyl radicals in oxidative coupling od methane directly confirmed by synchrotron VUV photoionization mass spectroscopy. Sci. Rep., 3:1625-1631, 2013.

[110] K. Takanabe and E. Iglesia. Rate and selectivity enhancements mediated by $\mathrm{OH}$ radicals in the oxidative coupling of methane catalyzed by $\mathrm{Mn} / \mathrm{Na}_{2} \mathrm{WO}_{4} / \mathrm{SiO}_{2}$. Angew. Chem. Int. 
Ed., 47:7689-7693, 2008.

[111] J.H. Lunsford. The catalytic oxidative coupling of methane 4046 Angew. Chem. Int. Ed, 34:970-980, 1995.

112] J. Sun, J.W. Thybaut, and G.B. Marin. Microkinetics of 4048 methane oxidative coupling. Catal. Today, 137:90-102, 2008. 4049

[113] G.B. Skinner, A. Lifshitz, K. Scheller, and A. Burcat. Kinetics 4050 of methane oxidation. J. Chem. Phys., 56:3853-3861, 1972. 4051

[114] J. Warnatz. Rate coefficients in the C/H/O system in combustion 4052 chemistry. Springer, Berlin, 1984.

[115] W. Tsang and R.F. Hampson. Chemical kinetic data base for 4054 combustion chemistry. Part I. Methane and related compounds. 4055 J. Phys. Chem. Ref. Data, 15:1087-1279, 1986.

[116] H. Zanthoff and M. Baerns. Oxidative coupling of methane 4057 in the gas phase. Kinetic simulation and experimental verifica- 4058 tion. Ind. Eng. Chem. Res., 29:2-10, 1990.

[117] M. Daneshpayeh, A. Khodadadi, N. Mostoufi, Y. Mortazavi, 4060 R. Sotudeh-Gharebagh, and A. Talebizadeh. Kinetic model- 4061 ing of oxidative coupling of methane over $\mathrm{Mn} / \mathrm{Na}_{2} \mathrm{WO}_{4} / \mathrm{SiO}_{2} 4062$ catalyst. Fuel Proc. Techn., 90:403-410, 2009.

[118] J.S. Ahari, S. Zarrinpashne, and M.T. Sadeghi. Micro-kinetic 4064 modeling of OCM reactions over $\mathrm{Mn} / \mathrm{Na}_{2} \mathrm{WO}_{4} / \mathrm{SiO}_{2}$ catalyst. 4065 Fuel Process. Technol., 115:79-87, 2013.

[119] Q. Chen, J.H.B.J. Hoebink, and G.B. Marin. Kinetics of the ox- 4067 idative coupling of methane at atmospheric pressure in the ab- 4068 sence of catalyst. Ind. Eng. Chem. Res., 30:2088-2097, 1991. 4069

120] Q. Chen, P.M. Couwenberg, and G.B. Marin. Effect of pressure 4070 on the oxidative coupling of methane in the absence of catalyst. 4071 AlChE J., 40:521-535, 1994.

121] O. Garnier, J. Shu, and B.P.A. Grandjean. Membrane-assisted 4073 two step process for methane conversion into hydrogen and 4074 higher hydrocarbons. Ind. Eng. Chem. Res., 36:553-558, 1997. 4075

[122] L. Guczi, L. Borko, Zs. Koppany, and I. Kiricsi. "One-step" 4076 methane conversion under non-oxidative conditions over Pt- 4077 $\mathrm{Co} / \mathrm{NaY}$ catalysts at low temperature. Stud. Surf. Sci. Catal., 4078 119:295-300, 1998.

[123] T. Koerts and R.A. van Santen. A low temperature reaction 4080 sequence for methane conversion. J. Chem. Soc., Chem. Com- 4081 mun., pages 1281-1283, 1991 .

[124] M.J. Bradford. Isothermal, non-oxidative two-step $\mathrm{CH}_{4}$ con- 4083 cversion over unsupported and supported Ru and Pt catalysts. 4084 Catal. Lett., 66:113-120, 2000.

[125] M. Belgued, P. Pareja, A. Amariglio, and H. Amariglio. Con- 4086 version of methane into higher hdydrocarbons on platinum. 4087 Nature, 352:789-790, 1991.

[126] S.F. Moya, R.L. Martins, A. Ota, E.L. Kunkes, M. Behrens, 4089 and M. Schmal. Nanostructured supported palladium catalysts- 4090 Non-oxidative methane coupling. Appl. Catal. A, 411- 4091 412:105-113, 2012.

127] H. Amariglio, J. Saintjust, and A. Amariglio. Homologation of 4093 methane under nonoxidative conditions. Fuel. Process. Tech- 4094 nol., 42:291-323, 1995.

[128] L. Wang, L. Tao, M. Xie, and G. Xu. Dehydrogenation 4096 and aromatization of methane under non-oxidizing conditions. 4097 Catal. Lett., 21:35-41, 1993.

129] J. Yang, F. Deng, M.J. Zhang, Q. Luo, and C.H. Ye. W/HZSM- 4099 5 catalyst for methane dehdyroaromatization:A multinuclear 4100 MAS NMR study. J. Mol. Catal. A: Chem., 202:239-246, 4101 2003.

130] L.-Q. Huang, Y.-Z. Yuan, H.-B. Zhang, Z.-T. Xiong, J.-L. 4103 Zeng, and G.-D. Lin. Dehydro-aromatization of $\mathrm{CH}_{4}$ over W- 4104 Mn(or Zn, Ga, Mo, Co)HZSM-5(or MCM-22) catalysts. Stud. 4105 Surf. Sci. Catal., 147:565-570, 2004.

[131] D.D. Anggoro and Istadi. Optimization of methane conversion 4107 to liquid fuels over W-Cu/ZSM-5 catalysts by responce surface 4108 methodology. J. Nat. Gas Chem., 17:39-44, 2008.
[132] M.R. Toosi, B. Sabour, T. Hamuleh, and M.H. Peyrovi. Methane dehydroaromatization over Mo and W catalysts supported on HZSM-5: the effect of preactivation and use of the $\mathrm{CH}_{4} / \mathrm{H}_{2}$ cycle. Reac. Kinet. Mech. Cat., 101:221-226, 2010.

[133] C.L. Zhang, S. Li, Y. Yuan, W.X. Zhang, T.H. Wu, and L.W. Lin. Aromatization of methane in the absence of oxygen over Mo-based catalysts supported on different types of zeolites. Catal. Lett., 56:207-213, 1998.

[134] C. Karakaya, H. Zhu, and R.J. Kee. Kinetic modeling of methane dehydroaromatization chemistry on Mo/Zeolite catalysts in packed-bed reactors. Chem. Engr. Sci., 123:474-486, 2015.

[135] D. Wang, J.H. Lunsford, and M.P. Rosynek. Catalytic converison of methane to benzene over Mo/ZSM-5. Top. Catal., 3:289-297, 1996.

[136] J.-P. Tessonier, B. Louis, S. Rigolet, M.J. Ledoux, and C. Pham-Huu. Methane dehydro-aromatization on Mo/ZSM5: About the hidden role of bronsted acid site. Appl. Catal. A, 336:79-88, 2008.

[137] A.K. Aboul-Gheit and A.E. Awadallah. Effect of combining the metals of group VI supported on H-ZSM-5 zeolite as catalysts for non-oxidative conversion of natural gas to petrochemicals. J. Nat. Gas Chem., 18:71-77, 2009.

[138] H. Liu, S. Yang, J. Hu, F. Shang, Z. Li, C. Xu, J. Guan, and Q. Kan. A comparison study of mesoporous Mo/H-ZSM-5 and conventional Mo/H-ZSM-5 catalyst in methane non-oxidative aromatization. Fuel Process. Technol., 96:195-202, 2012.

[139] Y.H Kim, R.W. Borry, and E. Iglesia. Genesis of methane activation sites in Mo-exchanged H-ZSM-5 catalysts. Micropor. Mesopor. Mat., 35-36:495-509, 2000.

[140] A.V. Kucherov. Effect of the formation of secondary pores in zeolite ZSM-5 on the properties of molybdenum-zeolite catalysts for methane aromatization. Russ. J. Phys. Chem. A, 88:386-392, 2014.

[141] C.H.L. Tempelman and E.J.M. Hensen. On the deactivation of Mo/HZSM-5 in the methane dehydrogenation reaction. Appl. Catal., B, 176:731-739, 2015.

[142] J. Hu, S.L. Wu, Y.Y. Ma, X.Y. Yang, Z.F. Li, H. Liu, Q.S, Huo, J.Q. Guan, and Q.B. Kan. Effect of the particle size of $\mathrm{MoO}_{3}$ on the catalytic acyivity of Mo/ZSM- 5 in methane nonoxidative aromatization. New J. Chem., 39:5459-5469, 2015.

[143] D. Ma, Y. Shu, X. Han, X. Liu, Y. Xu, and X. Bao. Mo/HMCM-22 catalysts for methane dehydroaromatization: A multinuclear MAS NMR study. J. Phys. Chem. B, 105:17861793, 2001.

[144] D. Ma, Q.J. Zhu, Z.L. Wu, D.H. Zhou, Y.Y Shu, Q. Xin, Y.D. $\mathrm{Xu}$, and X.H. Bao. The synergic effect between Mo species and acid sites in Mo/HMCM-22 catalysts for methane aromatization. J. Phys. Chem. Chem. Phys., 7:3102-3109, 2005.

[145] N.B. Chu, J.Q. Wang, Y. Zhang, J.H. Yang, J.M. Lu, and D.H. Yin. Nestlike hollow hierarchical MCM-22 microspheres: Synthesis and exceptional catalytic properties. Chem. Mater., 22:2757-2763, 2010.

[146] X.Y. Yin, N.B. Chu, J.H. Yang, J.Q. Wang, and Z.F. Li. Synthesis of the nanosized MCM-22 zeolite and its catalytic performance in methane dehyro-aromatization reaction. Catal. Commun., 43:218-222, 2014.

[147] P. Wu, Q. Kan, D. Wang, H. Xing, M. jia, and T. Wu. The synthesis of Mo/H-MCM-36 catalyst and its catalytic behavior in methane non-oxidative aromatization. Catal. Commun., 6:449-454, 2005.

[148] C.Y. Sun, S.D. Yao, W.J. Shen, and L.W. Lin. Hydrothermal post-synthesis of HMCM-49 to enhance the ctalaytic performance of the HMCM-49 catalyst for methane dehydroaromatization. Microporous Mesoporous Mater., 122:48-54, 2009. 
[149] S.D. Yao, C.Y. Sun, J. Li, X.M. Huang, and W.J. Shen. A 4175 ${ }^{13} \mathrm{CO}$ isotopic study on the $\mathrm{CO}$ promotion effect in methane 4176 dehydroaromatization reaction over a Mo/HMCM-49 catalyst. 4177 J. Nat. Gas Chem., 19:1-5, 2010.

150] D. Wang, J.H. Lunsford, and M.P. Rosynek. Charecterization 4179 of Mo/ZSM-5 catalyst for the conversion of methane to ben- 4180 zene. J. Catal., 169:347-358, 1997.

4181

151] E.V. Fadeeva, N.A. Mamonov, L.M. Kustov, and M.N. 4182 Mikhailov. The structure of active sites in a molybde- 4183 num/zeolite catalyst for methane dehydroaromatization: a DFT 4184 study. Russ. Chem. Bull., 62:1967-1973, 2013.

[152] J. Gao, Y. Zheng, j. M. Jehng, , Y. Yang, I.E. Wachs, and S.G. 4186 Podkolzin. Identification of molybdenum oxide nanostructures 4187 on zeolites for natural gas conversion. Science, 348:686-690, 4188 2015.

[153] W. Ding, S. Li, G.D. Meitzner, and R. Iglesia. Methane conver- 4190 sion to aromatics on Mo/H-ZSM5: Structure of molybdenum 4191 species in working catalysts. J. Phys. Chem. B, 105:506-513, 4192 2001

[154] J. Bedard, D.Y. Hong, and A. Bhan. $\mathrm{CH}_{4}$ dehydroaromati- 4194 zation on Mo/H-ZSM-5: 1. Effects of co-processing $\mathrm{H}_{2}$ and 4195 $\mathrm{CH}_{3} \mathrm{COOH}$. J. Catal., 306:58-67, 2013.

4196

[155] L. Chen, J. Lin, H.C. Zeng, and L.L. Tan. Non-oxidative 4197 methane conversion into aromatics on mechanically mixed 4198 Mo/HZSM-5 catalyst. Catal. Commun., 2:201-206, 2001.

[156] S.Qi and B. Yang. Methane aromatization using Mo-based cat- 4200 alysts prepared by microwave heating. Catal. Today, 98:639- 4201 $645,2004$.

[157] L. Chen, L. Lin, Z. Xu, X. Li, and T. Zhang. Dehydro- 4203 oligomerization of methane to ethylene and aromatics over 4204 molybdenum/HZSM-5 catalyst. J. Catal., 157:190-200, 1995. 4205

[158] P.L. Tan, K.W. Wong, C.T. Au, and S.Y. Lai. Effects of co-fed 4206 $\mathrm{O}_{2}$ and $\mathrm{CO}_{2}$ on the deactivation of Mo/HZSM-5 for methane 4207 aromatization. Appl. Catal. A, 253:305-316, 2003.

[159] V.I. Zaikovskii, A.V. Vosmerikov, V.F. Anufrienko, L.L. Koro- 4209 bitsyna, E.G. Kodonev, G.V. Echevskii, N.T. Vasenin, S.P. Zhu- 4210 ravkov, E.V. Matus, Z.R. Ismagilov, and V.N. Parmon. Proper- 4211 ties and deactivation of the active sites of an MoZSM-5 catalyst 4212 for methane dehydroaromatization: Electron microscopic and 4213 EPR studies. Kinet. Catal., 47:389-394, 2006.

[160] R.W. Borry, Y.H. Kim, A. Huffsmith, J.A. Reimer, and E. Igle- 4215 sia. Structure and density of Mo and acid sites in Mo- 4216 exchanged H-ZSM5 catalysts for nonoxidative methane con- 4217 version. J. Phys. Chem. B, 103:5787-5796, 1999.

4218

[161] H.S. Lacheen and E. Iglesia. Stability, structure and oxidation 4219 state of Mo/H-ZSM-5 catalysts during reactions of $\mathrm{CH}_{4}$ and 4220 $\mathrm{CH}_{4}-\mathrm{CO}_{2}$ mixtures. J. Catal., 230:173-185, 2005.

[162] D. Zhou, Y. Zhang, H. Zhu, D. Ma, and X. Bao. The structure, 4222 stability, and reactivity of Mo-oxo species in H-ZSM5 zeolites: 4223 Density functional theory study. J. Phys. Chem. C, 111:2081- 4224 2091, 2007.

[163] S. Xing, D. Zhou, L. Cao, and X. Li. Density functional the- 4226 ory study on structure of Molybdenum carbide and catalytic 4227 mechanism for methane activation over ZSM-5 zeolite. Chin. 4228 J. Catal., 31:415-422, 2010.

4229

[164] D. Zhou, S. Zuo, and S. Xing. Methane dehydrogenation and 4230 coupling to ethylene over a Mo/HZSM-5 catalyst: A density 4231 functional theory study. J. Phys. Chem. C, 116:4060-4070, 4232 2012.

4233

[165] S.T. Wong, Y. Xu, W. Liu, L. Wang, and X. Guo. Methane 4234 activation without using oxidants over supported Mo catalysts. 4235 Appl. Catal. A, 136:7-17, 1996.

4236

[166] W. Liu, Y. Xu, S.-T. Wong, L. Wang, J. Qui, and N. Yang. 4237 Methane dehydrogenation and aromatization on the absence of 4238 oxygen on Mo/HZSM-5: A study on the interaction between 4239
Mo species and HZSM- 5 by using a ${ }^{27} \mathrm{Al}$ and ${ }^{29}$ Si MAS NMR. J. Mol. Catal. A: Chem., 120:257-265, 1997.

[167] B. Li, H.Y. Chen, S.J. Li, N. Li, X.H. Bao, and B.X. Lin. Distribution of Mo in Mo/ZSM-5 catalyst prepared by impregnation method. Chin. J. Catal., 26:769-774, 2005.

[168] J. Lu, Y. Xu, Y. Suzuki, and Z.G. Zhang. A rapid and effective method for evaluating the initial activity of Mo/HZSM-5 catalyst in the methane dehydroaromatization reaction at severe conditions. Catal. Commun., 12:127-131, 2010.

[169] Y. Xu, X. Bao, and L. Lin. Direct conversion of methane under non-oxidative conditions. J. Catal., 216:386-395, 2003.

[170] Y. Shu, R. Ohnishi, and M. Ichikawa. Pressurized dehydrocondensation of methane toward benzene and naphthalene on Mo/HZSM-5 catalyst: Optimization of reaction parameters an promotion by $\mathrm{CO}_{2}$ addition. J. Catal., 206:134-142, 2002.

[171] E.V. Matus, I.Z. Ismagilov, O.B. Sukhova, V.I. Zaikovskii, L.T. Tsikoza, Z.R. Ismagilov, and J.A. Moulijin. Study of methane dehydroaromatization on impregnated Mo/ZSM-5 catalysts and characterization of nanostructured molybdenum phases and carboceous deposits. Ind. Eng. Chem. Res., 46:4063-4074, 2007.

[172] H. Ma, R. Kojima, R. Ohnishi, and M. Ichikawa. Efficient regeneration of Mo/HZSM-5 catalyst by using air with $\mathrm{NO}$ in methane dehydroaromatization reaction. Appl. Catal. A, 275:183-187, 2004.

[173] H. Ma, R. Kojima, S. Kikuchi, and M. Ichikawa. Effective coke removal in methane to benzene (MTB) reaction on Mo/HZSM5 catalyst by $\mathrm{H}_{2}$ and $\mathrm{H}_{2} \mathrm{O}$ co-addition to methane. Catal. Lett., 104:63-66, 2005.

[174] Y. Shu, H. Ma, R. Ohnishi, and M. Ichikawa. Highly stable performance of catalytic methane dehydrocondensation towards benzene on Mo/HZSM- 5 by a periodic switching treatment with $\mathrm{H}_{2}$ and $\mathrm{CO}_{2}$. Catal. Commun, 87:86-87, 2003.

[175] Y. Xu and L. Lin. Recent advances in methane dehydroaromatization over transition metal ion-modified zeolite catalysts under non-oxidative conditions. Appl. Catal. A, 188:5367, 1999.

[176] Y. Song, Y. Xu, Y. Suzuki, N. Nakagome, and Z.-G. Zhang. A clue to exploration of the pathways of coke formation on Mo/HZSM-5 catalyst in the non-oxidative methane dehydroaromatization at $1073 \mathrm{~K}$. Appl. Catal. A, 482:387-396, 2014.

[177] Y. Song, Y. Xu, Y. Suzuki, N. Nakagome, X. Ma, and Z.G. Zhang. The distribution of coke formed over a multilayer Mo/HZSM-5 fixed bed in $\mathrm{H}_{2}$ co-fed methane aromatization at $1073 \mathrm{~K}$ : Exploration of the coking pathway. J. Catal., 330:261-272, 2015.

[178] S. Liu, L. Wang, R. Ohnishi, and M. Ichikawa. Bifunctional catalysis of Mo/HZSM-5 in the dehydroaromatization of methane with $\mathrm{CO} / \mathrm{CO}_{2}$ to benzene and napththalene. Kinet. Catal., 41:148-160, 2000.

[179] K. Honda, T. Yoshida, and Z.G. Zhang. Methane dehdroaromatization over Mo/HZSM-5 in periodic $\mathrm{CH}_{4}-\mathrm{H}_{2}$ switching operation mode. Catal. Commun., 4:21-26, 2003.

[180] A.C.C. Rodrigues, A. Carlos, J.L.F. Monteiro, and J. Luiz. The use of $\mathrm{CH}_{4}-\mathrm{H}_{2}$ cycles on dehydroaromatization of methane over MoMCM-22. Catal. Commun., 9:1060-1065, 2008.

[181] Y.B. Xu, J.Y. Lu, J.D. Wang, Y. Suzuki, and Z.G. Zhang. The catalytic stability of Mo/HZSM-5 in methane dehydroaromatization at severe and periodic $\mathrm{CH}_{4}-\mathrm{H}_{2}$ switch operating conditions. Chem. Eng. J., 168:390-402, 2011.

[182] Y.B. Xu, Y. Song, Y. Suzuki, and Z.G. Zhang. Mechanism of Fe additive improving the activity stability of microzeolitebased Mo/HZSM-5 catalyst in non-oxidative methane dehydroaromatization at $1073 \mathrm{~K}$ under periodic $\mathrm{CH}_{4}-\mathrm{H}_{2}$ switching 
modes. Catal. Sci. Technol., 4:3644-3656, 2014.

[183] M.T. Portilla, F.J. Llopis, and C. Martinez. Non-oxidative 4306 dehydroaromatization of methane: an effective reaction- 4307 regeneration cyclic operation for catalyts life extension. Catal. 4308 Sci. Technol., 5:3806-3521, 2015.

[184] C.Y. Sun, G.Z. Fang, X.G. Guo, Y.L. Hu, S.Q. Ma, T.H. Yang, 4310 J. Han, H. Ma, D.L. Tan, and X.H. Bao. Methane dehy- 4311 droaromatization with periodic $\mathrm{CH}_{4}-\mathrm{H}_{2}$ switch: A promising 4312 process for aromatics and hydrogen. J. Energy Chem., 24:257- 4313 263, 2015

4314

[185] S. Yuan, J.Li, Z. Hao, Z. Feng, Q. Xin, P. Ying, and C. Li. 4315 The effect of oxygen on the aromatization of methane over the 4316 Mo/HZM-5 catalyts. Catal. Lett., 63:73-77, 1999.

[186] P.L. Tan, Y.L. Leung, S.Y. Lai, and C.T. Au. Methane aromati- 4318 zation over $2 \mathrm{wt} \% \mathrm{Mo} / \mathrm{HZSM}-5$ in the presence of $\mathrm{O}_{2}$ and NO. 4319 Catal. Lett., 78:251-258, 2002.

[187] J.M. Garza, D.E. Gerwien, D. Morris, J.R. Hamilton, L.L. Mar- 4321 shall, W.Y. Musallam, A. Nilekar, P. Tanev, and L.O. Cisneros 4322 Trevino. Process for the aromatization of a metane-containing 4323 gas stream. US 20150099914 A1, 2015.

[188] L.L. Iaccino, E.L. Stavens, N. Sangar, and J.J. Patt. Production 4325 of aromatics from methane. US 2007/0249880 A1, 2007.

[189] L.L. Iaccino, E.L. Stavens, N. Sangar, and J.J. Patt. Production 4327 of aromatics from methane. US 2010/0305374 A1, 2010.

[190] N. Sangar, L.L. Iaccino, and J.P. Jones. Production of aromat- 4329 ics from methane. US 7951985 B2, 2011.

191] A.C. Camacho Rodrigues and J.L. Fontes Monteiro. $\mathrm{CO}_{2}$ ad- 4331 dition on the non-oxidative dehydro-aromatization of methane 4332 over MoMCM-22. Catal. Lett., 117:166-170, 2007.

[192] S. Liu, Q. Dong, R. Ohnishi, and M. Ichikawa. Unique pro- 4334 motion effect of $\mathrm{CO}$ and $\mathrm{CO}_{2}$ on the catalytic stability for ben- 4335 zene and naphthalene production from methane on Mo/HZSM- 4336 5 catalysts. Chem. Commun., pages 1217-1218, 1998.

[193] S.L. Liu, R. Ohnishi, and M. Ichikawa. Promotional role of 4338 water added to methane feed on catalaytic performance in the 4339 methane dehydroaromatization reaction on Mo/HZSM-5 cata- 4340 lyst. J. Catal., 220:57-65, 2003.

[194] S. Yao, C. Sun, J. Li, L. Gu, and W. Shen. Reaction coupling of 4342 methane steam reforming and methane dehydroaromatization 4343 for improving durability of Mo/HMCM-49 catalyst. Chin. J. 4344 Catal., 30:1022-1028, 2009.

[195] B.S. Liu, L. Tian, L. Li, C.T. Au, and A.S.-C. Cheung. Perfor- 4346 mance of $3 \% \mathrm{Mo} / \mathrm{ZSM}-5$ catalyst in the presence of water dur- 4347 ing methane aromatization in supersonic jet expansion. AIChE 4348 J., 57:1852-1859, 2011.

[196] K. Skutil and M. Taniewski. Some technological aspects 4350 of methane aromatization (direct and via oxidative coupling). 4351 Fuel. Process. Technol., 87:511-521, 2006.

[197] W.P. Ding, G.D. Meitzner, and E. Iglesia. The effects of sila- 4353 nation of external acid sites on the structure and catalytic be- 4354 havior of Mo/H-ZSM-5. J. Catal., 206:14-22, 2002.

[198] D. Ma, L. Su, Z. Xu, Z. Tian, Y. Xu, L. Lin, and X. Bao. Re- 4356 markable improvement on the methane aromatization reaction: 4357 A highly selective and coking-resistant catalyst. J. Phys. Chem. 4358 B, 106:8524-8530, 2002.

[199] Y. Lu, D. Ma, Z. Tian, X. Bao, and L. Lin. A high coking- 4360 resistance catalyst for methane aromatization. Chem. Commun, 4361 pages 2048-2049, 2001.

[200] A.R.S. Darujati, D.C. LaMont, and W.J. Thomson. Oxidation 4363 stability of $\mathrm{Mo}_{2} \mathrm{C}$ catalysts under fuel reforming conditions. 4364 Appl. Catal. A, 253:397-407, 2003.

[201] L. Devi, K.J. Ptasinski, and F.J.J.G. Janssen. Decomposition of 4366 naphthalene as a biomass tar over pretreated olivine: Effect of 4367 gas composition, kinetic approach, and reaction scheme. Ind. 4368 Eng. Chem. Res., 44:9096-9104, 2005.
[202] P. R. Buchireddy, R. M. Bricka, J. Rodriguez, and W. Holmes. Biomass gassification: Catalytic removal of tars over zeolites and nickel supported zeolites. Energy Fuels, 24:2707-2715, 2010.

[203] Q. Wang, H. Fan, S. Wu, Z. Zhang, P. Zhang, and B. Han. Water as an additive to enhance the ring opening of naphthalene. Green Chem., 14:1152-1158, 2012.

[204] A. Jess. Mechanisms ans kinetics of thermal reactions of aromatics hydrocarbons from pyrolysis of solid fuels. Fuel, 75:1441-1448, 1996.

[205] P.D. Sily, F.B. Noronha, and F.B. Passos. Methane direct conversion on Mo/ZSM-5 catalyst modified by Pd and Ru. J. Nat. Gas Chem., 15:82-86, 2006.

[206] A.K. Aboul-Gheit, A.E. Awadallah, S.M. Kossy, and A.L.H. Mahmoud. Effect of Pd and Ir on the catalytic performance of Mo/H-ZSM-5 during the non-oxidative conversion of natural gas to petrochemicals. J. Nat. Gas Chem., 17:337-343, 2008.

[207] T.E. Eshabalala, Neil J. Coville, and M.S. Scurrell. Dehydroaromatization of methane over doped Pt/Mo/H-ZSM-5 zeolite catalysts:The promotional effect of tin. Appl. Catal. A, 485:238-244, 2014

[208] S. Burns, J.S.J. Hargreaves, P. Pal, K.M. Parida, and S. Parija. The effect of dopants on the activity of $\mathrm{MoO}_{3} / \mathrm{ZSM}-5$ catalysts for the dehydroaromatization of methane. Catal. Today, 114:383-387, 2006.

[209] A.K. Aboul-Gheit and A.E. Awadallah. Effect of combining the metals of group VI supported on H-ZSM-5 zeolite as catalysts for non-oxidative conversion of natural gas to petrochemicals. J. Nat. Gas Chem., 18:71-77, 2009.

[210] Y. Xu, J. Wang, Y. Suzuki, and Z.-G. Zhang. Effect of transition metal additives on the catalytic stability of Mo/HZSM-5 in the methane dehydroaromatization under periodic $\mathrm{CH}_{4}-\mathrm{H}_{2}$ switch operation at 1073 K. Appl. Catal. A, 409-410:181-193, 2011.

[211] A.K. Aboul-Gheit, M.S. El-Masry, and A.E. Awadallah. Oxygen free conversion of natural gas to useful hydrocarbons and hydrogen over monometallic Mo and bimetallic Mo-Fe, MoCo or Mo-Ni/HZMS-5 catalysts prepared by mechanical mixing. Fuel Process. Technol., 102:24-29, 2012.

[212] M. Ichikawa, R. Ohnishi, and L. Wang. Catalyst for the conversion of low carbon number aliphatic hydrocarbons to higher carbon number hydrocarbons, process for preparing the catalyst and process using the catalyst. US 6239057 B1, 2001.

[213] F. Kiesslich, J.C. Tsou, and A. Schulz. Method for the dehydroaromatization of mixtures containing methane by regenerating the corresponding catalysts that are devoid of precious metals. US 2011/0060176 A1, 2011.

[214] Y.-H. Yeh, J. Yu, J. Luo, and R.J. Gorte. Endothermic reforming of n-hexane on metal (Pt, Ga) containing H-ZSM-5 at high pressures. Ind. Eng. Chem. Res., page in press, 2015.

[215] D.S. Masiero, N.R. Marcilio, and O.W. Perez-Lopez. Aromatization of methane over Mo-Fe/ZSM-5 catalysts. Catal. Lett., 131:194-202, 2009.

[216] L. Li, R. Borry, and E. Iglesia. Reaction-transport simulations of non-oxidative methane conversion with continuous hydrogen removal - homogeneous-heterogeneous reaction pathways. Chem. Engr. Sci., 56:1869-1881, 2001.

[217] A.M. Dean. Detailed kinetic modeling of autocatalyis in methane pyrolysis. J. Phys. Chem., 94:1432-1439, 1990.

[218] K.S. Wong, J.W. Thybaut, E.Tangstad, M.W. Stocker, and G.B. Marin. Methane aromatization based upon elementary steps: Kinetic and catalyst descriptors. Micropor. Mesopor. Mat., 164:302-312, 2012.

[219] B. Yao, J. Chen, D. Liu, and D. Fang. Intrinsic kinetics of methane aromatization under non-oxidative conditions over modified Mo/HZSM-5 catalysts. J. Nat. Gas Chem, 17:64-68, 
2008.

[220] L.L. Korobitsyna, N.V. Arbuzova, and A.V. Vosmerikov. 4436 Physicochemical properties and activity of Mo-containing ze- 4437 olite catalyts of nonoxidative conversion of methane. Russ. J. 4438 Phys. Chem. A, 87:919-922, 2013.

[221] Y. Cui, Y. Xu, J. Lu, Y. Suzuki, and Z.G. Zhang. The ef- 4440 fect of zeolite particle size on activity of Mo/HZSM-5 in 4441 non-oxidative methane dehdroaromatization. Appl. Catal. A, 4442 393:348-358, 2011

[222] A.B. Mhadeshwar, H. Wang, and D.G. Vlachos. Thermo- 4444 dynamic consistency in microkinetic development of surface 4445 reaction mechanisms. J. Phys. Chem. B, 107:12721-12733, 4446 2003.

[223] R.S. Vincent, R.P. Lindstedt, N.A. Malik, I.A.B. Reid, and B.E. 4448 Messenger. The chemistry of ethane dehydrogenation over a 4449 supported platinum catalyst. J. Catal., 260:37-64, 2008.

[224] L. Maier, N. Schaedel, K.H. Delgado, S. Tisher, and 4451 O. Deutschmann. Steam reforming of methane over nickel: 4452 Development of a multi-step surface reaction mechanism. Top. 4453 Catal., 54:845-858, 2011.

[225] K.R. Hall. A new gas to liquids (GTL) or gas to ethylene (GTE) 4455 technology. Catal. Today, 106:243-246, 2005.

[226] S. Afandizadeh and E.A. Foumeny. Design of packed bed reac- 4457 tors: guides to catalyts shape, size and loading selection. Appl. 4458 Thermal Eng., 21:669-682, 2001.

[227] E.-J. Ras and S. Gomes-Quero. Oxidative coupling of methane 4460 in small scale parallel reactors. Top. Catal., 57:1392-1399, 4461 2014.

4462

[228] J. Cizeron, G. Radaelli, S. Lakhapatri, E. Freer, J.K. Hong, 4463 J. McCormick, D. Sheridan, C. Reid, R. Pellizzari, S. Wein- 4464 berger, and J.D. Edwards. Reactors and systems for oxidative 4465 coupling of methane. U.S. Patent Appl. US 2015/0152025 A1, 4466 2015.

[229] B. Zohour, D. Noon, and S. Senkan. Spatial concentration and 4468 temperature profiles in dual-packed-bed catalytic reactors: Ox- 4469 idative coupling of methane. ChemCatChem, 6:2815-2880, 4470 2014.

4471

[230] S. Stunkel, H. Trivedi, H.-R. Godini, S. Jaso, N. Holst, 4472 S. Arndt, J. Steinbach, and R. Schomacher. Oxidative cou- 4473 pling of methane: Process design, development and operation 4474 in a mini-plant scale. Chem. Ing. Tech., 84:1989-1996, 2012. 4475

[231] K.T. Do, J.H. Edwards, and R.J. Tyler. The catalytic oxidative 4476 coupling of methane. 1. Comparison of experimental perfor- 4477 mance data from various types of reactor. Can. J. Chem. Eng., 4478 73:327-336, 1995.

[232] M. Inomata, T. Katagiri, K. Imura, and E. Sun. Method for 4480 oxidtaive coupling of methane comprising catalytic cracking. 4481 U.S. Patent 005750821, 1998.

4482

233] A. Orth, M. Hirsh, P. Weber, S. Sneyd, D. Nuber, and 4483 M. Stroder. Method and plant for the heat treatment of solids 4484 containing iron oxide using a fluidized bed reactor. U.S. Patent 4485 007625422 B2, 2009.

[234] S. Sadjadi, S. Jaso, H.R. Godini, S. Arndt, M. Wollgarten, 4487 R. Blume, O. Gorke, R. Schomacher, G. Wozny, and U. Si- 4488 mon. Feasibility study of the $\mathrm{Mn}-\mathrm{Na}_{2} \mathrm{WO}_{4} / \mathrm{SiO}_{2}$ catalytic sys- 4489 tems for the oxidative coupling of methane in a fluidized-bed 4490 reactor. Catal. Sci. Technol., 5:942-952, 2015.

235] A.G. Dedov, V.A. Makhlin, M.V. Podlesnaya, A.G. Zyskin, 4492 A.S. Loktev, A.A. Tyunjaev, G.D. Nipan, T.N. Koltsova, V.A. 4493 Ketsko, M.N. Kartasheva, and I.I. Moiseev. Kinetics, mathe- 4494 matical modeling, and optimization of the oxidative coupling 4495 of methane over a $\mathrm{LiMnW} / \mathrm{SiO}_{2}$ catalyst. Theor. Found. Chem. 4496 Eng., 44:3-13, 2010.

[236] M.R. Lee, M.-J. Park, W. Jeon, J.-W. Choi, Y.-W. Suh, and D.- 4498 J. Suh. A kinetic model for the oxidative coupling of methane 4499 over $\mathrm{Na}_{2} \mathrm{WO}_{4} / \mathrm{Mn} / \mathrm{SiO}_{2}$. Fuel Process. Technol., 96:175-182, 2012.

[237] N. Yaghobi and M.H.R. Ghoreishy. Oxidative coupling of methane in a fixed-bed reactor over prevskite catalyts: A simulation study using experimental kinetic model. J. Nat. Gas. Chem., 17:8-16, 2008.

[238] N. Yaghobi and M.H.R. Ghoreishy. Modeling the oxidative coupling of methane: Heterogenous chemistry coupled with 3D flow field simulation. J. Nat. Gas. Chem., 18:39-44, 2009.

[239] Z. Zhang, Z. Guo, and S. Ji. Numerical simulation of packedbed reactor for oxidative coupling of methane. J. Energy Chem., 24:23-30, 2015.

[240] Y.K. Kao and Y.S. Lin. Optimum operation of oxidative coupling of methane in porous ceramic membrane reactors. Catal. Today, 82:255-273, 2003.

[241] H.R. Godini, S. Xiao, M. Kim, O. Gorke, S. Song, and G. Wozny. Dual-membrane reactor for methane oxidative coupling and dry methane reforming: Reactor integration and process intensification. Chem. Eng. Process., 74:153-164, 2013.

[242] J.W. Thybaut, G.B. Marin, C. Mirodatos, Y. Schuurman, A.C. van Veen, V.A. Sadykov, H. Pennemann, R. Bellinghausen, and L. Mleczko. A novel technology for natural gas conversion by means of integrated oxidative coupling and dry reforming of methane. Chem. Ing. Tech., 86:1588-1870, 2014.

[243] V. Hessel, A. Renken, J.C. Schouten, and J. Yoshida. Handbook of Microreactors. Wiley $\mathrm{VCH}$, Weinheim, Germany, 2009.

[244] R.J. Kee, B.B. Almand, J.M. Blasi, B.L. Rosen, M. Hartmann, N.P. Sullivan, H. Zhu, A.R. Manerbino, S. Menzer, W.G. Coors, and J.L. Martin. The design, fabrication, and evaluation of a ceramic counter-flow microchannel heat exchanger. Appl. Thermal Engr., 31:2004-2012, 2011.

[245] D.M. Murphy, A. Manerbino, M. Parker, J. Blasi, R.J. Kee, and N.P. Sullivan. Methane steam reforming in a novel ceramic microchannel reactor. Intl. J. Hydrogen Energy, 38:8741-8750, 2013.

[246] G. Tekautz, B. Zechner, L.E. Wiesegger, and D. Kirschneck. Principle and guidelines for selection of microstructured devices for mixing and reaction. In V. Hessel, A. Renken, J.C. Schouten, and J. Yoshida, editors, Handbook of Microreactors. Wiley VCH, Weinheim, Germany, 2009.

[247] R.J. Kee, P. Korada, K. Walters, and M. Pavol. A generalized model of the flow distribution in channel networks of planar fuel cells. J. Power Sources, 109:148-159, 2002.

[248] T.P. Tiemersma, A.S. Chaudhari, F. Gallucci, J.A.M. Kuipers, and M. van Sint Annaland. Integrated autothermal oxidative coupling and steam reforming of methane. Part 1: Design of a dual-function catalyst particle. Chem. Eng. Sci., 82:200-214, 2012.

[249] T.P. Tiemersma, A.S. Chaudhari, F. Gallucci, J.A.M. Kuipers, and M. van Sint Annaland. Integrated autothermal oxidative coupling and steam reforming of methane. Part 2: Development of a packed bed membrane reactor with a dual function catalyst. Chem. Eng. Sci., 82:232-245, 2012.

[250] C.F. Miller, Jack Chen, M.F. Carolan, and E.P. Foster. Advances in ion transport membrane technology for syngas production. Catal. Today, 228:152-157, 2014.

[251] M.F. Carolan, P.N. Dyer, K.B. Dyer, M.A. Wilson, T.R. Ohm, K.E. Kneidel, D. Peterson, C.M. Chen, and K.G. Rakers. Planar ceramic membrane assembly and oxidation reactor system. U.S. Patent 7279027 B2, 2007.

[252] B. Cook, D. Mousko, W. Hoelderich, and R. Zennaro. Conversion of methane to aromatics over $\mathrm{Mo}_{2} \mathrm{C} / \mathrm{ZSM}-5$ catalyst in different reactor types. Appl. Catal. A, 365:34-61, 2009.

[253] M. P. Gimeno, J. Soler, J. Herguido, and M. Menéndez. Coun- 
teracting catalyst deactivation in methane aromatization with a 4565 two-zone fluidized bed reactor. Ind. Eng. Chem. Res., 49:996- 4566 1000, 2010.

[254] Z. Liu, L. Li, and E. Iglesia. Catalytic pyrolysis of methane 4568 on Mo/H-ZSM-5 with continuous hydrogen removal by per- 4569 meation through dense oxide films. Catal. Lett., 82:175-180, 4570 2002.

4571

255] O. Rival, B.P.A. Grandjean, C. Guy, A. Abdelhamid, and 4572 F. Larachi. Oxygen-free methane aromatization in a catalytic 4573 membrane reactor. Ind. Eng. Chem. Res., 40:2212-2219, 2001. 4574

[256] F. Larachi H. Oudghiri-Hassani, M.C. Iliuta, B.P.A. Grand- 4575 jean, and P.H. McBreen. Ru-Mo/HZSM-5 catalyzed methane 4576 aromatization in membrane reactors. Catal. Lett., 84:183-192, 4577 2002.

257] M.C. Iliuta, B.P.A. Grandjean, and F. Larachi. Methane non- 4579 oxidtaive aromatization over Ru-Mo/HZSM-5 at temperatures 4580 up to $973 \mathrm{~K}$ in a palladium-silver/stainless steel membrane re- 4581 actor. Ind. Eng. Chem. Res., 42:323-330, 2003.

[258] S. Natesakhawat, N.C. Means, B.H. Howard, M. Smith, V. Ab- 4583 delsayed, J.P. Baltrus, Y. Cheng, J.W. Lekse, D. Link, and B.D. 4584 Morreale. Improved benzene production from methane de- 4585 hydroaromatization over Mo/HZSM-5 catalysts via hydrogen- 4586 permselective palladium membrane reactors. Catal. Sci. Tech- 4587 nol., 2015.

[259] R.D. Samarth, S.-Y. Chen, and K.M. Dooley. Dual-bed strate- 4589 gies to improve hydrocarbon yields in the oxidative coupling 4590 of methane. Appl. Catal. B, 5:71-78, 1994.

[260] Y. Li, L. Su, H. Wang, H. Liu, W. Shen, X. Bao, and Y. Xu. 4592 Combined single-pass conversion of methane via oxidative 4593 coupling and dehydroaromatization. Catal. Lett., 89:275-279, 4594 2003.

[261] Y. Li, T. Wu, W. Shen, X. Bao, and Y. Xu. Combined 4596 single-pass conversion of methane via oxidative coupling and 4597 dehydro-aromatization. Catal. Lett., 105:77-82, 2005.

[262] L. Jin, X. Zhou, X. He, and H. Hu. Integrated coal pyrolysis 4599 with methane aromatization over Mo/HZSM-5 for improving 4600 tar yield. Fuel, 114:187-190, 2013.

[263] G. Li, L. Yan, R. Zhao, and F. Li. Improving aromatic hdrocar- 4602 bons yield from caol pyrolysis volatile products over HZSM-5 4603 and Mo-modified HZSM-5. Fuel, 130:154-159, 2014.

[264] Y. Huang, L. Wei, Z. Crandall, J. Julson, and Z. Gu. Combin- 4605 ing Mo-Cu/HZSM-5 with a two-stage catalytic pyrolysis sys- 4606 tem for pine sawdust thermal conversion. Fuel, 150:656-663, 4607 2015.

[265] S. Majhi, A.K. Dalai, and K.K. Pant. Methanol assisted 4609 methane conversion for higher hydrocarbons over bi-functional 4610 Zn-modified Mo/HZSM-5 catalyst. J. Mol. Catal. A: Chem., 4611 398:368-375, 2015.

4612

266] E.V. Matus, O.B. Sukhova, I.Z. Ismagilov, L.T. Tsikoza, and 4613 Z.R. Ismagilov. Peculiarities of dehydroaromatization of $\mathrm{CH}_{4}-4614$ $\mathrm{C}_{2} \mathrm{H}_{6}$ and $\mathrm{CH}_{4}$ over Mo/ZSM-5 catalysts. React. Kinet. Catal. 4615 Lett., 98:59-67, 2009.

[267] C.Y. Sun, S.D. Yao, W.J. Shen, and L.W. Lin. Effect of ethane 4617 addition on methane dehydroaromatization over Mo/HZSM-5 4618 catalyst. Chin. J. Catal., 31:78-83, 2010.

268] V.R. Choudhary, A.K. Kinage, and T.V. Choudhary. Low 4620 temperature non-oxidative activation of methane over H- 4621 Galloaluminosilicate MFI zeolite. Science, 275:1286-1288, 4622 1997.

[269] L. Zheng, D. Xuan, J. Guo, H. Lou, and Z. Zheng. 4624 Non-oxidative aromatization of $\mathrm{CH}_{4}-\mathrm{C}_{3} \mathrm{H}_{8}$ over La-promoted 4625 Zn/HZSM-5 catalysts. J. Natur. Gas. Chem., 15:52-57, 2006. 4626

[270] M.V. Luzgin, A. Rogov, S.S. Arzumanov, A.V. Toktarev, A.G. 4627 Stepanov, and V.N. Parmon. Methane aromatization on Zn- 4628 modified zeolite in the presence of a co-reactant higher alkane: 4629
How does it occur? Catal. Today, 144:265-272, 2009.

[271] J.F. Liu, Y. Liu, and L.F. Peng. Aromatization of methane by using propane as co-reactant over cobalt and zinc-impregnated HZSM-5 catalysts. J. Mol. Catal. A: Chem., 280:7-15, 2008.

[272] M.V. Luzgin, A.V. Toktarev, V.N. Parmon, and A.G. Stepanov. Coaromatization of methane with propane on Mo containing zeolite H-BEA: A solid-state NMR and GC-MS study. J. Phys. Chem. C, 117:22867-22873, 2013.

[273] G.V. Echevsky, E.G. Kodenev, O.V. Kikhtyanin, and V.N. Parmon. Direct insertion of methane into $\mathrm{C}_{3}-\mathrm{C}_{4}$ paraffins over zeolite catalysts: a start to the development of new one-step catalytic processes for the gas-to-liquid transformation. Appl. Catal. A, 258:159-171, 2004.

[274] O.A. Anunziata, G.V.G. Mercado, and L.B. Pierella. Catalytic activation of methane using n-pentane as co-reactant over Zn/H-ZSM-11 zeolite. Catal. Lett., 87:167-171, 2003.

[275] O.A. Anunziata, G.G. Mercado, and L.B. Pierella. Improvement of methane activation using n-hexane as co-reactant over Zn/HZSM-11 zeolite. Catal. Commun., 5:401-405, 2004.

[276] O.A. Anunziata and G.G. Mercado. Methane transformation using light gasoline as co-reactant over Zn/H-ZSM11. Catal. Lett., 107:111-116, 2006.

[277] P.M. Bijani, M. Sohrabi, and S. Sahebdelfar. Nonoxidative aromatization of $\mathrm{ch}_{4}$ using $\mathrm{C}_{3} \mathrm{H}_{8}$ as a coreactant: Thermodynamic and experimental analysis. Ind. Eng. Chem. Res., 53:572-581, 2014.

[278] C.M. Naccache, P. Mériaudeau, G. Sapaly, L.V. Tiep, and Y.B. Taârit. Assessment of the low-temperature non-oxidative activation of methane over $\mathrm{H}$-Galloaluminasilicate (MFI) zeolite a C-13 labelling investigation. J. Catal., 205:217-220, 2002.

[279] U. Mueller and H. Freiberger. Integrated process for preparing benzene and ammonia from aliphatic hydrocarbons and nitrogen. US 8084658 B2, 2011.

[280] S.N. Paglieri and J.D. Way. Innovations in palladium membrane research. Separ. Purif. Method., 31:1-169, 2002.

[281] K. Li. Ceramic membranes for separation and reaction. Wiley, West Sussex, England, 2007.

[282] Ø. Hatlevik, S.K. Gade, M.K. Keeling, P.M. Thoen, A.P. Davidson, and J.D. Way. Palladium and palladium alloy membranes for hydrogen separation and production: History, fabrication strategies, and current performance. Sep. Purif. Technol., 73:59-64, 2010.

[283] W. Kiatkittipong, T. Tagawa, S. Goto, S. Assabumrungra, K. Silpasup, and P. Praserthdam. Comparative study of oxidative coupling of methane modeling in various types of reactor. Chem. Eng. J., 115:63-71, 2005.

[284] S. Bhatia, C.Y. Thien, and A.R. Mohamed. Oxidative coupling of methane (OCM) in a catalytic membrane reactor and comparison of its performance with other catalytic reactors. Chem. Eng. J., 148:525-532, 2009.

[285] H.R. Godini, H. Trivedi, A. Gili de Villasante, O. Gorke, S. Jaso, U. Simon, A. Berthold, W. Witt, and G. Wozny. Design and demonstration of an experimental membrane reactor set-up for oxidative coupling of methane. Chem. Eng. Res. Des., 91:2671-2681, 2013.

[286] R. Suwanwarangkul, E. Croiset, M.W. Fowler, P.L. Douglas, E. Entchev, and M.A. Douglas. Performance comparison of Ficks, dusty-gas and Stefan-Maxwell models to predict the concentration overpotential of a SOFC anode. J. Power Sources, 122:9-18, 2003.

[287] H. Zhu, R.J. Kee, V.M. Janardhanan, O. Deutschmann, and D.G. Goodwin. Modeling elementary heterogeneous chemistry and electrochemistry in solid-oxide fuel cells. J. Electrochem. Soc., 152:A2427-A2440, 2005.

[288] Y. Vural, L. Ma, D.B. Ingham, and M. Pourkashanian. Com- 
parison of the multicomponent mass transfer models for the 4695 prediction of the concentration overpotential for solid oxide 4696 fuel cell anodes. J. Power Sources, 195:4893-4904, 2010.

289] E.A. Mason and A.P. Malinauskas. Gas Transport in Porous 4698 Media: The Dusty-Gas Model. American Elsevier, New York, 4699 1983.

290] R.J. Kee, M.E. Coltrin, and P. Glarborg. Chemically Reacting 4701 Flow. Wiley, Hoboken, NJ, 2003.

[291] D. Lafarga, J. Santamaria, and M. Menendez. Methane oxida- 4703 tive coupling using porous ceramic membrane reactors-I. Re- 4704 actor development. Chem. Eng. Sci., 49:2005-2013, 1994.

[292] J. Coronas, J. Santamaria, and M. Menendez. Methane ox- 4706 idative coupling using porous ceramic membrane reactors-II. 4707 Reaction studies. Chem. Eng. Sci., 49:2015-2025, 1994.

[293] N.W. Ockwig and T.M. Neoff. Membranes for hydrogen sepa- 4709 ration. Chem. Rev., 107:4078-4110, 2007.

[294] H. Wang and Y.S. Lin. Synthesis and modification of ZSM- 4711 5/silicalite bilayer membrane with improved hydrogen separa- 4712 tion performance. J. Membr. Sci., 396:128-137, 2012.

[295] B. Michalkiewicz and Z.C. Koren. Zeolite membranes for hy- 4714 drogen production from natural gas: State of the art. J. Porous 4715 Mater, 22:635-646, 2015.

[296] N. Kosinov, J. Gascon, F. Kaptejin, and E.J.M. Hensen. Recent 4717 developents in zeolite membranes for gas separation. J. Membr. 4718 Sci., 499:65-79, 2016.

4719

[297] T. Masuda, N. Fukumoko, M. Kitamura, S.R. Mukai, 4720 K. Hashimoto, T. Tanaka, and T. Funabiki. Modification of 4721 pore size of MFI-type zeolite by catalytic cracking of silane 4722 and application to preparation of $\mathrm{H}_{2}$-separating zeolite mem- 4723 brane. Micro. Meso. Mater., 48:239-245, 2001.

4724

298 ] Z. Hong, Z. Wu, Y. Zhang, and X. Gu. Catalytic crack- 4725 ing deposition of methyldiethoxysilane for modification of ze- 4726 olitic pores in $\mathrm{MFI} / \alpha-\mathrm{Al}_{2} \mathrm{O}_{3}$ zeolite membrane with $\mathrm{H}^{+}$ion ex- 4727 change pretreatment. Ind. Eng. Chem. Res., 52:13113-13119, 4728 2013.

[299] H. Wang, X. Dong, and Y.S. Lin. Highly stable bilayer MFI 4730 zeolite membranes for high temperature hydrogen separation. 4731 J. Membr. Sci., 450:425-432, 2014.

[300] D. Casanave, P. Ciavarella, K. Fiaty, and J.-A. Dalmon. Zeolite 4733 membrane reactor for isobutane dehydrogenation: Experimen- 4734 tal results and theoretical modeling. Chem. Eng. Sci., 54:2807- 4735 2815, 1999.

[301] B.-H. Jeong, K.-I. Sotowa, and K. Kusakabe. Catalytic dehy- 4737 drogenation of cyclohexane in a membrane reactor. Korean J. 4738 Chem. Eng., 15:136-140, 1998.

[302] K. Sasaki and J. Maier. Re-analysis of defect equilibria and 4740 transport parameters in $\mathrm{y}_{2} \mathrm{O}_{3}$-stabilized $\mathrm{zro}_{2}$ using epr and op- 4741 tical relaxation. Solid State Ionics, 134:303-321, 2000.

[303] M. Liu. Distribution of charged defects in mixed ionic- 4743 electronic conductors. I. General equations for homogeneous 4744 mixed ionic-electronic conductors. J. Electrochem. Soc., 4745 144:1813-1834, 1997.

[304] W. Lai and S.M. Haile. Electrochemical impedance spec- 4747 troscopy of mixed conductors under a chemical potential gradi- 4748 ent: A case study of Pt|SDC|BSCF. Phys. Chem. Chem. Phys., 4749 10:865-883, 2008.

[305] R.J. Kee, H. Zhu, B.W. Hildenbrand, E. Vøllestad, M.D. 4751 Sanders, and R.P. O'Hayre. Modeling the steady-state and 4752 transient response or polarized and non-polarized proton- 4753 conducting doped-perovskite membranes. J. Electrochem. 4754 Soc., 160:F290-F300, 2013.

[306] H. Zhu, S. Ricote, W.G. Coors, C. Chatzichristodoulou, and 4756 R.J. Kee. Equilibrium and transient conductivity for gadolium- 4757 doped ceria under large perturbations: II. Modeling. Solid 4758 State Ionics, 268:198-207, 2014.
[307] E. Vøllestad, H. Zhu, and R.J. Kee. Interpretation of defect and gas-phase fluxes through mixed-conducting ceramics using Nernst-Planck-Poisson and integral formulations. J. Electrochem. Soc., 161:F114-F124, 2014.

[308] M.D. Sanders and R.P. O'Hayre. Development of a multispecies transport space theory and its application to permeation behavior in proton conducting doped perovskites. J. Mater. Chem., 20:6271-6281, 2010.

[309] M.D. Sanders and R.P. O'Hayre. Coupled transport and uphill permeation of steam and oxygen in a dense ceramic membrane. J. Membrane Sci., 376:96-101, 2011.

[310] M.D. Sanders, H. Zhu, R.J. Kee, and R.P. O'Hayre. Modelbased characterization of charged-defect transport and apparent gas-phase permeation in mixed-conducting perovskite membranes. Solid State Ionics, 249-250:6-16, 2013.

[311] S.J. Xu and W.J. Thomson. Oxygen permeation rates through ion-conducting perovskite membranes. Chem. Eng. Sci., 54:3839-3850, 1999.

[312] J. Hong, P. Kirchen, and A.F. Ghoniem. Numerical simulation of ion transport membrane reactors: Oxygen permeation and transport and fuel conversion. J. Membr. Sci., 407:71-85, 2012.

[313] P. Kirchen, D.J. Apo, A. Hunt, and A.F. Ghoniem. A novel ion transport membrane reactor for fundamental investigations of the permeation and oxy-combustion under reactive flow conditions. Proc. Combust. Inst., 34:3463-3470, 2013.

[314] S.H. Lee, V.R. Manga, M.F. Carolan, and Z.-K. Liu. Defect chemistry and phase equilibria of $\left(\mathrm{La}_{1-x} \mathrm{Ca}_{x}\right) \mathrm{FeO}_{3-\delta}$ thermodynamic modeling. J. Electrochem. Soc., 160:F1103-F1108, 2013.

[315] A. Hunt, G. Dimitrakopoulos, P. Kirchen, and A.F. Ghoniem. Measuring the oxygen profile and permeation flux across an ion transport $\mathrm{La}_{0.9} \mathrm{Ca}_{0.1} \mathrm{FeO}_{3-\delta}$ membrane and the development and validation of a multistep surface exchange model. J. Membr. Sci., 468:62-72, 2014.

[316] A. Hunt, G. Dimitrakopoulos, and A.F. Ghoniem. Surface oxygen vacancy and oxygen permeation flux limits of perovskite ion transport membranes. J. Membr. Sci., 489:248-257, 2015.

[317] T.C. Geary and S.B. Adler. Oxygen nonstoichiometry and defect chemistry of the mixed conductor $\mathrm{La}_{0.9} \mathrm{Ca}_{0.1} \mathrm{FeO}_{3-\delta}$ at low oxygen partial pressure. Solid State Ionics, 253:88-93, 2013.

[318] K.D. Kreuer. Proton-conducting oxides. Annu. Rev. Mater. Res., 33:333-359, 2003.

[319] K.J. Yoon, P.A. Zink, S. Gopalan, U.B. Pal, and L.R. Pederson. Defect chemistry and electrical properties of $\left(\mathrm{la}_{0.8} \mathrm{ca}_{0.2}\right)_{0.95} \mathrm{feO}_{3-\delta}$. J. Electrochem. Soc., 156:B795-B800, 2009.

[320] M.Z. Bazant, K. Thornton, and A. Ajdari. Diffuse-charge dynamics in electrochemical systems. Phys. Rev. E, 70:021506, 2004.

[321] M.Z. Bazant, K.T. Chu, and B.J. Bayly. Current-voltage relations for electrochemical thin films. SIAM J. Appl. Math., 65:1463-1484, 2005.

[322] H. Cohen and J.W. Cooley. The numerical solution of the timedependent Nernst-Planck equations. Biophysical J., 5:145$162,1965$.

[323] R.P. Buck. Kinetics of bulk and interfacial ionic motion: Microscopic basis and limits for the Nernst-Planck equation applied to membrane systems. J. Membrane Sci., 17, 1984.

[324] H. Zhu and R.J. Kee. Membrane polarization in mixedconducting ceramic fuel cells and electrolyzers. Intl. J. Hydrogen Energy, page in press, 2015.

[325] C.G. Vayenas, S. Bebelis, and S. Ladas. Dependence of catalytic rates on catalyst work function. Nature, 343:625-627, 1990.

[326] C.G. Vayenas, S. Brosda, and C. Pliangos. Rules and mathe- 
matical modeling of electrochemical and chemical promotion, 4825 1. Reaction classification and promotional rules. J. Catal., 4826 203:329-350, 2001.

\section{7}

[327] D. Poulidi, A. Thursfield, and I.S. Metcalfe. Electrochemical 4828 promotion of catalysis controlled by chemical potential differ- 4829 ence across a mixed ionic-electronic conducting ceramic mem- 4830 brane - An example of wireless NEMCA. Topics in Catalysis, 4831 44:435-449, 2007.

328] N.A. Anastasijevic. NEMCA-From discovery to technology. 4833 Catal. Today, 146:308-311, 2009.

329] R. Imbihl. Electrochemical promotion of catalytic reactions. 4835 Prog. Surf. Sci., 85:241-278, 2010.

330] P. Vernoux and C.G. Vayenas. Note on "electrochemical pro- 4837 motion of catalytic reactions". Prog. Surf. Sci., 86:83-93, 4838 2011.

[331] T.M. Gur and R.A. Huggins. Decomposiition of nitric oxide on 4840 zirconia in a solid-state electrochemical cell. J. Electrochem. 4841 Soc., 126:1067-1075, 1979.

[332] M. Stoukides. Solid-electrolyte membrane reactors: Current 4843 experience and future outlook. Catal. Rev. Sci. Eng., 42:1-70, 4844 2000.

[333] D. Eng and M. Stoukides. Catalytic and electrocatalytic 4846 methane oxidation with solid oxide membranes. Catal. Rev. 4847 Sci. Eng., 1991:375-412, 33.

334] C. G. Vayenas, S. Brosda, and C. Pliangos. The double-layer 4849 approach to promotion, electrocatalysis, electrochemical pro- 4850 motion, and metalsupport interactions. J. Catal., 216, pages $=4851$ 487-504,, 2003.

[335] K. Li. Ceramic Membranes for Separation and Reaction. Wi- 4853 ley, Hoboken, NJ, 2007.

[336] Z. Shao, H. Dong, G. Xiong, Y. Cong, and W. Yang. Perfor- 4855 mance of a mixed-conducting ceramic membrane reactor with 4856 high oxygen permeability for methane conversion. J. Membr. 4857 Sci., 183:181-192, 2001

[337] N.H. Othman, Z. Wu, and K. Li. An oxygen permeable membrane microreactor with an in-situ deposited $\mathrm{Bi}_{1.5} \mathrm{Y}_{0.3} \mathrm{Sm}_{0.2} \mathrm{Fe}_{0.8} \mathrm{O}_{3-\delta}$ catalyst for oxidative coupling of methane. J. Membr. Sci., 488:182-193, 2015.

[338] M.L. Rodriguez, D.E. Ardissone, E. Lopez, M.N. Pedernera, and D.O. Borioi. Reactor designs for ethylene production via ethane oxidative dehydrogenation: Comparison of performance. Ind. Eng. Chem. Res., 50:2690-2697,, 2011.

[339] Y. Zheng, Y.S. Lin, and S.L. Swartz. Perovskite-type ceramic membrane: synthesis, oxygen permiation and the membrane reactor performance for oxidative coupling of methane. $J$. Membr. Sci., 150:87-98, 1998.

[340] L. Wang, K. Murata, A. Sayari, B. Grandjean, and M. Inaba. Production of ultra higly pure $\mathrm{H}_{2}$ and higher hydrocarbons from methane in one step at mild temperatures and development of the catalyst under non-equilibrium reactions. Chem. Commun., pages 1952-1953, 2001.

[341] A.K. Kinage, R. Ohnishi, and M. Ichikawa. Marked enhancement of the methane dehydrocondensation toward benzene using effective Pd catalytic membrane reactor with Mo/ZSM-5. Catal. Lett., 88:199-202, 2003.

342] E.C. Lu R.W. Borry III, Y.H. Kim, and E. Iglesia. Studies in surface science and catalysis. Elsevier Sci., Amsterdam, Netherlands, 1998.

[343] L.S. Woldman and V.D. Sokolovskii. Electrocatalytic methane coupling in the absence of oxygen on a high-temperature proton-conducting electrolyte. Catal. Lett., 8:61-66, 1991.

[344] J. Langguth, R. Dittmeyer, H. Hofmann, and G. Tomandl. Studies on oxidative coupling of methane using hightemperature proton-conducting membranes. Appl. Catal. A, 158:287-305, 1997.
[345] J.C. Tsou, A. Panchenko, A.E. Wentink, S. Ahrens, T. Heidemann, G. Huber, and A. Kostova. Method for electrochemically removing hydrogen from a reaction mixture. US 8729331 B2, 2014.

[346] P. Chitta and M. Karanjkar. System and process for converting natural gas into benzene. US Patent Appl. 2014/0171708 A1, 2014.

[347] E.C. Corredor, P. Chitta, and M. Deo. Membrane reactor system model for gas conversion to benzene. Fuel, 179:202-209, 2016

[348] K. Otsuka, S. Yokoyama, and A. Morikawa. Catalytic activity and selectivity control for oxidative coupling of methane by oxygen pumping through yttria stabilized zirconia. Chem. Lett., pages 319-322, 1985.

[349] T. Schiestel, M. Kilgus, S. Peter, K.J. Caspary, H. Wang, and J. Caro. Hollow fiber perovskite membranes for oxygen separation. J. Membr. Sci., 258:1-4, 2005.

[350] X. Tan, Y. Liu, and K. Li. Mixed conducting ceramic hollowfiber membranes for air separation. AIChE J., 51:1991-2000, 2005.

[351] S. Liu and G.R. Gavalas. Oxygen selective ceramic hollow fiber membranes. J. Membr. Sci., 246:103-108, 2005.

[352] O. Czuprat, T. Schiestel, H. Voss, and J. Caro. Oxidative coupling of methane in a BCFZ perovskite hollow fiber membrane reactor. Ind. Eng. Chem. Res., 49:10230-10236, 2010.

[353] N.H. Othman, Z. Wu, and K. Li. A micro-structured $\mathrm{La}_{0.6} \mathrm{Sr}_{0.4} \mathrm{Co}_{0.2} \mathrm{Fe}_{0.8} \mathrm{O}_{3-\delta}$ hollow fibre membrane reactor for oxidative coupling of methane. J. Membr. Sci., 468:31-41, 2014.

[354] J. Zhu, S. Guo, Z. Zhang, X. Jiang, Z. Liu, and W. Jin. $\mathrm{CO}_{2}$ tolerant mixed conducting multichannel hollow fiber membrane for efficient oxygen separation. J. Membr. Sci, 485:79-86, 2015 